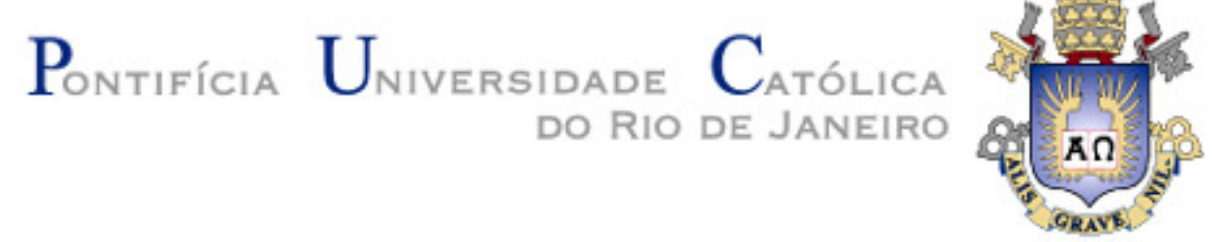

Oliver Eugenio Everett Espino

Estudo de nano partículas de ferro suportadas e não suportadas para a reação de Fischer Tropsch

Dissertação de Mestrado

Dissertação apresentada como requisito parcial para obtenção do título de Mestre pelo Programa de PósGraduação em Química da PUC-Rio.

Orientador: Profa ${ }^{a}$ Maria Isabel Pais Da Silva

Rio de Janeiro

Setembro de 2015 


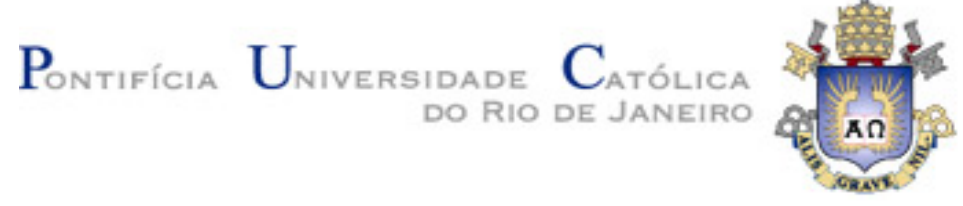

Oliver Eugenio Everett Espino

\title{
Estudo de nano partículas de ferro suportadas e não suportadas para a reação de Fischer Tropsch
}

\begin{abstract}
Dissertação apresentada como requisito parcial para obtenção do grau de Mestre pelo Programa de Pós-graduação em Química da PUC-Rio. Aprovada pela Comissão Examinadora abaixo assinada.
\end{abstract}

Profa. Maria Isabel Pais da Silva

Orientador

Departamento de Química - PUC-Rio

Prof ${ }^{a}$. Laurinda Fátima da F. P. Guimarães Bragança

Co-orientador

UFF

Prof ${ }^{\text {a }}$ Elizabeth Roditi Lachter UFRJ

Prof. Roberto Ribeiro de Avillez Departamento de Engenharia de Materiais e de Processos Químicos e Metalúrgicos PUC-Rio

Prof. José Eugenio Leal Coordenador Setorial do Centro Técnico-Científico - PUC-Rio

Rio de Janeiro, 11 de setembro de 2015 
Todos os direitos reservados. É proibida a reprodução total ou parcial do trabalho sem autorização da universidade, do autor e do orientador.

\section{Oliver Eugenio Everett Espino}

Graduou-se em Engenharia Química Industrial na Universidad Nacional Autónoma de Honduras em 2010. Trabalhou como instrutor de laboratório no departamento de Física UNAH (2007-2013) e como gerente de qualidade na empresa têxtil FINESSA (2010-2013).

Ficha Catalográfica

Espino, Oliver Eugenio Everett

Estudo de nano partículas de ferro suportadas e não suportadas para a reação de Fischer Tropsch / Oliver Eugenio Everett Espino ; orientador: Maria Isabel Pais da Silva. -2015.

103 f. : il. (color.) ; $30 \mathrm{~cm}$

Dissertação (mestrado)-Pontifícia Universidade Católica do Rio de Janeiro, Departamento de Química, 2015.

Inclui bibliografia

1. Química - Teses. 2. Nano partículas de ferro. 3. Sílica alumina. 4. Síntese de Fischer Tropsch. I. Silva, Maria Isabel Pais da. II. Pontifícia Universidade Católica do Rio de Janeiro. Departamento de Química. III. Título. 
Dedico este trabalho primeiramente a Deus, meus Pais, Brenda e Edmundo meus irmãos e minha esposa Melissa. 


\section{Agradecimientos}

A minha orientadora Professora Maria Isabel Pais da Silva pela confiança e paciência para a realização deste trabalho.

A minha co-orientadora Professora Laurinda Fátima da F. P. Guimarães Bragança, pelo apoio brindado neste trabalho.

Ao Professor Roberto Ribeiro de Avillez pela importante contribuição para a realização deste trabalho.

Aos professores Ricardo Aucelio, Aurora Pérez, Camilla Buarque e Nicolás A. Rey pelos ensinamentos e ajuda.

A minha esposa Melissa Cruz pelo apoio brindado.

Aos funcionários e amigos, Henrique, Gisele, Lorhanna, Tania, Bruna, Dalila e Felipe.

À Fatima Almeida pelo todo apoio brindado durante estes dois anos.

Aos meus colegas do departamento de Química PUC RIO pela bela amizade formada. 
Aos meu Professores de Honduras, Prof. Andrés Cruz, Prof. Nabil Kawas e Prof. Ramon Espinoza, os quais confiaram em mim no momento da realização das cartas de recomendação.

Ao meu chefe Prof. Addi Elvir pela apreciação mostrada.

Ao Departamento de Engenharia Química e de Materiais por ter-me aberto as portas quando eu mais precisava.

À PUC-Rio e CAPES, pelo auxilio financeiro concedido para o desenvolvimento desde trabalho. 


\section{Resumo}

Espino, Oliver Eugenio Everett; Pais da Silva, Maria Isabel. Estudo de nano partículas de ferro suportadas e não suportadas para a reação de Fischer Tropsch Rio de Janeiro, 2015. 103p. Dissertação de Mestrado - Departamento de Química, Pontifícia Universidade Católica do Rio de Janeiro.

Catalisadores de ferro suportados em sílica alumina e em sílica mesoporosa, além de nano partículas de ferro não suportadas, foram estudados. A preparação dos catalisadores suportados ocorreu pelo método de impregnação do ponto úmido incipiente com soluções aquosas de cloreto de ferro, para obter $2 \%$ ou $5 \%$ de metal, sendo um desses preparado pelo método da ureia, onde uma quantidade apropriada de uma solução aquosa de $\mathrm{FeCl}_{3} \cdot 6 \mathrm{H}_{2} \mathrm{O}$ (99\% -Merck) foi misturada com ureia. As amostras foram caracterizadas por medidas de fisissorção de N2, difração de Raios-X (DRX), redução com temperatura programada (RTP) e microscopia eletrônica de transmissão (TEM). A quantidade de metal foi determinada usando espectroscopia de absorção atômica (EAA). Os suportes de sílica alumina e de sílica mesoporosa foram caracterizados ainda por análise termogravimétrica (ATG/DTG). As propriedades texturais mostraram que após a introdução do metal nos suportes, a área específica, o volume de poros e o diâmetro de poro decresceram conforme o teor metálico foi aumentado. As análises de DRX com refinamento de Rietveld detectaram a formação das fases de $\mathrm{FeO}, \mathrm{Fe}_{3} \mathrm{O}_{4}, \mathrm{Fe}^{0}$, para todas as amostras suportadas. Os perfis de redução (RTP) para as amostras de ferro suportadas mostraram, principalmente, duas regiões de redução, a primeira atribuída a redução de $\mathrm{Fe}_{2} \mathrm{O}_{3}$ para $\mathrm{FeO}$ e a segunda a redução de $\mathrm{FeO}$ para $\mathrm{Fe}^{0}$.

\section{Palavras-Chave}

Nano partículas de ferro; sílica alumina; síntese de Fischer Tropsch. 


\section{Abstract}

Espino, Oliver Eugenio Everett; Pais da Silva, Maria Isabel (Advisor). Study of supported and not supported iron nano particles in the reaction of Fischer Tropsch. Rio de Janeiro, 2015. 103p. Masters Degree- Departamento de Química, Pontifícia Universidade Católica do Rio de Janeiro.

Iron catalysts supported on silica alumina and mesoporous material, beside non supported iron nanoparticles, were studied. The preparation of supported catalysts occurred by incipient wetness impregnation method with aqueous solutions of iron chloride to give $2 \%$ or $5 \%$ of metal. One iron catalyst supported on silica alumina was prepared by the method of urea, in which an appropriate amount of an aqueous solution of $\mathrm{FeCl} 3.6 \mathrm{H} 2 \mathrm{O}$ (99\% -Merck) was mixed with urea for impregnation. The samples were characterized by measurements of N2 physisorption, X-ray diffraction (XRD), temperature programmed reduction with (TPR), transmission electron microscopy (TEM). The amount of metal embedded in each sample was determined using atomic absorption spectroscopy (AAS). The silica alumina and mesoporous silica supports were also characterized by thermogravimetric analysis (DTA/TGA). The textural properties showed that after introduction of the metal into the supports, the specific area, pore volume and pore diameter decreased as the metal content was increased. $\mathrm{XRD}$ analysis with Rietveld refinement showed the formation of phases the following phases $\mathrm{FeO}, \mathrm{Fe} 3 \mathrm{O} 4, \mathrm{Fe}$, for all supported samples. Reduction profiles (TPR) for the supported iron samples showed mainly two reduction regions, assigned for $\mathrm{Fe} 2 \mathrm{O} 3$ to $\mathrm{FeO}$ and for $\mathrm{FeO}$ to $\mathrm{Fe}^{0}$, respectively.

\section{Keywords}

Iron nano particles; sílica alumina; Fischer Tropsch synthesis. 


\section{Sumário}

1 Introdução

2 Revisão Bibliográfica 19

2.1. Gás a líquidos (GTL) 19

2.2. Formação de gás de síntese 20

2.3. Síntese de Fischer-Tropsch 23

2.4. Hidroprocessamento 24

2.5. Mecanismos da síntese de Fischer Tropsch 25

2.5.1. Mecanismo de carbeno 25

2.6. Mecanismo de hidroxicarbenos 26

2.6.1. Mecanismo de inserção de $\mathrm{CO} \quad 27$

2.6.2. Mecanismo de enol 28

2.7. Distribuição de produtos 29

2.8. Tecnologias para a síntese Fischer-Tropsch 31

2.8.1. Reator de lama 32

2.8.2. Reator tubular de leito fixo (Arge) 33

2.8.3. Reator de leito fluidizado circulante 33

2.8.4. Sistemas de leito fluidizado 33

2.9. Catalisadores 35

2.9.1. Catalisadores a base de ferro 35

2.9.2. Catalisadores de Cobalto 37

2.10. Aspectos cinéticos 38

2.11. Suporte 40

2.12. Promotores 43

2.13. Ativação 45

2.14. Regeneração 47

3 Metodologia Experimental e Métodos 49 
3.1. Preparação dos suportes e catalisadores 49

3.1.1. Reagentes 49

3.1.2. Síntese da sílica mesoporosa 50

3.1.3. Preparação dos catalisadores suportados em Silica-Alumina 51

3.1.4. Preparação dos catalisadores suportados em silica mesoporosa $\quad 51$

3.1.5. Preparação do catalisador a base de nano partículas de ferro 52

3.2. Caracterização dos catalisadores 52

3.2.1. Composição Química 52

3.2.2. Análise Termogravimétrica 53

3.2.3. Propriedades Texturais 54

3.2.4. Difração de raios $-X(D R X)$

3.2.5. Redução à Temperatura Programada (RTP) 56

3.2.6. Microscopia Eletrônica de Transmissão (MET) 57

4 Resultados e Discussões 58

4.1. Composição Química 58

4.2. Análise Termogravimétrica (ATG) 59

4.3. Propiedades Texturais 61

4.4. Difração de raios-X (DRX) 68

4.4.1. Suportes 68

4.4.1.1. Silica Alumina 68

4.4.1.2. Silica mesoporosa 70

4.4.2. Catalisadores suportados calcinados $\quad 70$

$\begin{array}{ll}\text { 4.4.2.1. Catalisadores de Fe/Si-Al } & 70\end{array}$

4.4.2.2. Catalisador de $2 \% \mathrm{Co} / \mathrm{Si}-\mathrm{Al}$

4.4.2.3. Catalisador de 2\% Fe/sílica mesoporosa 73

4.4.3. Catalisadores suportados reduzidos $\quad 73$

4.4.3.1. Catalisadores Fe/Si-Al reduzidos $\mathrm{com} \mathrm{H}_{2}$ puro 74

4.4.3.2. Catalisador de $5 \% \mathrm{Fe} / \mathrm{Si}$-Al reduzido $\mathrm{com} \mathrm{CO} / \mathrm{H}_{2}$

4.4.3.3. Catalisador de $2 \% \mathrm{Co} / \mathrm{Si}$-Al reduzido $\mathrm{com} \mathrm{H}_{2}$

4.4.3.4. Catalisador de 2\% Fe/sílica mesoporosa reduzido $\mathrm{com} \mathrm{H}_{2} \quad 81$ 
4.4.4. Catalisador de ferro não suportado FeNP 82

4.5. Redução com Temperatura Programada (RTP) 84

4.6. Microscopia Eletrônica de Transmissão 88

5 Conclusões $\quad 95$

6 Sugestões 97

7 Referências Bibliográficas 98 


\section{Lista de figuras}

Figura 1. Distribuição dos produtos de Fischer-Tropsch antes e depois do Hidroprocessamento.

Figura 2. Representação esquemática de três mecanismos básicos de reação de Fischer-Tropsch: mecanismo de carbeno, mecanismo de hidroxicarbeno e mecanismo de inserção de CO. 27

Figura 3. Mecanismo do Enol. 28

Figura 4. A distribuição aromática mononuclear ASF de um óleo HT-FT.

Figura 5. Distribuição de produtos de Fischer Tropsch de baixa temperatura usando a expressão de ASF e os obtidos experimentalmente.

Figura 6. (a) Reator de leito fluidizado circulante; (b) Sistemas de leito fluidizado; (c) Reator de lama; (d) Reator tubular de leito fixo (Arge). 34 Figura 7. Curvas ATG/DTG da sílica alumina.

Figura 8. Curvas ATG/DTG da sílica mesoporosa.

Figura 9. Isotermas de adsorção/dessorção de $\mathrm{N}_{2}$ do suporte de sílica alumina e amostras de 2\% Fe/Si-Al, 5\% Fe/Si-Al e $5 \% \mathrm{Fe} / \mathrm{Si}$-Al método ureia.

Figura 10. Isotermas de adsorção/dessorção de $\mathrm{N}_{2}$ do suporte de sílica mesoporosa e amostras 2\% Co/Si-Al, 2\% Fe/Sílica mesoporosa.

Figura 11. Curva de distribuição de diâmetro de poros para o suporte de sílica alumina e amostras de $5 \% \mathrm{Fe} / \mathrm{Si}$-Al método ureia, $2 \% \mathrm{Fe} / \mathrm{Si}-\mathrm{Al}$ e $5 \% \mathrm{Fe} / \mathrm{Si}$-Al.

Figura 12. Curva de distribuição de diâmetro de poros para o suporte de sílica mesoporosa, amostras de 2\% Fe/sílica mesoporosa e 2\% Co/Si-Al. 
Figura 14. Refinamento de Rietveld para o suporte de sílica sílica alumina calcinada. Índice de qualidade do ajuste (gof-goodnes of fit) $2.45 \%$.

Figura 15. Análise de DRX do suporte de sílica mesoporosa calcinada .

Figura 16. Análise de DRX do suporte de sílica alumina e das amostras de $2 \% \mathrm{Fe} / \mathrm{Si}-\mathrm{Al}$, 5\% Fe/Si-Al método ureia, 5\% Fe/Si-Al, $10 \% \mathrm{Fe} / \mathrm{Si}$-Al calcinadas.

Figura 17. Análise de DRX da amostra $2 \%$ Co/Si-Al calcinada.

Figura 18. Análise de DRX da amostra $2 \% \mathrm{Fe} / \mathrm{Si}$-Al calcinada.

Figura 19. Análise de DRX do suporte de sílica alumina e das

amostras de 2\% Fe/Si-Al, 5\% Fe/Si-Al método ureia, 5\% Fe/Si-Al

e $10 \% \mathrm{Fe} / \mathrm{Si}$-Al reduzidas.

Figura 20. Amostra de 2\% Fe/Si-Al reduzida. Índice de qualidade do ajuste (gof-goodnes of fit) $2.16 \%, R w p=1.95 \%$.

Figura 21. Amostra 5\% Fe/Si-Al método ureia reduzida.

Índice de qualidade do ajuste (gof-goodnes of fit) $2.13 \%$,

$\mathrm{Rwp}=1.94 \%$.

Figura 22. Amostra de 5\% Fe/Si-Al reduzida índice de qualidade do ajuste (gof-goodnes of fit) $2.13 \%$, Rwp $=1.93 \%$.

Figura 23. Amostra $10 \% \mathrm{Fe} / \mathrm{Si}$-Al reduzida. Índice de qualidade do ajuste (gof-goodnes of fit) $2.4 \%$, Rwp $=2.1 \%$.

Figura 24. Análise de DRX do catalisador de $5 \% \mathrm{Fe} / \mathrm{Si}$-AI

reduzido com $\mathrm{CO} / \mathrm{H}_{2}$ e $5 \% \mathrm{Fe} / \mathrm{Si}$-Al reduzido com $\mathrm{H}_{2}$.

Figura 25. Amostra 5\% Fe/Si-Al impregnação reduzida com $\mathrm{CO} / \mathrm{H}_{2}$. Índice de qualidade do ajuste (gof-goodnes of fit) $2.47 \%$, $\mathrm{Rwp}=2.13 \%$.

Figura 26. Análise de DRX da amostra $2 \%$ Co/Si-Al reduzida com $\mathrm{H}_{2}$. 
Figura 27. Amostra $2 \% \mathrm{Co} / \mathrm{Si}-\mathrm{Al}$ reduzida com $\mathrm{H}_{2}$. Índice de qualidade do ajuste (gof-goodnes of fit) $2.03 \%$. Rwp $=1.98 \%$.

Figura 28. Análise de DRX da amostra 2\% Fe/sílica mesoporosa reduzida com $\mathrm{H}_{2}$.

Figura 29. Amostra 2\% Fe/silica mesoporosa reduzida com $\mathrm{H}_{2}$.

Índice de qualidade do ajuste (gof-goodnes of fit) $2.02 \%, R w p=1.99 \%$.

Figura 30. Análise de DRX das nano partículas de ferro não suportadas (FeNp).

Figura 31. Amostra de FeNp. Índice de qualidade do ajuste a (gof-goodnes of fit) $2.49 \%$, Rwp $=2.3 \%$.

Figura 32. Perfis de RTP para as amostras de $2 \% \mathrm{Fe} / \mathrm{Si}-\mathrm{Al}$, $2 \% \mathrm{Co} / \mathrm{Si}-\mathrm{Al}, 5 \% \mathrm{Fe} / \mathrm{Si}-\mathrm{Al}$ e $5 \% \mathrm{Fe} / \mathrm{Si}-\mathrm{Al}$ método ureia e $2 \% \mathrm{Fe} / \mathrm{sílica}$ mesoporosa.

Figura 33. Reações de redução para o ferro. Óxido de ferro (hematita) é sucessivamente reduzida para magnetita, wustite $(\mathrm{FeO})$ e, finalmente, reduzido a ferro metálico. Figura 34. Análise de RTP para as amostras $2 \% \mathrm{Fe} / \mathrm{Si}-\mathrm{Al}$, $2 \% \mathrm{Co} / \mathrm{Si}-\mathrm{Al}$, 5\% Fe/Si-Al, 5\% Fe/Si-Al método ureia e $2 \% \mathrm{Fe} / \mathrm{sílica}$ mesoporosa.

Figura 35. Imagens obtidas por MET para a amostra de $2 \% \mathrm{Fe} / \mathrm{Si}$-Al a e b; histogramas de distribuição de tamanho de partícula c.

Figura 36. Imagens a e b e seus respetivas regiões ampliadas $a+e b+$ obtidas por MET para o suporte de sílica alumina. 
Figura 37. Imagens $c$ e d e seus respetivas regiões ampliadas

$\mathrm{c}+\mathrm{e} d+$ obtidas por MET para o suporte de sílica alumina

Figura 38. Imagens obtidas por MET para a amostra de

$5 \% \mathrm{Fe} / \mathrm{Si}$-Al método ureia, a), b) campo claro e c) campo escuro.

92

Figura 39. Imagens obtidas por MET para a amostra de $5 \% \mathrm{Fe} / \mathrm{Si}$-Al.

93

Figura 40. Imagens obtidas por MET para a amostra de nano partículas de ferro não suportadas FeNp. 


\section{Lista de tabelas}

Tabela 1. Distribuição do número de carbono na reação de Fischer-Tropsch de alta temperatura e de baixa temperatura dos produtos de $\mathrm{FT}$, excluindo os hidrocarbonetos $C_{1}-C_{2}$. 32 Tabela 2. Reagentes utilizados. 50

Tabela 3. Percentual metálico Fe determinado através de A.A.

Tabela 4. Quantificação dos eventos de perda de massa da sílica alumina e da silica mesoporosa.

61

Tabela 5. Propriedades texturais das amostras

Tabela 6. Consumo de hidrogênio e grau de redução dos catalisadores suportados. 


\section{Introdução}

As fontes fósseis em todo o mundo estão se esgotando, e o óleo de petróleo que é a principal fonte de energia utilizada atualmente no setor de transporte precisa ter uma fonte alternativa renovável que possa substituí-lo no futuro. Além disso, as preocupações com o aquecimento global e as mudanças climáticas estão crescendo cada vez mais e as fontes fosseis são as maiores responsáveis por isso.

Em consequencia, vários países estão realizando ações governamentais, políticas e legais para reduzir as emissões de dióxido de carbono, ja que o $\mathrm{CO}_{2}$ é um dos responsávels pelo aumento do efeito estufa. Muitas pesquisas estão sendo desenvolvidas para buscar novas fontes de energias renováveis que possam sustentar a demanda global por combustíveis (SAJJAD et al. 2014).

A tecnologia de Gás a Líquidos (GTL) pode ser considerada como uma cadeia de processos para converter gás natural em óleo sintético, no qual é refinado em combustíveis síntéticos e hidrocarbonetos. O gas liquefeito de petroleo proveniente da tecnologia GTL é conhecido como um líquido incolor, inodoro, não tóxico, biodegradável reduzindo significativamente as emissões do veículo que o utiliza, proporcionando uma melhor combustão. A tecnologia GTL também permite a produção de produtos de qualidade superior e com menos poluentes, para os quais há uma demanda crescente. Os produtos GTL contêm basicamente GLP (Gás liquefeito de petróleo), nafta, querosene e diesel. Os teores destes produtos dependem do tipo de tecnologia aplicada aos catalisadores e condições ótimas de reações, etc. (SAJJAD et al. 2014). 
O processo pelo qual os combustíveis são obtidos é conhecido como a síntese de Fischer-Tropsch (FTS) pela conversão do gás de síntese ("syngas"), uma mistura de monóxido de carbono e hidrogénio, produzido a partir de combustíveis fósseis e biomassas, em produtos líquidos. Em 1923, Franz Fischer e Hans Tropsch foram os primeiros a estudar a conversão de gás de síntese a partir do carvão em hidrocarbonetos, dando origem ao nome do proceso. Este proceso também depende fundamentalmente, da utilização de um catalisador adequado (SWAIN; DAS; NAIK, 2011).

O gás natural está se tornando o combustível para geração de energia e para uma infinidade de aplicações termomecânicas nas indústrias de petróleo e gás. Também é cada vez maior a sua participação como matéria prima numa vasta gama de processos petroquímicos. Esta tendência é impulsionada por considerações ambientais e econômicas. Apesar da recente dificuldade econômica global que afeta principalmente o setor financeiro, a indústria de petróleo e gás deve continuar o seu crescimento a nível mundial. (Second Annual Gas Processing Symposium book editors, 2010).

O objetivo deste trabalho é estudar nano partículas de ferro suportadas e não suportadas para a reação de Fischer Tropsch (FT). Verificando a influência do tipo de suporte e o teor metálico mediante técnicas de caracterização tais como difração de raios $X$ com refinamento de Rietveld, Análise química elementar por absorção atômica de chama, medida de área especifica BET, volume e distribuição de poros por absorção de nitrogênio, microscopia eletrônica de transmissão, redução com temperatura programada RTP e análise termogravimétrica ATG. 


\section{2 \\ Revisão Bibliográfica}

\section{1.}

Gás a líquidos (GTL)

O declínio do fornecimento de petróleo forçou a busca por matériaprima alternativa que possa ser utilizada como fonte de combustível, o carvão pode ser uma alternativa, tendo em vista que os depósitos de carvão podem oferecer uma reserva equivalente a mais de 1.000 anos. Enquanto isso, o gás natural é uma fonte de matéria-prima mais econômica e ambientalmente atraente. As principais fontes de gás natural estão localizadas na parte asiática da Rússia e países do Oriente Médio, enquanto os principais consumidores são os países da Europa e América do Norte. A questão atual enfoca o transporte de gás natural, uma vez que exige tubulações longas ou tanques resfriados de gás liquefeito, tornando o transporte muito caro. A solução oferecida para esses problemas é sua liquefação diretamente nos campos de gás (ELISEEV, 2010).

O preço do gás natural no mercado internacional é afetado por custos operacionais e custos de transporte, bem como o mecanismo da oferta e demanda. O processo GTL oferece uma solução para o tratamento de gás natural produzido a partir das reservas isoladas. O valor do gás de síntese comercializado atualmente no mercado tem um valor agregado relativo ao gás bruto mais o custo do transporte para comercialização. Deste modo, o preço de comercialização só será reduzido se os custos do transporte também forem reduzidos. (AL-SHALCHI, 2006) 


\section{2.}

\section{Formação de gás de síntese}

Al-shalchi (2006) define como gás de síntese uma mistura constituída por monóxido de carbono e hidrogênio, que pode ser classificada de acordo com os materiais de partida utilizados na sua produção:

a) Gaseificação: É o processo pelo qual um material não gasoso contendo carbono é convertido em gás de síntese, os exemplos deste materiais são: carvão, biomassa, coque de petróleo e resíduos de refinaria. Esta é uma tecnologia interessante, especialmente devido às grandes reservas de carvão.

b) A partir de gás Natural: Hoje o gás natural é a maior fonte de gás de síntese, seu uso está aumentando devido ao menor custo e melhor desempenho ambiental do mesmo, em relação a outras possíveis fontes. (Simbeck; KARP; DICKENSON, 2000).

Assim o gás de síntese pode ser produzido a partir de várias matériasprimas, incluindo gás natural, nafta, óleo residual, coque de petróleo, biomassa e carvão, sendo o gás natural a principal matéria-prima do interesse atual. As outras matérias-primas restantes requerem um investimento de capital elevado do processo de gaseificação devido ao custo associado com a purificação, refrigeração do gás de síntese, manuseio de materiais e remoção de fuligem. (Simbeck; KARP; DICKENSON, 2000).

O gás natural é composto de hidrocarbonetos leves, principalmente metano, mas também contém propano, butano em quantidades inferiores, bem como um baixo nível de contaminantes (enxofre, nitrogênio, dióxido de carbono e água). 
Vosloo (2001) descreve a geração de gás de síntese a partir de gás natural pelas seguintes tecnologias:
a) Reforma a vapor
b) Reforma por oxidação parcial (POX)
c) Reforma autotérmica
d) Reforma combinada
e) Reforma a seco

A tecnologia comercial atual que rege a geração de gás de síntese é reforma a vapor, em que o hidrogênio e monóxido de carbono são obtidos pela conversão catalítica de metano e vapor na presença de um catalisador. (Simbeck; Karp; Dickenson, 2000).

$$
\mathrm{CH}_{4}+\mathrm{H}_{2} \mathrm{O} \stackrel{\text { cat }}{=} \mathrm{CO}+3 \mathrm{H}_{2} \quad \Delta \mathrm{H}_{(298 \mathrm{~K})}=+206 \mathrm{Kj} / \mathrm{mol}
$$

De acordo com Simbeck e colaboradores (2000) a reforma a vapor se caracteriza por:

- Não requerer oxigênio.

- Ter vasta aplicação industrial.

Entre as desvantagens que o mesmo apresenta pode-se citar:

- Relação $\mathrm{H}_{2}$ / CO, muitas vezes mais elevada (maior do que 4) do que o necessário para a síntese de Fischer-Tropsch.

- Conversão baixa de metano devido a uma temperatura máxima de operação abaixo de $900^{\circ} \mathrm{C}$.

- Alto consumo de água. 
Uma proporção de $\mathrm{H}_{2}$ / $\mathrm{CO}$ inferior a 2, próximo do ótimo requerido pela síntese de Fischer-Tropsch pode ser alcançada pela tecnologia de reforma por oxidação parcial, a qual consiste de uma combustão parcial não catalítica de metano.

$$
\mathrm{CH}_{4}+1 / 2 \mathrm{O}_{2} \rightleftharpoons \mathrm{CO}+2 \mathrm{H}_{2} \quad \Delta \mathrm{H}=-36 \mathrm{Kj} / \mathrm{mol}
$$

Quanto a razão $\mathrm{H}_{2}$ / CO é baixa, devido à pequena quantidade de vapor que é usada no processo, o reformador opera a uma temperatura cerca de $1400{ }^{\circ} \mathrm{C}$ de saída, algumas desvantagens se apresentam:

- Formação de elevado nível de amoníaco e de HCN bem como fuligem, o que requer uma operação adicional de limpeza do gás no lavador.

- Maior consumo de oxigênio.

- O metano não convertido, bem como o metano obtido a partir da síntese de Fischer-Tropsch não pode ser reciclado diretamente para o reformador, se estiver misturado com o $\mathrm{CO}_{2}$ (Vosloo, 2001).

A tecnologia de reforma autotérmica oferece um procedimento alternativo com uma razão $\mathrm{H}_{2} / \mathrm{CO}$ mais favorável para a síntese de Fischer Tropsch, é uma combinação de reforma a vapor da oxidação parcial em uma única etapa (ARMOR, 2005). O processo é autotérmico, devido que a reação de reformação endotérmica prossegue como resultado da oxidação de uma parte dos hidrocarbonetos de alimentação (Simbeck; Karp; Dickenson, 2000). O gás de síntese pode ser obtido a partir de biomassa pelo processo chamado BTL (biomassa a líquidos). Resíduos agrícolas, grama e lascas de madeira são alguns dos insumos empregados nesta tecnologia (BALIBAN; ELIA; FLOUDAS, 2013). 
Ao combinar a reforma a vapor com a reforma autotérmica, pode ser obtido um melhor aproveitamento da energia. Dependendo do grau de integração de energia e as condições de operação específicas, a eficiência térmica da planta de GTL pode ser melhorada em 1-2\%. Embora a reforma combinada seja mais económica que a reforma a vapor, ela resulta ser mais cara que a reforma autotérmica, a escolha entre reforma combinada e a reforma autotérmica vai depender do custo do gás natural (VOSLOO, 2001).

O processo pelo qual o gás natural (principalmente metano) é reformado com $\mathrm{CO}_{2}$ é chamado reforma a seco. Esta tecnologia tem a vantagem de diminuir o efeito estufa pois o dióxido de carbono é um dos maiores contribuintes, bem como um meio barato de fonte não tóxica de carbono (SHI et al., 2013). A principal reação envolvida na reforma do metano com $\mathrm{CO}_{2}$ (Martin, 1993) é:

$\mathrm{CH}_{4}+\mathrm{CO}_{2} \leftrightarrow 2 \mathrm{CO}+2 \mathrm{H}_{2} \quad \Delta \mathrm{H}=247 \mathrm{~kJ} / \mathrm{mol}$

\section{3.}

Síntese de Fischer-Tropsch

A síntese de Fischer Tropsch (FT) é um processo que converte o gás de síntese $\left(\mathrm{H}_{2}\right.$ e $\left.\mathrm{CO}\right)$ em hidrocarbonetos líquidos sintéticos, de preferência tendo a formula $C_{n} H_{(2 n+2)}$ (ANDREW, 2014). Os principais produtos são cadeias parafínicas ou olefínicas (Equação 1 e 2):

Parafinas $n \mathrm{CO}+(2 n+1) \mathrm{H}_{2} \stackrel{\text { cat }}{\longrightarrow} \mathrm{C}_{n} \mathrm{H}_{2 n}+2+n \mathrm{H}_{2} \mathrm{O}$

Olefinas $\quad n \mathrm{CO}+2 n \mathrm{H}_{2} \stackrel{\text { cat }}{\longrightarrow} \mathrm{C}_{n} \mathrm{H}_{2 n}+n \mathrm{H}_{2} \mathrm{O}$

A formação de cadeias parafínicas é uma síntese altamente exotérmica com uma entalpia de reação de $-150 \mathrm{~kJ} / \mathrm{mol}$.

A reação de deslocamento de água (WGS) também acontece com o propósito de converter a $\mathrm{H}_{2} \mathrm{O}$, bem como $\mathrm{CO}$ em dióxido de carbono e hidrogênio. 
(WGS) $\quad \mathrm{CO}+\mathrm{H}_{2} \mathrm{O} \longleftrightarrow \mathrm{CO}_{2}+\mathrm{H}_{2}$

Além disso, as reações secundárias incluem a formação de metano (equação 4), bem como a reação de Boudouard (equação 5) e a formação de algum álcool (equação 6) (Guettel; Kunz; Turek, 2008).

$$
\begin{aligned}
& \mathrm{CO}+3 \mathrm{H}_{2} \rightleftharpoons \mathrm{CH}_{4}+\mathrm{H}_{2} \mathrm{O} \\
& 2 \mathrm{CO} \rightleftharpoons \mathrm{CO}+\mathrm{CO}_{2} \\
& n \mathrm{CO}+2 n \mathrm{H}_{2} \rightleftharpoons \text { cat } \\
& \mathrm{C}_{n} \mathrm{H}_{2 n+2} \mathrm{O}+(n-1) \mathrm{H}_{2} \mathrm{O}
\end{aligned}
$$

\section{4.}

\section{Hidroprocessamento}

O processo de Fischer-Tropsch gera hidrocarbonetos de cadeia longa, principalmente $\mathrm{C}^{2} 0^{+}$de natureza cerosa, o que não é desejável para combustíveis de transporte, por conseguinte, uma fase de hidroprocessamento deve ser incluída, pois a produção direta de uma fração com alto rendimento de moléculas de cadeia baixa é impossível por síntese direta no processo de Fischer-Tropsch (SIE, ST; Senden, MMG; VAN WECHEM, 1991).

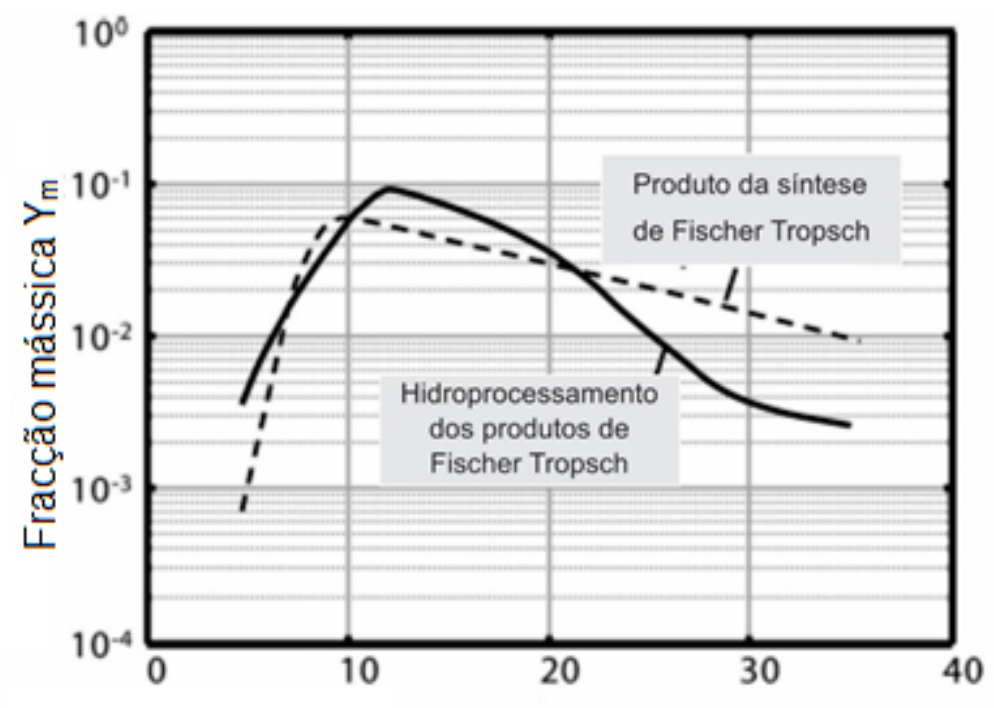

Número de carbono NC

Figura 1. Distribuição dos produtos de Fischer-Tropsch antes e depois do Hidroprocessamento (Adaptado de Sie et al. 1991) (Pabst; KraushaarCzarnetzki; SCHAUB, 2013). 
Neste processo hidrocarbonetos de cadeia longa são convertidos em combustívels, principalmente $C_{5}$ a $C_{20}$, sendo a hidrogenação a primeira etapa no hidroprocessamento (equação 7 ), ocorrendo posteriormente a reação de isomerização reversível (equação 8) seguida de craqueamento (equação 9) dos componentes (Pabst; Kraushaar-Czarnetzki; SCHAUB, 2013). A Figura 1 Apresenta a distribuição dos produtos de Fischer-Tropsch antes e depois do Hidroprocessamento.

$$
\begin{aligned}
\mathrm{nC}_{n} \mathrm{H}_{2 \mathrm{n}}+\mathrm{H}_{2} & \longrightarrow \mathrm{nC}_{n} \mathrm{H}_{2 \mathrm{n}+2} \\
\mathrm{nC}_{n} \mathrm{H}_{2 \mathrm{n}+2} & \longrightarrow \text { iso- } \mathrm{C}_{n} \mathrm{H}_{2 \mathrm{n}+2} \\
\text { iso- } \mathrm{C}_{\mathrm{n}} \mathrm{H}_{2 \mathrm{n}+2}+\mathrm{H}_{2} & \longrightarrow \text { iso- } \mathrm{C}_{\mathrm{m}} \mathrm{H}_{2 \mathrm{~m}+2}+\mathrm{n}-\mathrm{C}_{\mathrm{n}-\mathrm{m}} \mathrm{H}_{2(\mathrm{n}-\mathrm{m})+2}
\end{aligned}
$$

\section{5 . Mecanismos da síntese de Fischer Tropsch}

A síntese de Fischer-Tropsch converte o gás de síntese em uma ampla gama de hidrocarbonetos predominantemente alcanos e alcenos, bem como uma diversidade de produtos menores, incluindo os produtos oxigenados. Embora o mecanismo exato da reação não seja definido com certeza, a segur descrevem-se alguns dos principais mecanismos que foram proposto (DAVIS, 2001).

\subsection{1.}

\section{Mecanismo de carbeno}

No mecanismo de carbeno são formados intermediários C1 adsorvidos, livres de oxigênio, pela hidrogenação de carbono superficial após a dissociação do CO adsorvido. O crescimento da cadeia ocorre por meio da inserção de uma espécie $\mathrm{CHx}$ adsorvida na ligação metal-carbono de uma 
espécie de $\mathrm{CxHy}$ adsorvida. O mecanismo é representado na Figura 2, onde a espécie de metileno ( $\mathrm{CH} 2$ adsorvido) é o intermediário chave do mecanismo.

O mecanismo foi proposto, primeiramente, por Fischer e Tropsch, em 1926, e na sua proposta a síntese procede por meio da hidrogenação de carbetos superficiais a grupos metileno. Estes grupos metileno polimerizam a espécies alquilas superficiais que originam os produtos da reação. Há um número vasto de estudos que suportam o mecanismo de carbeno e este é, com freqüência, o mais aceito para a síntese de Fischer-Tropsch. Estes estudos incluem a análise de espécies superficiais, a adição de moléculas sonda, traçadores de carbono, e o uso de uma olefina adicionada ao metano na reação (DA SILVA, 2004).

\section{6. Mecanismo de hidroxicarbenos}

No mecanismo hidroxicarbeno, o crescimento da cadeia ocorre através da reacção de condensação de duas espécies hidroxicarbeno $\mathrm{CHOH}$ adsorvidas com a eliminação de água. O mecanismo é apresentado na Figura 2, na qual as espécies hidroxicarbeno sao os intermediários chaves. Eles são formados por meio da hidrogenação parcial de $\mathrm{CO}$ adsorvido. O mecanismo explica a formação de álcoois através de hidrogenação de aldeídos através de dessorção e hidrocarbonetos por meio da eliminação de hidrogénio do grupo $\mathrm{OH}$.

A base para o mecanismo encontra-se na observação de que a alimentação de álcoois durante a reação Fischer-Tropsch conduz à participação destes álcoois no crescimento da cadeia. Entretanto, a adsorção desses álcoois e a participação dos intermediários resultantes, nos processos de crescimento de cadeia, não evidenciam que a cadeia crescente na superfície do catalisador é uma espécie contendo Oxigenio. Além disso, a formação da ligação $C$-C entre duas espécies hidroxicarbenos eletrofílicas não é evidente (Johannes van Dijk, 2001). 


\subsubsection{Mecanismo de inserção de CO}

No mecanismo de inserção de $\mathrm{CO}$, o crescimento da cadeia procede via inserção de um intermediário carbonil adsorvido na ligação metal-alquila. Para que a reação de acoplamento de C-C tenha lugar, as espécies resultantes são primeiramente hidrogenadas a uma cadeia alquila. Este mecanismo explica a formação de álcoois, hidrocarbonetos e aldeídos. Este mecanismo é mostrado na Figura 2, onde a espécie carbonil é o intermediário chave.

Mecanismo de carbeno Mecanismo de hidroxicarbeno Mecanismo de inserção de CO
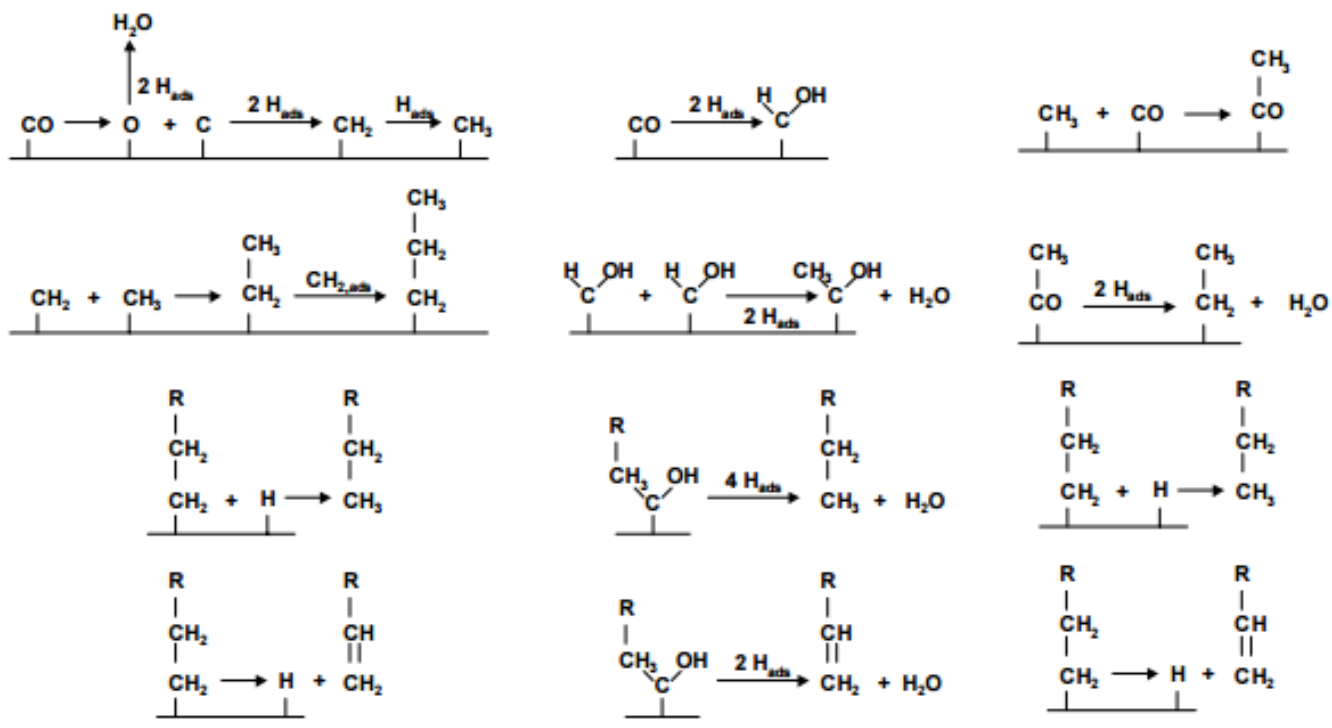

Figura 2. Representação esquemática de três mecanismos básicos de reação de Fischer-Tropsch: mecanismo de carbeno, mecanismo de hidroxicarbeno e mecanismo de inserção de CO (Johannes van Dijk, 2001).

Este mecanismo de inserção de $\mathrm{CO}$ foi primeiramente proposto por Pichler e Schulz em 1970. Ele é baseado em complexos organometálicos. Assumindo que a superfície ativa durante a catálise heterogênea, consiste de sítios ativos individuais que possuem uma coordenação específica, os complexos organometálicos representam sítios de crescimento da cadeia durante a síntese de Fischer-Tropsch. Verdadeiramente, a inserção de CO em 
um complexo metal-alquila é frequentemente observada com complexos de Fe e complexos de Ru. Porém, a inserção de metileno de acordo com o mecanismo de carbeno, também é reportada para sistemas organometálicos. Ainda não há evidência experimental para que a inserção de CO seja considerada o mecanismo chave para a formação de hidrocarbonetos durante a síntese de Fischer-Tropsch (Johannes van Dijk, 2001).

\subsection{2.}

\section{Mecanismo de enol}

Na década de 1950, o mecanismo de enol ganhou grande aceitação, e envolve a quimiossorção do $\mathrm{CO}$ que reage com hidrogênio adsorvido. $\mathrm{A}$ estrutura enol cresce por uma combinação de condensação e eliminação de água usando os grupos vizinhos, o processo esta mostrado na Figura 3.
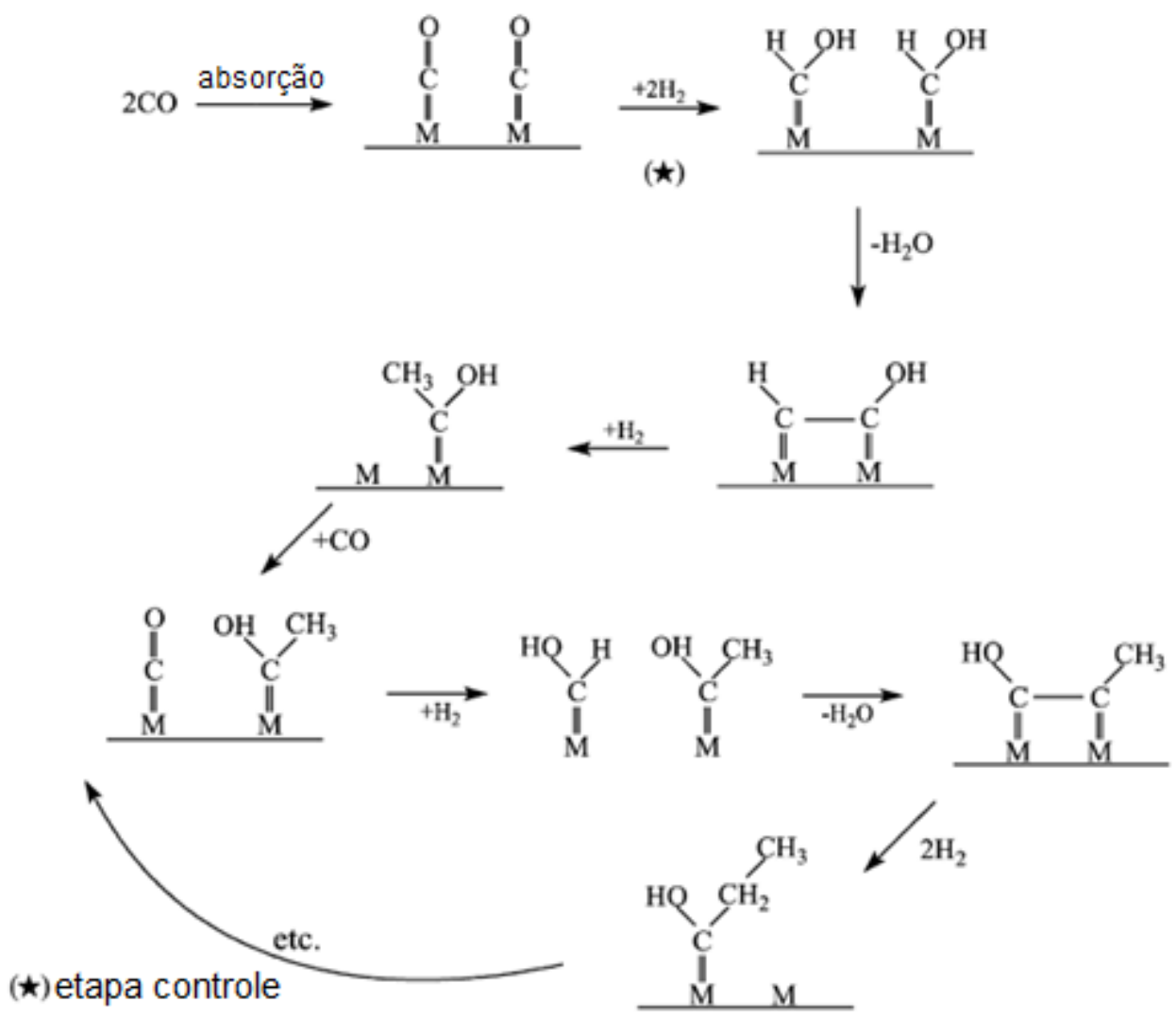

Figura 3. Mecanismo do Enol (DAVIS, 2001). 
De acordo com DRY (2002) surgem algumas perguntas, a fim de definir o mecanismo de Fischer-Tropsch, a molécula adsorvida quimicamente primeiro dissocia-se em $\mathrm{C}$ e $\mathrm{O}$ e os átomos de $\mathrm{C}$ são hidrogenados a monômeros $\mathrm{CH} 2$, ou o $\mathrm{CO}$ é hidrogenado para $\mathrm{CHO}$, ou espécies $\mathrm{HCOH}$ que são inseridos na cadeia em crescimento ou, finalmente, o CO é inserido diretamente e posteriormente hidrogenado.

\section{7.}

Distribuição de produtos

Várias tentativas foram feitas para modelar a distribuição de produtos no processo de Fischer-Tropsch, sendo ela associada com um tipo de função exponencial, sendo a probabilidade de crescimento da cadeia um fator importante.

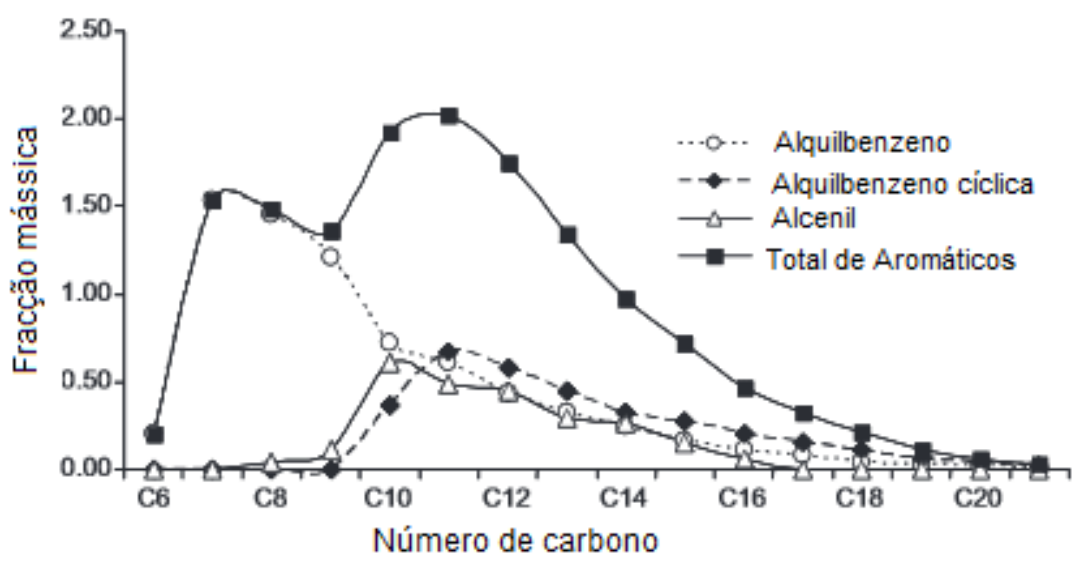

Figura 4. A distribuição aromática mononuclear ASF de um óleo HT-FT (VAN DER Westhuizen et al., 2010).

O melhor modelo desenvolvido em anos recentes para o processo Fischer-Tropsch assumindo uma probabilidade constante de crescimento da cadeia foi o modelo de Anderson-Schultz-Flory (ASF) que determina uma relação entre o rendimento do produto e o número de carbonos. A Figura 4 mostra um exemplo de uma distribuição aromática mononuclear de ASF. 


$$
\frac{W_{n}}{n}=\alpha^{n} \frac{(1-\alpha)^{2}}{\alpha}
$$

Onde,

$\alpha=$ probabilidade de crescimento da cadeia

Wn = fração (massa/massa) de produtos.

$\mathrm{n}=$ número de átomos de carbono.

A expressão para a equação de ASF (equação 10) é geralmente expressa como uma função logarítmica (equação 11), considerando-se uma distribuição do produto a partir de um processo de polimerização (VAN DER Westhuizen et al., 2010).

$$
\log \left(\frac{\mathrm{W}_{n}}{\mathrm{n}}\right)=\mathrm{n} \log (\alpha)+\log \left((1-\alpha)^{2} / \alpha\right.
$$

Van Der Westhuizen et al. (2010) descrevem que a é muito influenciado pelo catalisador, pelas condições de processo específicas e representa a probabilidade de uma molécula para continuar reagindo de tal forma que possa formar cadeias mais longas.

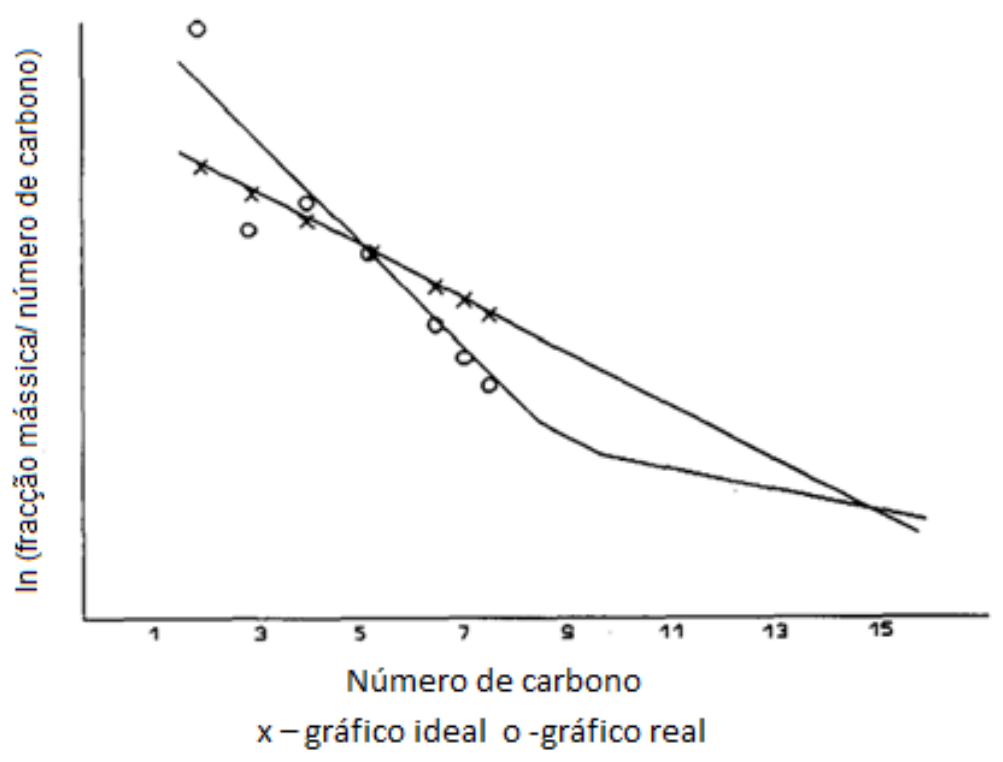

Figura 5. Distribuição de produtos de Fischer Tropsch de baixa temperatura usando a expressão de ASF e os obtidos experimentalmente (baseado em JAGER; ESPINOZA, 1995). 
A linearização da expressão de ASF dara os valores de a a partir dos coeficientes angulares das retas e pode variar entre 0 e 1 . A Figura 5 mostra a linearização dos produtos de ASF.

\section{8 .}

Tecnologias para a síntese Fischer-Tropsch

De acordo com o tipo de catalisador e as condições de operação, o processo de Fischer-Tropsch pode ser dividido em duas classes principais, "Low Temperature Fischer-Tropsch" (LTFT) e "High Temperature FischerTropsch" (HTFT). Os reatores usados na obtenção de produtos FT usando o processo LTFT incluem:

- Reator lama

- Reator tubular de leito fixo (Arge)

As temperaturas de operação LTFT estão na faixa de $210-260^{\circ} \mathrm{C}$. O processo de Fischer-Tropsch de alta temperatura (HTFT) opera a temperaturas mais elevadas $\left(310-340^{\circ} \mathrm{C}\right)$ do que o processo LTFT. Alguns tipos de reatores para a produção dos hidrocarbonetos são os seguintes:

- leito circulante

- Leito fluidizado, normalmente usados nos processos Synthol (LAMPRECHT; Dancuart, 2007).

A Tabela 1 mostra as distribuições de número de carbono, bem como a dependência na temperatura dos produtos de cada processo. 
Tabela 1. Distribuição do número de carbono na reação de Fischer-Tropsch de alta temperatura e de baixa temperatura dos produtos de FT, excluindo os hidrocarbonetos $C_{1}-C_{2}$ (KLERK, 2008).

\begin{tabular}{lll}
\hline \multicolumn{1}{c}{ Descrição } & \multicolumn{1}{c}{ HTFT } & \multicolumn{1}{c}{ LTFT } \\
\hline \hline Distribuição do Número de carbonos (\% massa) & & 10 \\
C3-C4, GLP & 30 & 19 \\
C5-C10, nafta & 40 & 22 \\
C11-C22, destilados & 16 & 46 \\
C22 e pesados & 6 & 3 \\
Produtos aquosos & 8 & \\
Classes dos compostos & & Principal produto \\
Parafinas & $>10 \%$ & $>10 \%$ \\
Olefinas & Principal produto & $<1 \%$ \\
Aromáticos & $5-10 \%$ & $5-15 \%$ \\
Oxigenados & $5-15 \%$ & Inexistente \\
Espécies S- e N- & Inexistente & Principal subproduto \\
Água & Princil subproduto \\
\hline
\end{tabular}

\subsubsection{Reator de lama}

A mistura de gás $\left(\mathrm{CO} / \mathrm{H}_{2}\right)$ circula na parte inferior e se eleva através da lama. A pasta é formada por produtos de reação no estado líquido, em que a cera é o produto principal, com partículas de catalisador em suspensão na mesma. Hidrocarbonetos e água são os produtos resultantes do reagente gasoso que se difunde através da fase líquida para o catalisador em suspensão. Os produtos gasosos mais leves e água se difundem através do líquido para as bolhas de gás, enquanto que os hidrocarbonetos mais pesados fazem parte da fase de pasta. Os produtos gasosos, juntamente com gás de síntese que não reagiu passam através do leito de lama para a área livre acima do leito e, em seguida, são direcionados para a saída de gás (ESPINOZA et al., 1999). 


\subsection{2.}

\section{Reator tubular de leito fixo (Arge)}

A parte lateral do reator é utilizada para a remoção de calor gerado na síntese da reação exotérmica, as condições de operação são de cerca de 220 - C e 25 bar, para a temperatura e pressão, respectivamente. Um ponto chave no reator tubular de leito fixo é que pode facilmente separar o produto de cera do catalisador, este reator apresenta a desvantagem de ter um alto custo de capital de investimento (Espinoza et al., 1999).

\subsection{3.}

\section{Reator de leito fluidizado circulante}

O reator de leito fluidizado circulante foi utilizado na planta de Sasolburg na década de 1950. Os reatores Synthol na Sasolburg foram operados com um catalisador de ferro a cerca de $340^{\circ} \mathrm{C}$ e $2 \mathrm{MPa}, \mathrm{O}$ catalisador é removido a partir da secção de reação pelo gás de alimentação que foi pré-aquecido a cerca de $200^{\circ} \mathrm{C}$ (Steynberg et al., 2004).

Neste processo, o catalisador fino é arrastado por uma alta velocidade (1-2 $\mathrm{m} / \mathrm{s})$ de fluxo de gás através de um reator ascendente. $\mathrm{O}$ catalisador separado do efluente por ciclones é retornado para a entrada do reator. Duas zonas de resfriamento no reator ascendente de subida fazem a remoção de calor na reação. Estes reatores tinham sido originalmente desenvolvidos pela Kellog. (SIE; KRISHNA, 1999).

\subsubsection{Sistemas de leito fluidizado}

Steynberg et al. (2004) descrevem que "o tipo de reator de leito fluidizado preferido é multitubular com o catalisador colocado dentro dos tubos, sendo a água utilizada, como meio de arrefecimento no casco. Tendo uma pequena distância entre as partículas de catalisador e as paredes do tubo (usando os diâmetros dos tubos estreitos) e operando a elevadas velocidades 
lineares de gás, para garantir um fluxo turbulento, melhorar a transferência de calor da reação a partir das partículas de catalisador para o meio de arrefecimento. A fim de alcançar conversões elevadas do gás de alimentação, é prática comum reciclar uma porção do efluente do reator ".A Figura 6 mostra alguns dos modelos de reatores de Fischer Tropsch.

a)
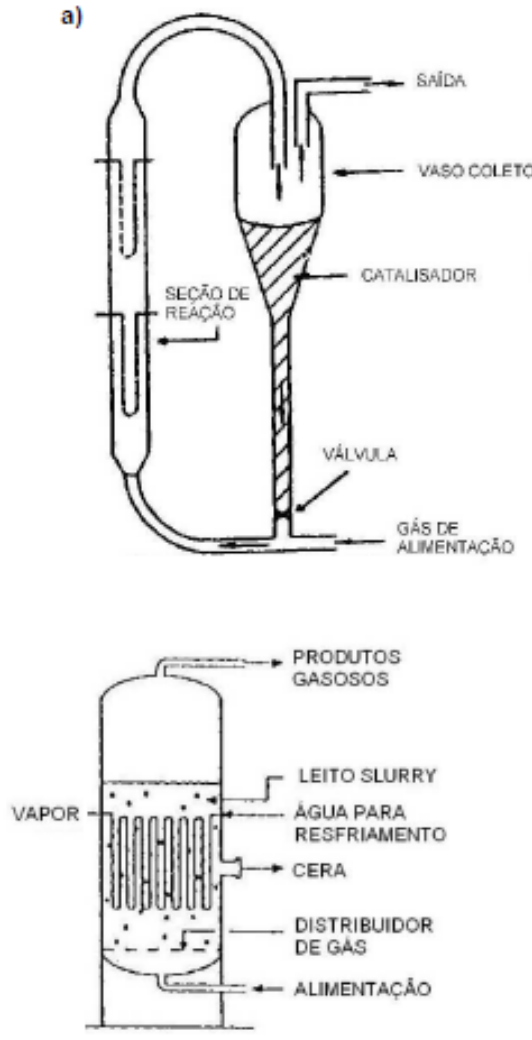

c) b)
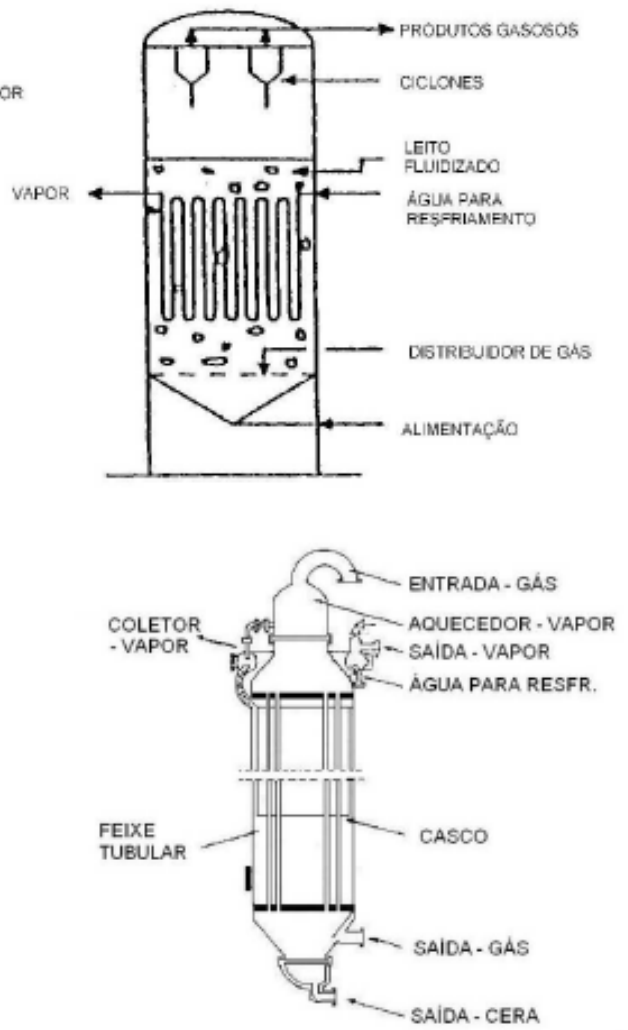

d)

Figura 6. (a) Reator de leito fluidizado circulante; (b) Sistemas de leito fluidizado; (c) Reator de lama; (d) Reator tubular de leito fixo (Arge) (DRY, 2002). 


\section{9 .}

\section{Catalisadores}

A maioria dos catalisadores de Fischer-Tropsch são metais do grupo VIII-B da tabela periódica como ferro, cobalto e rutênio, principalmente ferro e cobalto por terem aplicação industrial. $O$ rutênio tem a desvantagem de apresentar um elevado custo (KREUTZ; Larson, 2008).

O tipo de catalisador, bem como as condições de operação determinam os produtos da reação de Fischer-Tropsch. A tecnologia de Fischer-Tropsch de alta temperatura (HTFT) é usada apenas com o catalisador de ferro em reatores de leito fluidizado e de leito fluidizado circulante, no entanto, a tecnologia de Fischer-Tropsch (LTFT) de baixa temperatura utilizam catalisadores de ferro ou cobalto (KLERK, 2008).

\subsection{1.}

\section{Catalisadores a base de ferro}

O uso de catalisador a base de ferro chamou a atenção devido ao seu baixo custo, bem como sua flexibilidade de mudanças nas condições de operação: como a temperatura e a pressão. Além disso, eles podem ser utilizados em diferentes proporções de $\mathrm{H}_{2} / \mathrm{CO}(0,5-2,5)$, entretanto, os catalisadores de ferro têm dificuldades para resistir à desativação devido ao efeito de oxidação pela água e têm a desvantagem de ativar a reação de deslocamento de agua (WGSR) ( $\mathrm{CO}+\mathrm{H}_{2} \mathrm{O} \longleftrightarrow \mathrm{CO}_{2}+\mathrm{H}_{2}$ ). Esta reação consome $\mathrm{CO}$ e água formada pela reação FTS para produzir hidrogênio adicional, bem como o dióxido de carbono, mesmo que os catalisadores de ferro sejam menos desativados por agentes venenosos.

Catalisadores à base de ferro são utilizados comumente sem suporte com o inconveniente de ter baixa área de superfície e degradação física. Quando um suporte é aplicado ao catalisador de ferro melhora a estabilidade catalítica gerando uma taxa mais baixa de desativação, mas provoca uma 
menor atividade devido à interação da fase ativa com o suporte que afeta a redução dos óxidos de ferro (PIROLA et al., 2009).

DAVIS (2003) descreve a utilização de promotores tais como potássio e cobre, sendo o primeiro o responsável por aumentar a atividade e seletividade do catalisador, mas com a desvantagem da redução da fração de $\mathrm{CH}_{4}$ (luo; Hamdeh; Davis, 2009). O cobre por exemplo afeta a velocidade do catalisador para atingir uma máxima atividade. A adição destes promotores é feita, por impregnação do precipitado de ferro com uma solução aquosa contendo os promotores.

Ll et al. (2001) estudaram a influência de promotores $\mathrm{Cu}$, Zn e K em catalisador de ferro, descobriram que o $\mathrm{Cu}$ aumenta a redução da taxa de $\mathrm{Fe}_{2} \mathrm{O}_{3}$ para $\mathrm{Fe}_{3} \mathrm{O}_{4}$, fornecendo locais de dissociação de $\mathrm{H}_{2}$. As taxas de ativação de $\mathrm{CO}$ e carburação de $\mathrm{Fe}_{3} \mathrm{O}_{4}$ foram aumentadas pela presença de potássio. Desta forma, Cu e K promovem a nucleação das espécies do FeOx deficientes de oxigênio, que participam como intermediário na redução e carburação de Fe2O3. Estes promotores também ajudam a diminuir o tamanho final das partículas de óxido e das estruturas de carbeto de Fe formados durante a ativação com gás de síntese. Como resultado, $\mathrm{Cu}$ e $\mathrm{K}$ aumentam as taxas do FTS em catalisadores formados a partir de precursores de óxidos de Fe-Zn. Cu aumenta a produção de $\mathrm{CH}_{4}$ e o conteúdo de parafina nos produtos de Fischer-Tropsch, em quanto a presença de K inibe esta produção.

Lou et al (2009) mencionaram que a influência no pré-tratamento de catalisador de ferro na reação de Fischer-Tropsch é uma fase crucial para as propriedades de atividade e seletividade. Comumente $\mathrm{H}_{2}$ é usado para ativar o catalisador de cobalto e ferro, e consequentemente, cobalto metálico é a fase ativa para Fischer-Tropsch para catalisador de Co, mas para o catalisador de ferro não é tão simples identificar a fase ativa. Os óxidos de ferro 
transformam-se em estruturas ativas, durante o contato inicial com o gás de síntese em condições típicas, tais como: $\mathrm{Fe}$, carbetos $\mathrm{Fe}$ ( $\mathrm{FeCx}$ ) ou óxidos de ferro ( $\mathrm{FeOx}$ ), e estas têm sido propostas como estruturas ativas durante o estado estacionário de síntese de Fischer-Tropsch (LI et al., 2001b).

Zhang et al. (2006) pesquisou a interação de nano partículas de ferrosílica como catalisador na reação do FTS e descobriu que misturas de óxido de ferro existiam no catalisador preparado enquanto $\mathrm{FeO}$ e silicato de ferro foram as principais fases após a redução. A formação destas nano partículas e a presença de fases metaestáveis resultou em menor atividade na reação de Fischer Tropsch e maior produção de hidrocarbonetos leves. Portanto, a utilização de catalisadores de Fe suportados tem suas limitações tendo os não suportados propriedades superiores (O'Brien et al., 1997; Wielers et al., 1989; Guczi; 1993).

Bukur et al. (2002) fizeram um trabalho para estudar a redução e o comportamento catalítico na síntese Fischer-Tropsch de catalisadores de ferro suportados tanto em sílica como em alumina, promovidos com potássio e cobre. Verificou-se que a alumina inibe a redução do ferro, enquanto que o comportamento de redução do catalisador suportado em sílica foi semelhante ao de um não suportado. O catalisador suportado em sílica tinha maior seletividade em leves e mais baixo teor em olefinas que o catalisador suportado em alumina e no não suportado.

\subsection{2.}

\section{Catalisadores de Cobalto}

Os catalisadores à base de cobalto são usados somente no processo LTFT, pois em temperaturas mais elevadas excesso de $\mathrm{CH}_{4}$ é produzido. Por causa do alto preço do Co é desejável minimizar a quantidade utilizada, maximizando a área de superfície disponível do metal. Para alcançar isto o Co é disperso em suportes como $\mathrm{Al}_{2} \mathrm{O}_{3}, \mathrm{TiO}_{2}$ ou $\mathrm{SiO}_{2}$ (Oukaci et al., 1999). 
Os catalisadores de cobalto também são geralmente promovidos com uma pequena quantidade de metal nobre, por exemplo $\mathrm{Pt}$, Ru, Re, que é necessária para melhorar o processo de redução e também manter a superfície do metal Co "limpa" durante a síntese de FT (Iglesia et al., 1993).

Os catalisadores à base de cobalto no processo de FT são geralmente preferidos para a síntese de parafinas de cadeia longa (Dry,1990; Chanenchuk, 1991), já que eles são mais ativos por peso do metal, mais estáveis frente a desativação por água, menos ativos para a reação de WGS, e produzem menos oxigenados que os sistemas baseados em ferro (Martínez et al., 2003).

Reuel \& Bartholomew (1984) analisaram a atividade específica e a seletividade de cobalto não suportados e suportado em alumina, sílica, titânia, carbono, e magnésia. A ordem decrescente da atividade de hidrogenação de $\mathrm{CO}$ a $1 \mathrm{~atm}$ e $225^{\circ} \mathrm{C}$ para catalisadores contendo $3 \%$ em peso de cobalto foi $\mathrm{Co} / \mathrm{TiO}_{2}>\mathrm{Co} / \mathrm{SiO}_{2}>\mathrm{Co} / \mathrm{Al}_{2} \mathrm{O}_{3}>\mathrm{Co} / \mathrm{C}>\mathrm{Co} / \mathrm{MgO}$. Em relação a seletividade, os catalisadores possuindo as dispersões mais elevadas e extensões de redução mais baixas geraram hidrocarbonetos de baixo peso molecular e elevadas razões $\mathrm{CO}_{2} / \mathrm{H}_{2} \mathrm{O}$.

\subsection{0.}

\section{Aspectos cinéticos}

A descrição cinética da reação de Fischer-Tropsch é muito importante para a prática industrial, como um pré-requisito para o processo de projeto, otimização e simulação. Para desenvolver as expressões da taxa de consumo de $\mathrm{CO}$, as informações sobre a produção de hidrocarbonetos são sempre de grande importância (Arsalanfar et al.; 2012). 
A formação de monômero é geralmente assumida como o passo determinante da taxa de reação de Fischer-Tropsch (VAN STEEN; SCHULZ, 1999).

NIKPARSAA et al. (2014) desenvolveram um estudo cinético para o catalisador de Co-Ni/ $/ \mathrm{Al}_{2} \mathrm{O}_{3}$ com base na teoria de adsorção do LangmuirHinshelwood-Hougen-Watson. Usando a regressão não linear e parâmetros estatísticos como a variância e Marr, verificou-se que o mecanismo enólico com a interação entre a adsorção de $\mathrm{HCO}$ e a adsorção dissociada de hidrogênio como a etapa controladora da velocidade é o único mecanismo plausível, tendo como resultado a seguinte equação cinética:

$$
-r_{\mathrm{CO}}=\frac{k p_{\mathrm{CO}} p_{\mathrm{H}_{2}}}{\left(1+a p_{\mathrm{CO}} p_{\mathrm{H}_{2}}^{0.5}\right)^{2}}
$$

Enquanto para o catalisador de ferro, Atwood e Bennet (1979) sugerem que a expressão de equação cinética seja

$$
r_{\mathrm{FTS}}=\frac{k P_{\mathrm{CO}} P_{\mathrm{H}_{2}}}{P_{\mathrm{CO}}+b P_{\mathrm{H}_{2} \mathrm{O}}}
$$

Dry (2002) também estudou a cinética da reação de Fischer-Tropsch com o propósito de avaliar a diferença entre as taxas de reação dos catalisadores de ferro e cobalto, utilizando as seguintes equações

Para ferro,

$$
r=\frac{m p_{\mathrm{H}_{2}} p_{\mathrm{CO}}}{p_{\mathrm{CO}}+a p_{\mathrm{H}_{2} \mathrm{O}}}
$$

Para cobalto,

$$
r=\frac{k p_{\mathrm{H}_{2}} p_{\mathrm{CO}}}{\left(1+b p_{\mathrm{CO}}\right)^{2}}
$$


A diferença mais significativa entre as equações de ferro e de cobalto é a ausência do termo de pressão de vapor de água na equação 15. Quimicamente, é bem conhecido que o ferro é mais oxidado em baixas proporções de $\mathrm{H}_{2} \mathrm{O} / \mathrm{H}_{2}$ do que o cobalto metálico e assim pode-se argumentar que sob as condições da síntese de Fischer-Tropsch uma maior fração da superfície exposta de ferro vai ser ocupada por átomos/ íons de oxigênio, em qualquer instante, resultando numa perda de sítios ativos na reação de FT, ou seja, a proporção $\mathrm{H}_{2} \mathrm{O} / \mathrm{H}_{2}$, aumenta ao longo do comprimento do reator, tendo assim o catalisador de cobalto uma vantagem grande na atividade sobre 0 catalisadores de ferro.

Espinoza (1999) descreve que, para os catalisadores de cobalto, é mais fácil conseguir maior conversão do que para os catalisadores de ferro. $O$ catalisador de ferro é mais produtivo em maiores velocidades espaciais e mais elevadas pressões de operação. Os catalisadores de cobalto são mais produtivos nas velocidades espaciais mais baixas (maiores pressões parciais de água). Isto significa que o cobalto é mais produtivo em mais elevado regimes de conversão por passe.

\subsection{1.}

Suporte

Os catalisadores de ferro comercial não suportados apresentam boa atividade e seletividade, mas apesar disso, os catalisadores de ferro não suportados são em geral mecanicamente frágeis para uso em reatores de tipo lama devido às altas taxas de desgaste das partículas finas no reator que aumentam a dificuldade de separação do sólido da cera. Por exemplo, grande atrito do catalisador foi observado em um reator de leito de lama operado pela companhia DOE em LaPorte, Texas, acarretando a parado do reator depois de apenas um dia de operação (Bhatt et al., 1992). É bem conhecido que os 
catalisadores de metais suportados têm mais resistência ao atrito devido à alta força mecânica do suporte (O'BRIEN et al., 2000).

De acordo com CAGNOLI et al., (1990) as vantagens do uso de catalisadores suportados são as seguintes:

- O suporte pode interagir com o metal, alterando a sua propriedade eletrônica e simultaneamente a sua atividade e seletividade.

- A dispersão do metal torna-se um parâmetro que pode ser variado para o propósito de estudar a estrutura do catalisador.

- Uma menor sinterização de metal pode ocorrer.

O suporte também ajuda ao catalisador nos seguintes aspectos:

- Facilitar a preparação de catalisadores com maior dispersão da fase ativa.

- Estabilizar a(s) fase(s) ativa(s) contra a sinterização (Bhatt et al., 1992).

Estudos prévios para desenvolver catalisadores de ferro suportados têm sido feitos sem muito sucesso, apresentando em grande parte uma baixa atividade e alta seletividade pelo metano (BUKUR; SIVARAJ, 2002; O'BRIEN et al., 2000; Bartholomew et al., 2003).

CAGNOLI et al., (1990) estudaram a influência dos suportes de $\mathrm{Al}_{2} \mathrm{O}_{3} \mathrm{e}$ $\mathrm{SiO}_{2}$ sobre a atividade e seletividade de catalisadores de ferro de alta dispersão e com cristalito de diâmetro pequeno de (diâmetro médio de 1,2 e $1,4 \mathrm{~nm}$ para $\mathrm{Al}_{2} \mathrm{O}_{3}$ e $\mathrm{SiO}_{2}$, respectivamente). A atividade do catalisador que foi suportado em alumina tinha uma ordem de grandeza menor do que o suportado em sílica. O diâmetro de cristalito em ambos os catalisadores foi o mesmo, esta diferença na atividade foi atribuída à alta interação metal-suporte do ferro com a alumina. Esta suposição foi também verificada pela formação 
dos dois compostos; ou seja, $\mathrm{FeAlO}_{3}$ e $\mathrm{FeAl}_{2} \mathrm{O}_{4}$. Os catalisadores suportados em alumina também mostraram maior seletividade pelo metano e menor em olefinas.

KEYVANLOO et al., (2014) analisaram os efeitos de seis catalisadores de $\mathrm{FeCuK}$ suportados em alumina (contendo $20 \%$ e $40 \%$ de ferro) levando em conta as seguintes propriedades: o tamanho dos poros, a concentração do grupo hidroxila e o estabilizador do suporte. Os catalisadores foram suportados em alumina e estabilizados com $\mathrm{La}_{2} \mathrm{O}_{3}$ ou $\mathrm{SiO}_{2}$. A ativação do catalisador gerou um aumento do tamanho dos poros de suporte, menores concentrações de grupo $\mathrm{OH}$, e extensões maiores de redução. Os autores verificaram que o $\mathrm{SiO}_{2}$ é um estabilizador hidrotérmico mais eficaz do que o $\mathrm{La}_{2} \mathrm{O}_{3}$ devido ao fato de suprimir a transformação de $\gamma-\mathrm{Al}_{2} \mathrm{O}_{3}$ para $\alpha-\mathrm{Al}_{2} \mathrm{O}_{3}$ a $1200{ }^{\circ} \mathrm{C}$, permitindo ao catalisador estabilizado com $\mathrm{SiO}_{2}$ ser hidroxilado em temperaturas mais altas.

$\mathrm{SiO}_{2}, \mathrm{Al}_{2} \mathrm{O}_{3}, \mathrm{ZnO}, \mathrm{MgO}$ e $\mathrm{TiO}_{2}$ têm sido extensivamente investigado como suportes para os catalisadores na reação de Fischer-Tropsch (CAGNOLI et al., 1990; O'BRIEN et al., 2000). $\mathrm{SiO}_{2}$ foi escolhido como o suporte principal para a preparação de catalisadores à base de ferro com elevada resistência ao atrito utilizando o método de co-precipitação e tecnologia de secagem por pulverização. No entanto, os catalisadores contendo $\mathrm{SiO}_{2}$ geralmente apresentam baixa atividade na reação de FTS. Por isso, muitos estudos têm sido realizados para investigar a relação entre o suporte $\mathrm{SiO} 2$ e os desempenhos dos catalisadores na síntese de Fischer-Tropsch (WAN et al., 2006).

Yang et al. (2005) investigaram o impacto do teor de $\mathrm{SiO}_{2}$ na redução e desempenho catalítico sobre catalisador Fe-Mn precipitado e preparado via secagem normal. Os resultados mostraram que certa quantidade de $\mathrm{SiO}_{2}$ incorporado no catalisador de Fe-Mn diminuiu o tamanho do cristalito, 
favorecendo a redução do $\mathrm{Fe}_{2} \mathrm{O}_{3} \rightarrow \mathrm{FeO}$, e melhorando a seletividade para hidrocarbonetos pesados e a estabilidade do catalisador.

O suporte é muito importante para as propriedades finais do catalisador de Fischer-Tropsch. A atividade e seletividade são indiretamente afetadas pelas propriedades físicas do suporte, por exemplo Borg et al. (2007) encontraram uma correlação positiva entre o catalisador suportado em $\gamma-\mathrm{Al}_{2} \mathrm{O}_{3}$ e o diâmetro dos poros e a seletividade em $\mathrm{C}^{+}$. A mesma tendência foi encontrada para catalisadores de cobalto suportados em sílica mesoporosa. Este último fato foi corroborado pelo autores LESAINT et al., (2008), o material usado apresentou as melhores propriedades porosas (grande tamanho de poro) e resultou em melhores propriedades catalíticas em relação à atividade e seletividade em $\mathrm{C} 5{ }^{+}$.

\subsection{2. \\ Promotores}

Acredita-se que a adição de promotores químicos é importante na melhoria do comportamento químico dos catalisadores de ferro, por exemplo, facilitando a redução do catalisador e a adsorção e dissociação de $\mathrm{H}_{2}$ e CO na superfície do mesmo. Os promotores são concebidos para auxiliar ou o suporte ou o componente ativo. Um exemplo importante da ajuda ao suporte é o controle de estabilidade (ARSALANFAR et al., 2014).

Os catalisadores heterogeneos são tipicamente sistemas de componentes múltiplos contendo a fase cataliticamente ativa e diferentes tipos de promotores para aumentar a atividade, seletividade e estabilidade do catalisador (CHONCO et al., 2013). 
Os promotores foram classificados de acordo com suas funções principais (Dry et al., 1989) como:

- Promotor estrutural: ajuda ou mantém a dispersão da fase cataliticamente ativa.

- Promotor de redução: facilita a transformação para a fase reduzida cataliticamente ativa.

- Promotor químico: que afeta a atividade catalitica intrínseca do sítio ativo cataliticamente.

XIONG et al., (2010) encontraram que a adição de $\mathrm{K}$ diminuiu a atividade catalítica, mas aumentou a seletividade de olefinas, conduzindo a uma seletividade mais elevada de hidrocarbonetos de cadeia longa.

A adição de $\mathrm{K}$ ou $\mathrm{Na}$ ao catalisador de $\mathrm{FeCu} / \mathrm{SiO}_{2}$ tem sido reportada para melhorar a atividade catalítica e mudar a distribuição dos produtos de hidrocarbonetos pesados na reação de Fischer Tropsch (AN et al., 2007). Em contraste, XIONG et al. (2010), afirmaram que para um catalisador de ferro suportado em esferas de carbono reduzida por meio de $\mathrm{H}_{2}$, o $\mathrm{K}$ gerou um efeito negativo na atividade, quando a reação FT foi realizada num reator de leito fixo (carga de K: 0,05-1\%), mas aumentou a seletividade em olefinas e em hidrocarbonetos de cadeia longa.

XIONG et al., (2015) investigaram o efeito dos promotores de metal alcalino ( $\mathrm{Li}, \mathrm{Na}$ e $\mathrm{K}$ ) sobre as propriedades e desempenhos catalíticos do catalisador de Fe suportado em nanotubos de carbono (CNT) na reação de FTS considerando ausência de fortes interações metal/suporte encontrado para óxido de metal suportado. Verificou-se que a adição de promotores alcalinos levou a um aumento no tamanho de cristalito do óxido de ferro e reduziu as áreas de superfície, em comparação com o catalisador Fe / CNT não promovido. A presença de promotores de $\mathrm{Na}$ e $\mathrm{K}$ dificultou a redutibilidade 
do catalisador através do aumento da temperatura de redução do óxido de ferro; enquanto o catalisador promovido com potássio mostrou o efeito mais pronunciado e nenhum efeito foi observado para o Li. Os catalisadores promovidos com sódio e potássio foram reportados para diminuir a seletividade para produzir metano, aumentar a produção de olefinas e deslocar a seletividade para hidrocarbonetos de maior peso molecular durante a reação de FTS. Por outro lado, Na e Li aumentaram a conversão de CO, enquanto a adição de $\mathrm{K}$ diminuiu a atividade.

DLAMINI et al., (2002) realizaram um estudo interessante sobre o efeito da adição de $\mathrm{SiO}_{2}$ para um catalisador de ferro precipitado usando análise de microscopia eletrônica de varredura e encontrou que a quantidade eficaz de $\mathrm{K}_{2} \mathrm{O}$ associada com $\mathrm{Fe}$ é menor quando a $\mathrm{SiO}_{2}$ é adicionada como um ligante.

Em um estudo similar YANG et al., (2005) analisaram um catalisador contendo potássio, sem adição de $\mathrm{SiO}_{2}$, apresentando atividade mais elevada do que os catalisadores contendo $\mathrm{SiO}_{2}$. A diminuição da atividade com adição de $\mathrm{SiO}_{2}$ foi atribuída pelos autores à diminuição da efetividade do potássio devido à interação entre potássio e sílica.

\subsection{3.}

Ativação

Os catalisadores de $\mathrm{Co}, \mathrm{Ni}, \mathrm{Ru}, \mathrm{Fe}$, são geralmente sintetizados na forma de óxido metálico, e devem ser expostos a um tratamento de ativação antes do catalisador ser usado para a reação de Fischer Tropsch. Co, Ni, Ru são normalmente reduzidos por um fluxo de hidrogênio, em temperatura de 473K a 723K, permanecendo em estado metálico durante a síntese de Fischer-Tropsch (SHROFF et al., 1995) No entanto, o processo de ativação não é tão simples para os catalisadores à base de ferro que foram relatados como sendo ativados, sob monóxido de carbono (O'BRIEN et al., 1996;(BUKUR; LANG; DING, 1999)), hidrogênio (DRY; ANDERSON; 
BOUDART, M., 1981), ou tratamento com gás de síntese (KÖLBEL; RALEK, 1980; Bukur et al., 1999).

Durante a etapa de pré-tratamento e durante a reação de FischerTropsch, os catalisadores a base ferro podem sofrer várias transformações de fase. A natureza da(s) fase(s) final após o pré-tratamento, ou mais provavelmente, a(s) fase(s) mais estável(eis) no âmbito do Fischer Tropsch, irá determinar o desempenho do catalisador. Durante o processo de ativação, o óxido de ferro na forma de hematita $\left(\alpha-\mathrm{Fe}_{2} \mathrm{O}_{3}\right)$ se transforma em magnetita $\left(\mathrm{Fe}_{3} \mathrm{O}_{4}\right)$ independentemente do gás de ativação utilizado para o prétratamento. A partir deste ponto, a natureza da atmosfera ativante determinará a natureza das fases Fe formado (HERRANZ et al., 2006). No caso de uso de $\mathrm{CO}+\mathrm{H}_{2}$ se formará o carbeto de ferro.

Dois modelos foram propostos para explicar o papel da fase de carbeto. Por um lado, o modelo de carbeto (RAUPP; DELGASS, 1979) propõe que a reação do FT ocorre na superfície de uma massa da fase de carbeto de ferro, sendo a densidade de tais locais dependentes da extensão da carbonetação ocorrida.

Por outro lado, o modelo de competição propõe que um ou mais átomos de carbono em conjunto com o ferro metálico formam o local ativo em que os átomos de carbono são hidrogenados (NIEMANTSVERDRIET et al., 1980)

Conforme a Herranz et al., (2006) a carburação de ferro e a formação de hidrocarbonetos a partir de espécies superficiais contendo "carbono" ocorre simultaneamente numa reação competitiva.

Deve notar-se que em ambos modelos, a formação de carbeto de Fe é um passo necessário para produzir o catalisador atual do Fischer-Tropsch, no entanto os autores Dry et al., (1981) e O'BRIEN et al., (1995) concordam que 
a correlação entre espécies de carbeto, na superfície de carbono e atividade catalítica ainda não foi estabelecida. Nem se sabe ainda o papel real do carbeto na reação do Fischer Tropsch; se eles estão realmente envolvidos na reação ou não.

\subsection{4 .}

\section{Regeneração}

O método de regeneração deve ser considerado para a recuperação do catalisador após a desativação do catalisador; a desativação se refere a etapa após o qual um catalisador perdeu tanto da sua atividade inicial que deve ser regenerado ou substituído; embora como a fase ativa do catalisador de ferro para a reação de FT ainda não está totalmente estabelecida, a oxidação do ferro metálico é um dos fatores para a desativação do catalisador. $\mathrm{H}_{2} \mathrm{O}$ (o produto principal na reação de $\mathrm{FT}$ ) e $\mathrm{CO}_{2}$ (produzido de reação de deslocamento de água e gás WGSR) são geralmente consideradas como agentes oxidantes para as fases do ferro (LI et al., 2001).

Para ELIASON e BARTHOLOMEW (1999) existem três principais causas de desativação do catalisador, sendo a principal deles por formação do coque, a segunda causa é originada a partir de alteração da estrutura da fase ativa e da dispersão, enquanto que a terceira é a contaminação por vários produtos químicos que adsorvem sobre os locais ativos, sendo os contaminantes provenientes da linha de alimentação (principalmente: vanádio, níquel, arsénio, sódio), ou de aditivos utilizados durante as operações de refino (silício, chumbo), ou a partir de corrosão.

O tratamento com hidrogênio é um dos métodos de regeneração mais importante para este caso, no qual o fluxo de hidrogênio passa no interior de reator em contato com o catalisador. O fim do ciclo de uso do catalisador é geralmente determinado por um nível de baixa atividade para satisfazer as especificações do produto. A quantidade de coque removido da superfície do 
catalisador é medida pela quantidade de $\mathrm{CH}_{4}$ produzido durante o tratamento de regeneração.

O processo de regeneração com ar para remoção de coque consiste no contato de um catalisador desativado de Fischer-Tropsch com ar em condições de oxidação em período de tempo suficiente tal que possa reativar o catalisador de Fischer Tropsch. O experimento é executado até que a quantidade de $\mathrm{CO}_{2}$ produzido seja insignificante. Após a regeneração, o catalisador é novamente reduzido (NAKHAEI POUR et al., 2014).

A regeneração é possível algumas vezes mas há um limite. No final do ciclo de vida após as várias regenerações o catalisador é reciclado ou eliminado. É óbvio que a eliminação deve ser evitada o quanto possível e que a reciclagem está se tornando cada vez mais utilizada (MOULIJN; VAN DIEPEN; KAPTEIJN, 2001). 


\section{3 \\ Metodologia experimental e métodos}

\section{1.}

Preparação dos suportes e catalisadores

O seguinte capítulo tem como objetivo principal dar a conhecer os detalhes experimentais, equipamentos utilizados assim como a metodologia empregada.

Um sistema catalítico contendo nano partículas de ferro não suportado foi preparado para ser comparado com catalisadores suportados de ferro. Estes catalisadores foram preparados com diferentes suportes e teor metálico.

3.1.1.

Reagentes

Os reagentes utilizados para a preparação dos catalisadores são especificados na Tabela 2. 
Tabela 2. Reagentes utilizados.

\begin{tabular}{|l|c|}
\hline \multicolumn{1}{|c|}{ Reagente } & Marca \\
\hline $\begin{array}{l}\text { Cloreto férrico } \\
\text { Hexaidratado P.A. }\end{array}$ & VETEC \\
\hline Al2O3 + SiO2 & Siral (Sasol) \\
\hline N-Hexadecano & Sigma-Aldrich \\
\hline Cloreto de Paladio II (99\%) & Sigma-Aldrich \\
\hline Boroidreto de Sodio (99\%) & Sigma-Aldrich \\
\hline $\begin{array}{l}\text { Nitrato de cobalto } \\
\text { hexaidratado P.A. }\end{array}$ & VETEC \\
\hline Ureia P.A. & ISOFAR \\
\hline Água Deionizada & \\
\hline $\begin{array}{l}\text { Acido Poliacrilico 3.5\% } \\
\text { peso }\end{array}$ & Sigma-Aldrich \\
\hline $\begin{array}{l}\text { Copolímero tribloco } \\
\text { Pluronic ® P123 }\end{array}$ & BASF \\
\hline Tetraetilortosilicato (TEOS) & Merck-Schuchardt \\
\hline Acido Cloridico & Sigma-Aldrich \\
\hline & \\
\hline
\end{tabular}

\subsection{2.}

\section{Síntese da sílica mesoporosa}

O suporte de sílica mesoporosa foi sintetizado a partir $4 \mathrm{~g}$ do copolímero tribloco Pluronic ${ }^{\circledR} 123$ [poli- (óxido de etileno) -poli (óxido de propileno) -poli (óxido de etileno)] EO20PO70EO20, o qual foi disperso em $30 \mathrm{~g}$ de água deionizada. À solução foi então acrescentado, sob agitação, $120 \mathrm{~g}$ de $\mathrm{HCl} 2 \mathrm{~mol}$ $\mathrm{L}^{-1}$, de modo a se obter uma solução homogênea com $\mathrm{pH}$ neutro. Posteriormente, adicionou-se 9,50g de tetraetilortosilicato (TEOS, Aldrich) que é a fonte de sílica, levando à formação do gel reativo. O gel obtido foi levado ao micro-ondas numa temperatura de $373 \mathrm{~K}$ por 2 horas.O produto formado foi centrifugado, duplamente lavado com água deionizada e novamente centrifugado. Após seca a $393 \mathrm{~K}$, a amostra foi calcinada por 6 horas a $673 \mathrm{~K}$ em atmosfera de ar sintético (BACHARI; TOUILEB; LAMOUCHI, 2009). 
3.1.3.

Preparação dos catalisadores suportados em Silica-Alumina

Dois catalisadores de Fe suportados em sílica-alumina, além de outro de cobalto suportado também em sílica alumina foram preparadas pelo método de impregnação incipiente do ponto úmido, através de quantidades apropriadas de soluções aquosas de $\mathrm{FeCl}_{3} \cdot 6 \mathrm{H}_{2} \mathrm{O}$ (99\% -Merck) e nitrato de cobalto hexaidratado P.A. como fonte de ferro e cobalto, respetivamente. $O$ teor metálico total incorporado nas amostras foi de 5\% p/p e 2\% p/p. Após misturar o suporte sílica alumina com a solução respectiva do metal, a agitação manual foi procedida por cerca de 30 minutos, seguida de secagem em estufa a $343 \mathrm{~K}$ por $24 \mathrm{~h}$. Posteriormente, as amostras foram calcinadas a $673 \mathrm{~K}$ (taxa de aquecimento de $1 \mathrm{~K} / \mathrm{min}$ ), sob fluxo de ar de $30 \mathrm{ml} / \mathrm{min}$ durante $6 \mathrm{~h}$, para a decomposição do cloreto de ferro e os nitratos.

Um terceiro catalisador de ferro contendo $5 \% \mathrm{p} / \mathrm{p}$ do teor metálico foi preparado de forma diferente, neste uma quantidade apropriada de uma solução aquosa de $\mathrm{FeCl}_{3} \cdot 6 \mathrm{H}_{2} \mathrm{O}$ (99\% -Merck) foi misturada com ureia, depois aquecida na estufa até $363 \mathrm{~K}$ durante 24 horas, este último foi baseado no procedimento empregado por XIONG et al., (2014) na preparação de um catalisador de ferro suportado em esferas de carbono $\mathrm{N}$-dopadas.

\subsection{4.}

\section{Preparação dos catalisadores suportados em silica mesoporosa}

Os catalisadores de ferro suportado em sílica mesoporosa foram preparados pelo método de impregnação incipiente do ponto úmido, através de quantidades apropriadas de uma solução aquosa de $\mathrm{FeCl}_{3} \cdot 6 \mathrm{H}_{2} \mathrm{O}(99 \%$ Merck) como fonte de ferro. O teor metálico total incorporado na amostra foi de $2 \% \mathrm{p} / \mathrm{p}$. Após misturar o suporte sílica mesoporosa com a solução respectiva do metal, a agitação manual foi procedida por cerca de 30 minutos, seguida de secagem em estufa a $343 \mathrm{~K}$ por $24 \mathrm{~h}$. Posteriormente, as amostras 
foram calcinadas a $673 \mathrm{~K}$ (taxa de aquecimento de $1 \mathrm{~K} / \mathrm{min}$ ), sob fluxo de ar de $30 \mathrm{ml} / \mathrm{min}$ durante $6 \mathrm{~h}$, para a decomposição do cloreto de ferro.

\subsection{5.}

Preparação do catalisador a base de nano partículas de ferro

Nano partículas de ferro de 1,6 nm foram formados pela redução do boroidreto de sódio $\left(\mathrm{NaBH}_{4}\right)$ e cloreto férrico hexaidratado $\left(\mathrm{FeCl}_{3} \cdot 6 \mathrm{H}_{2} \mathrm{O}\right)$.

A síntese foi realizada misturando duas soluções, aqui chamados de soluções $C$ e $D$. Para a solução $C, 0,27 \mathrm{~g}$ de cloreto férrico foram dissolvidos em $20 \mathrm{~mL}$ de água deionizada, e em seguida, misturados com $20 \mathrm{ml}$ de solução de PAA (Acido Poliacrilico $3,5 \%$ em peso) seguido de $0,1 \mathrm{ml}$ de solução de cloreto de paládio. Depois da mistura, a cor da solução de cloreto férrico virou de amarelo para laranja. Para a solução $D, 0,75 \mathrm{~g}$ de boroidreto de sódio foram dissolvidos em $10 \mathrm{ml}$ de água deionizada. A solução $D$ foi, em seguida, adicionada gota a gota à solução $C$ sob agitação vigorosa. Gradualmente, a adição de solução $D$, tornou a solução $C$ completamente preta. A reação foi acompanhada por numerosas gerações de bolhas, foi considerado que a reação se completara quando a formação de bolhas cessou. Para separar as nano partículas de ferro, foi utilizado um ímã forte. As nano partículas de ferro depois foram lavadas, redispersadas em água deionizada, e liofilizadas durante a noite.

\section{2.}

Caracterização dos catalisadores

\subsection{1.}

\section{Composição Química}

Para determinação do percentual do metal, efetivamente incorporado às amostras calcinadas e preparadas por impregnação do ponto úmido, foi 
empregada a técnica de espectroscopia de absorção atômica (AA). As análises foram realizadas num aparelho Varian Spectraa 200.

A solubilização das amostras foi feita com a adição de $0,1 \mathrm{~g}$ de catalisador em uma solução contendo $5 \mathrm{ml}$ de ácido fluorídrico, $2,5 \mathrm{ml}$ de ácido clorídrico e 2,5 $\mathrm{ml}$ de ácido nítrico (todos ácidos concentrados), deixando a solução em banho maria durante 30 min a $353 \mathrm{~K}$. A seguir, a solução obtida foi transferida para um balão volumétrico de $50 \mathrm{~mL}$, e, depois de resfriada, avolumada com ácido nítrico $5 \%$ até $50 \mathrm{ml}$. Para avaliação dos teores metálicos, foi feito, também, um branco dos reagentes. Os resultados obtidos por espectroscopia de absorção atômica serviram para avaliar o teor metálico efetivamente obtido na impregnação.

\subsection{2.}

\section{Análise Termogravimétrica}

$\mathrm{Na}$ análise termogravimétrica (ATG), a variação de massa devido a uma transformação física ou química é medida em função do tempo ou da temperatura.

$O$ analise DTG mostra a diferença entre a temperatura medida da amostra e do material de referência, em função do tempo (temperatura constante) ou da temperatura atingido em todos os momentos.

A análise termogravimétrica (ATG) com análise térmica diferencial (DTG) das amostras sintetizadas e não calcinadas foi feita em cada catalisador usando um aparelho Shimadzu modelo DTG-60.

Aproximadamente 7 a $10 \mathrm{mg}$ da amostra, em um cadinho, foram submetidas a um aumento programado de temperatura, desde $298 \mathrm{~K}$ até 873 $\mathrm{K}$, sob fluxo de gás inerte. $O$ gás utilizado foi nitrogênio, na vazão de $30 \mathrm{~mL} / \mathrm{min}$ e uma taxa de aquecimento de $10 \mathrm{~K} / \mathrm{min}$. Os dados coletados, a partir das 
curvas termogravimétricas, permitiram acompanhar as perdas de massa ocorridas com os suportes, bem como as faixas de temperatura onde essas perdas ocorreram.

\subsection{3.}

\section{Propriedades Texturais}

A área específica $\left(\mathrm{m}^{2} / \mathrm{g}\right)$ de um catalisador ou de um suporte pode ser obtida pela utilização do método de B.E.T. (Brunauer, Emmett e Teller).

O próprio autor BRUNAUER et al., (1940) descreve o procedimento experimental utilizando o gás de nitrogênio devido a sua facilidade de obtenção em estado puro e por apresentar interação relativamente alta com a grande maioria dos sólidos. Devido ao fenômeno de adsorção física estar relacionado a forças de interação molecular fracas entre o adsorbato moléculas de gás - e adsorvente - superfície sólida da amostra - as medidas no equipamento são realizadas na temperatura de nitrogênio líquido, a fim de se obter valores detectáveis de adsorção. A análise é realizada adicionando, em etapas, quantidades conhecidas de nitrogênio pelo aumento de pressão ao recipiente da amostra, de forma que diferentes pressões de vapor $(\boldsymbol{p})$ sejam alcançadas no equilíbrio do sistema. Durante o procedimento, um sensor de pressão monitora as variações da pressão $(\boldsymbol{p})$ e os volumes de adsorção são também obtidos. Quando a pressão de saturação é alcançada não ocorre mais adsorção física independente de acréscimo na pressão. Após as camadas de adsorção serem formadas - pressão $(\boldsymbol{p})$ for igual a pressão de saturação $(\boldsymbol{p} 0)$ - a amostra é removida da atmosfera de nitrogênio, e aquecida para que ocorra a dessorção e quantificação das moléculas de nitrogênio adsorvidas no material. Os dados coletados de pressão são apresentados na forma da isoterma de BET — equação (14) —, que relaciona o volume de gás adsorvido $\boldsymbol{v}$ em função da pressão relativa $\mathbf{p} / \mathbf{p 0}$. 


$$
\frac{1}{V a\left[\left(\frac{P o}{p}\right)-1\right]}=\frac{C-1}{V m C}\left(\frac{P}{P o}\right)+\frac{1}{V m C}
$$

Onde,

$\mathrm{P}=$ pressão parcial de vapor de gás adsorvido em equilíbrio com a superfície a 77,4 K (ponto ebullicao do nitrogênio líquido).

Po = pressão de saturacao do gás adsorvido.

$\mathrm{V} a=$ volume de gás adsorvido à temperatura e pressão padrão, $273,15 \mathrm{~K}$ e pressão atmosférica.

Vm = volume de gás adsorvido, nas STP, para produzir uma monocamada aparente na superfície da amostra.

$\mathrm{C}=$ constante sem dimensão, que está relacionada com a entalpia de adsorção do gás adsorvido sobre a amostra em pó.

O equipamento utilizado para estas determinações foi um ASAP 2010, da Micromeritics, sendo o gás nitrogênio usado como adsorbato. Foi realizado um pré-tratamento nas amostras a $400^{\circ} \mathrm{C}$ sob vácuo por aproximadamente 5 horas, tendo em vista eliminar eventuais impurezas adsorvidas.

\subsection{4.}

\section{Difração de raios -X (DRX)}

A técnica de difração de raios-x fornece informações sobre estrutura e composição do material cristalino, tamanho médio das partículas, grau e forma de cristalinidade.

Neste trabalho, as amostras foram caracterizadas antes e depois de calcinar, para identificar sua estrutura e cristalinidade. Um dos equipamentos utilizado foi da marca Bruker AXS, modelo D8-Discover o sistema é equipado com tubo de cobre, filtro de níquel e detector de estado sólido Lynxeye, sendo 
os dados coletados na faixa de $2 \theta$ de $10-90$ graus. As varreduras foram realizadas usando um tempo de contagem de $3 \mathrm{~s}$ com intervalos de $0,02^{\circ}$. Um segundo equipamento foi também utilizado da marca Rigaku Miniflex com radiação CuKa na tensão de $30 \mathrm{KV}$ e corrente de $15 \mathrm{~mA}$, sendo o ângulo percorrido $10^{\circ}<2 \theta<80^{\circ}$.

O método de refinamento numérico de Rietveld utilizando o programa Maud, de livre de acesso na internet (www.ing.unitn.it/ maud/download.html), na análise de difração de raios- $X$, foi utilizado para verificar quantitativamente as diferentes fases cristalinas presentes nos diversos catalisadores, sendo qualidade do ajuste avaliada pelo índice de qualidade do ajuste (gof goodness of fit).

As fases cristalinas foram identificadas comparando os picos de difração com as fichas JCPDS (Joint Committe on Powder Diffraction Standards). Os arquivos de informação cristalográfica (CIFs) utilizados foram 17013-ICSD, 9865-ICSD, 99017-ICSD e 181367-ICSD.

\subsection{5.}

\section{Redução à Temperatura Programada (RTP)}

Com a finalidade de identificar as fases redutíveis do catalisador a técnica de caracterização de redução a temperatura programada (RTP) foi empregada. O processo foi feito em um aparelho RTP convencional equipado com um detector de condutividade térmica (DCT). Cada uma das amostras continha 10-15 mg de fase ativa ( $\mathrm{Fe})$. Um reator de quartzo em forma de $U$ foi utilizado para colocar a amostra calcinada, que incialmente for submetida a um pré-tratamento com um fluxo de gás argônio (99.9\%) a $423 \mathrm{~K}$ por $1 \mathrm{~h}$ para remoção de água e outros contaminantes.

A seguir uma mistura de gás redutor, composta de $\mathrm{H}_{2} / \mathrm{Ar}$, com $1,63 \%$ vol. de hidrogênio foi alimentada com uma vazão de $30 \mathrm{ml} / \mathrm{min}$ ao reator. $\mathrm{O}$ 
incremento de temperatura foi programado para uma taxa de aquecimento de $5 \mathrm{~K} / \mathrm{min}$, desde a temperatura ambiente até $1123 \mathrm{~K}$. O consumo de hidrogênio, monitorado por meio de um detector de condutividade térmica (DCT) e a temperatura da amostra foram registrados simultaneamente. Uma "armadilha" (trap) foi instalada para remover a água liberada presente na corrente de saída do reator. O banho utilizado para remoção da água gerada pela redução foi preparado através da mistura de álcool isopropílico e nitrogênio líquido. O grau de redução foi calculado através da seguinte expressão:

$\mathrm{GR}(\%)=\left(\mathrm{mol} \mathrm{H}_{2}\right.$ consumido/massa de metal $) \times$ massa molecular do metal $\times 100 \times$ coeficiente estequiométrico)

\subsection{6.}

\section{Microscopia Eletrônica de Transmissão (MET)}

A microscopia eletrônica de transmissão permite obter informação estrutural de um material. As mostras foram analisadas num microscópio eletrônico de transmissão, marca JEOL, modelo JEM-2010, com uma voltagem de aceleração de feixe de elétrons de 200 KV.

Primeiramente, as amostras calcinadas foram reduzidas sob fluxo de gás hidrogênio a $673 \mathrm{~K}$ por $8 \mathrm{~h}$. A taxa de aquecimento foi de $5 \mathrm{~K} / \mathrm{min}$ e vazão de $30 \mathrm{ml} / \mathrm{min}$. Após a etapa de redução, os catalisadores a base de ferro foram submetidos ao tratamento de passivação através de um fluxo de $\mathrm{O}_{2} / \mathrm{He} 5 \%$ a temperatura ambiente por uma hora, as amostras foram analisadas imediatamente para prevenir reoxidação.

Para obter as micrografias as amostras foram, inicialmente, misturadas com álcool isopropílico e submetidas a ultra-som, para dispersar as partículas do catalisador. Depois, gotas da suspensão obtida foram depositadas em uma membrana de carbono suportada por uma tela de cobre seguindo para análise no microscópio. 
4

Resultados e Discussões

\section{1.}

Composição Química

A tabela 3 mostra os resultados da análise química realizada, através de espectroscopia de absorção atômica (A.A.) e espectrometria de fluorescência de raios- $X$ para a determinação dos teores metálicos e da razão Si/Al para o suporte e os diferentes catalisadores.

Tabela 3. Percentual metálico Fe determinado através de A.A.

\begin{tabular}{|c|c|c|c|}
\hline Amostras & $\mathrm{Fe}(\%)$ & $\mathrm{Co}(\%)$ & $\mathrm{Si} / \mathrm{Al}$ \\
\hline Sílica Alumina (Comercial) & & & $13 / 87$ \\
\hline $5 \% \mathrm{Fe} / \mathrm{Si}-\mathrm{Al}$ & 4,4 & - & \\
\hline $5 \% \mathrm{Fe} / \mathrm{Si}-\mathrm{Al}$ Método Ureia & 4,45 & - & \\
\hline $2 \% \mathrm{Fe} / \mathrm{Si}-\mathrm{Al}$ & 2,3 & - & \\
\hline $10 \% \mathrm{Fe} / \mathrm{Si}-\mathrm{Al}$ & 9,9 & - & \\
\hline $2 \% \mathrm{Co} / \mathrm{Si}-\mathrm{Al}$ & - & 2,5 & \\
\hline $2 \% \mathrm{Fe} / \mathrm{Si}-\mathrm{Al}$ & 1,9 & - & \\
\hline
\end{tabular}

Os teores metálicos obtidos mediante A.A. ficaram próximos dos valores pretendidos, provando que a incorporação dos metais, tanto via o método de impregnação do ponto úmido, quanto o método da ureia, foram eficientes. A sílica alumina utilizada é comercial (Sasol Siral 20) cuja composição terica é 20/80 Si/Al respectivamente. 


\section{2.}

\section{Análise Termogravimétrica (ATG)}

A análise termogravimétrica feita para os suportes de sílica alumina e sílica mesoporosa na forma não calcinada é mostrada nas Figura 7 e Figura 8 respectivamente através dos gráficos de ATG e sua respectiva derivada DTG, esta última tem como propósito melhorar a resolução das perdas de massas mais acentuadas. O suporte de sílica alumina registrou uma perda de massa total de $28 \%$ na região de temperatura de 299 a $780 \mathrm{~K}$ em dois eventos. O primeiro ocorrido no intervalo de 299 a $365 \mathrm{~K}$, onde a curva ATG mostrou uma perda de massa de $16 \%$ associada a um pico em $338 \mathrm{~K}$, devido à remoção de água. O segundo evento, correspondente a uma perda de massa de $12 \%$ associada a um pico em $690 \mathrm{~K}$, na faixa de 435 e $780 \mathrm{~K}$, devido a remoção de $\mathrm{CO}_{2}$. KEYVANLOO et al., (2014b) encontraram também dois eventos de perda de massa para um suporte de sílica alumina, atribuindo a primeira perda ao remoção da água fisicamente adsorvida na faixa de temperatura de 298-403 $\mathrm{K}$ e a segunda etapa atribuída a uma desidratação mais lenta do hidróxido de alumina, na faixa de temperatura de $403-1373 \mathrm{~K}\left(2 \mathrm{AL}(\mathrm{OH})_{3} \rightarrow \mathrm{Al}_{2} \mathrm{O}_{3}+3 \mathrm{H}_{2}\right)$. SABER e GOBARA (2014) realizaram uma análise termogravimétrica para a sílica alumina encontrando três faixas de perda de massa, sendo a primeira e a segunda concordantes com as reportadas por KEYVANLOO et al., (2014b), e a terceira resultando da remoção de água quimissorvida oriunda de um processo de recristalização.

A análise ATG/DTG realizada para o material mesoporoso revelou uma perda total de massa de $29 \%$ na faixa de temperatura de 299 a $875 \mathrm{~K}$ atribuídas às seguintes etapas: a primeira com perda de 14\% na região de 299 a $435 \mathrm{~K}$ representada por um pico à $320 \mathrm{~K}$ (DTG). Devido a dessorção da água. A segunda etapa registrou uma perda de massa de 15\% entre 460 e 718 $\mathrm{K}$, com um pico a $530 \mathrm{~K}$ associada à decomposição do direcionador orgânico usado na sintese. DE BARROS et al., (2015) encontraram para uma sílica 
mesoporosa SBA 16, perda de massa de $32 \%$ na faixa de temperatura de $423-$ $923 \mathrm{~K}$, devido a decomposição dos grupos alcoxissilanos.

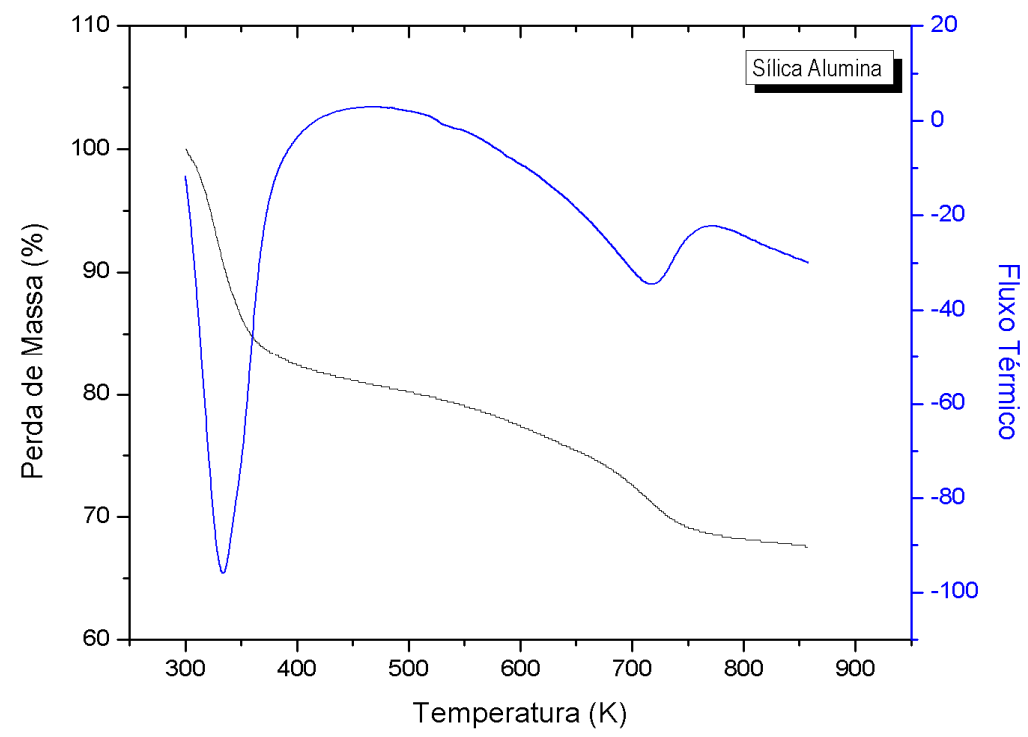

Figura 7. Curvas ATG/DTG da sílica alumina

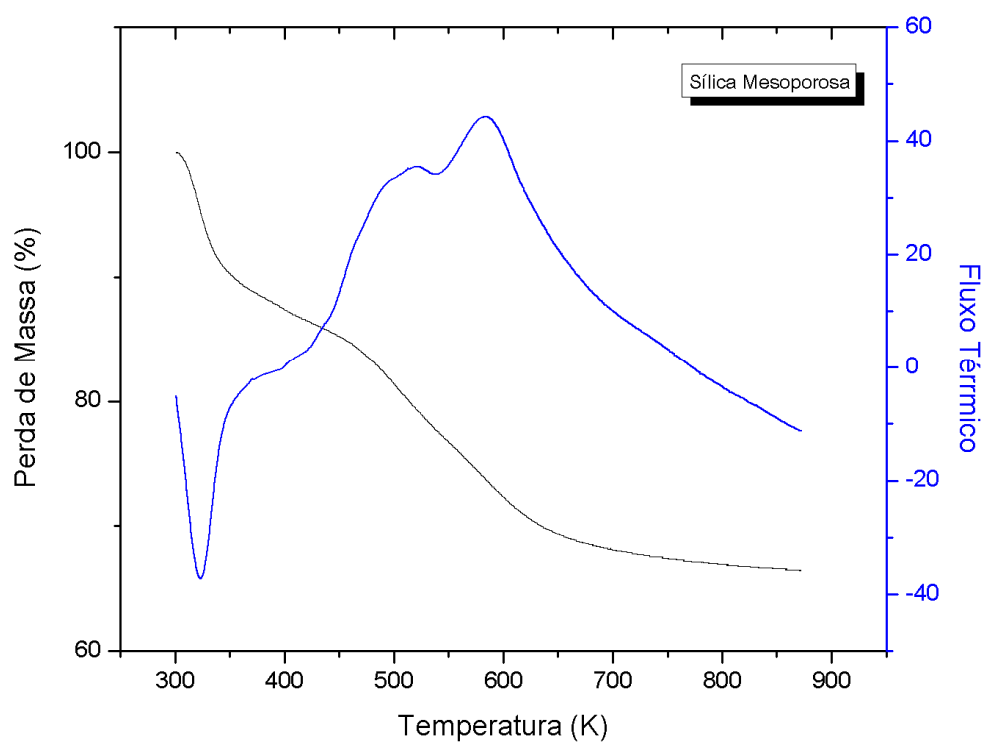

Figura 8. Curvas ATG/DTG da sílica mesoporosa. 
A análise $A T G / D T G$ indicou perdas de massa totais similares entre os suportes de sílica alumina e sílica mesoporosa, conforme pode ser visto na tabela 4.

Tabela 4. Quantificação dos eventos de perda de massa da sílica alumina e da silica mesoporosa.

\begin{tabular}{l|c|c|c|c|c}
\multicolumn{1}{c|}{ Suporte } & Etapa & $\mathrm{Ti}(\mathrm{K})$ & $\mathrm{Tf}(\mathrm{K})$ & $\operatorname{Tmax}(\mathrm{K})$ & $\Delta \mathrm{m}(\%)$ \\
\hline \hline Sílica Alumina & 1 & 299 & 365 & 338 & 16 \\
Sílica & 2 & 435 & 780 & 690 & 12 \\
Mesoporosa & 1 & 299 & 435 & 320 & 14 \\
& 2 & 460 & 718 & 530 & 15
\end{tabular}

\section{3. \\ Propiedades Texturais}

$\mathrm{Na}$ tabela 5 são apresentados os resultados das análises texturais das amostras calcinadas, tais como, a determinação da área especifica total, volume total de poros, diâmetro de poro e o volume de microporo presente na estrutura.

O volume de microporos foi calculado mediante o método de t-plot, a área especifica foi calculada pelo método BET e o volume de mesoporos foi calculado pelo método Barret-Joyner-Halenda (BJH). 
Tabela 5. Propriedades texturais das amostras

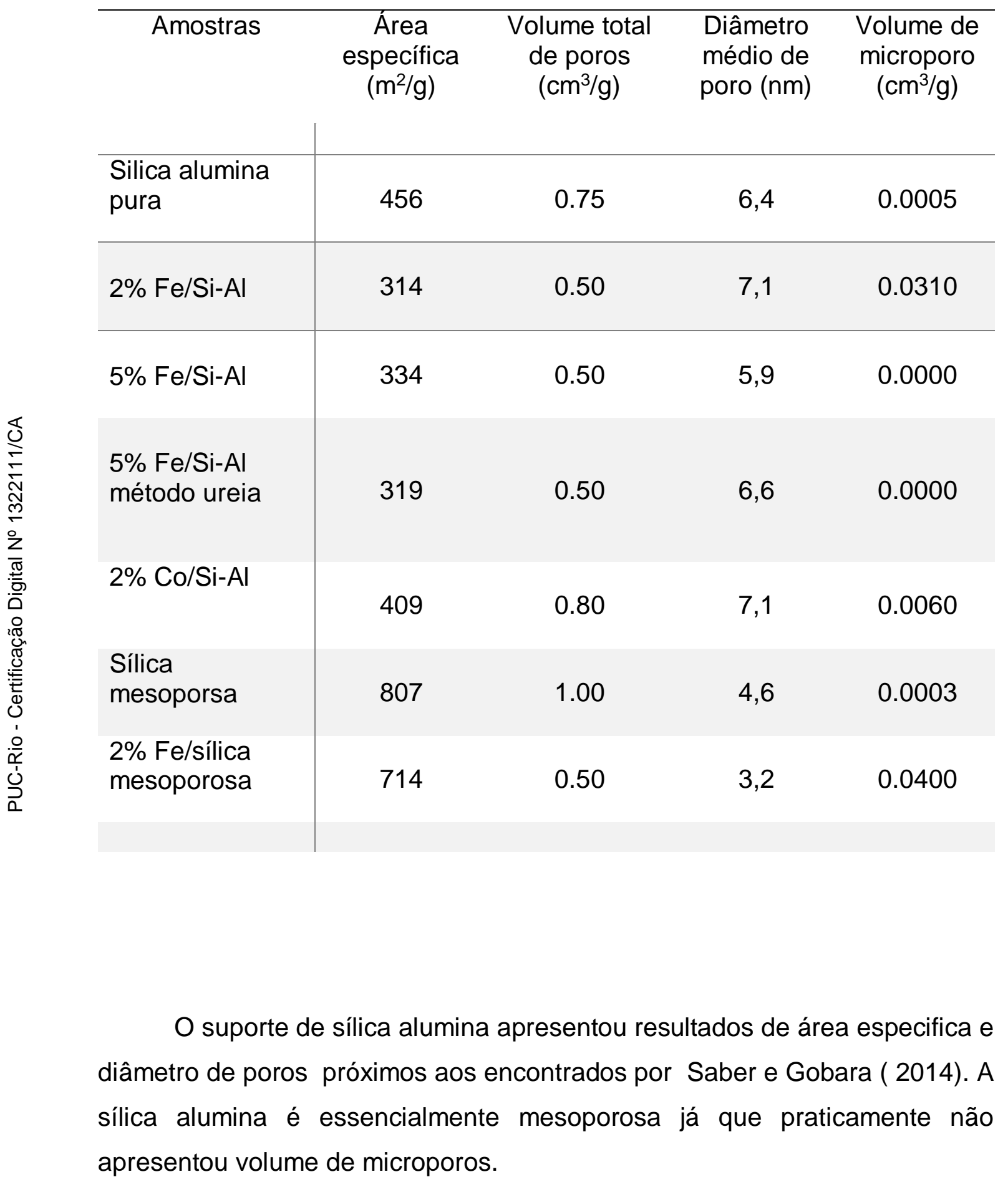


Para a amostra 5\% Fe/Si-Al preparada pelo método de impregnação, a área especifica e o volume de poros diminuíram em comparação com o suporte de sílica alumina em aproximadamente $27 \%$ e $33 \%$, respectivamente, devido à introdução do metal.Para a amostra de $2 \% \mathrm{Fe} / \mathrm{Si}$-Al preparada pelo o método de impregnação a área especifica e o volume de poros diminuíram cerca de $19 \%$ e $5 \%$, respetivamente. Para a amostra $5 \% \mathrm{Fe} / \mathrm{Si}-\mathrm{Al}$ preparada pelo método da ureia a área especifica e o volume de poros diminuíram em $30 \%$ e $33 \%$ respectivamente. Os resultados são coerentes reduzindo tanto a área como o volume de poros a medida que o teor de metal aumenta. Para amostra de $2 \% \mathrm{Co} / \mathrm{Si}$-Al a área especifica diminui em $10 \%$ e o volume de poros permaneciu quase inalterado. Neste caso parece que o Co está mais disperso sobre o suporte pouco afetando a área e o volume de poros.

Por outro lado, o suporte de sílica mesoporosa apresentou uma área especifica maior $\left(807 \mathrm{~m}^{2} / \mathrm{g}\right)$ em comparação com aquela apresentada pela sílica alumina $\left(456 \mathrm{~m}^{2} / \mathrm{g}\right)$. Estes resultados concordam com os encontrados por JUNG et al. (2012) na caracterização de sílicas mesoporosas especificamente em amostras de MCM-41 e HMS que também apresentaram áreas especificas altas, 865 e $721 \mathrm{~m}^{2} / \mathrm{g}$ respetivamente. Com a introdução do ferro na sílica mesoporosa a área especifica diminui cerca de $12 \%$ e volume de poros $50 \%$ o que indicaria que a maior parte do ferro estaria dentro dos poros.

Keyvanloo et al., (2014) desenvolveram um trabalho utilizando sílica alumina como suporte, com razão $\mathrm{Al}_{2} \mathrm{O}_{3}: \mathrm{SiO}_{2}$ de 95:5, encontrando uma área especifica de $184 \mathrm{~m}^{2} / \mathrm{g}$ sugerindo assim que quanto maior o teor de sílica, maior área especifica estará presente do suporte de sílica alumina.

De acordo com a classificação IUPAC, as isotermas das amostras calcinadas são do tipo IV; esta informação é baseada nas curvas de adsorção de nitrogênio, representadas na Figura 9 e Figura 10, com ponto de inflexão em pressões relativas ( $\mathrm{p} / \mathrm{po}$ ) altas, característico dos materiais mesoporosos, 
apresentando histereses do tipo $\mathrm{H} 4$ para todas as amostras suportadas em sílica alumina. Histereses de tipo $\mathrm{H} 2$ foram encontradas para as amostras suportadas em sílica mesoporosa, indicando a existência de cavidades de poros maiores em diâmetro do que as aberturas dos mesmos.

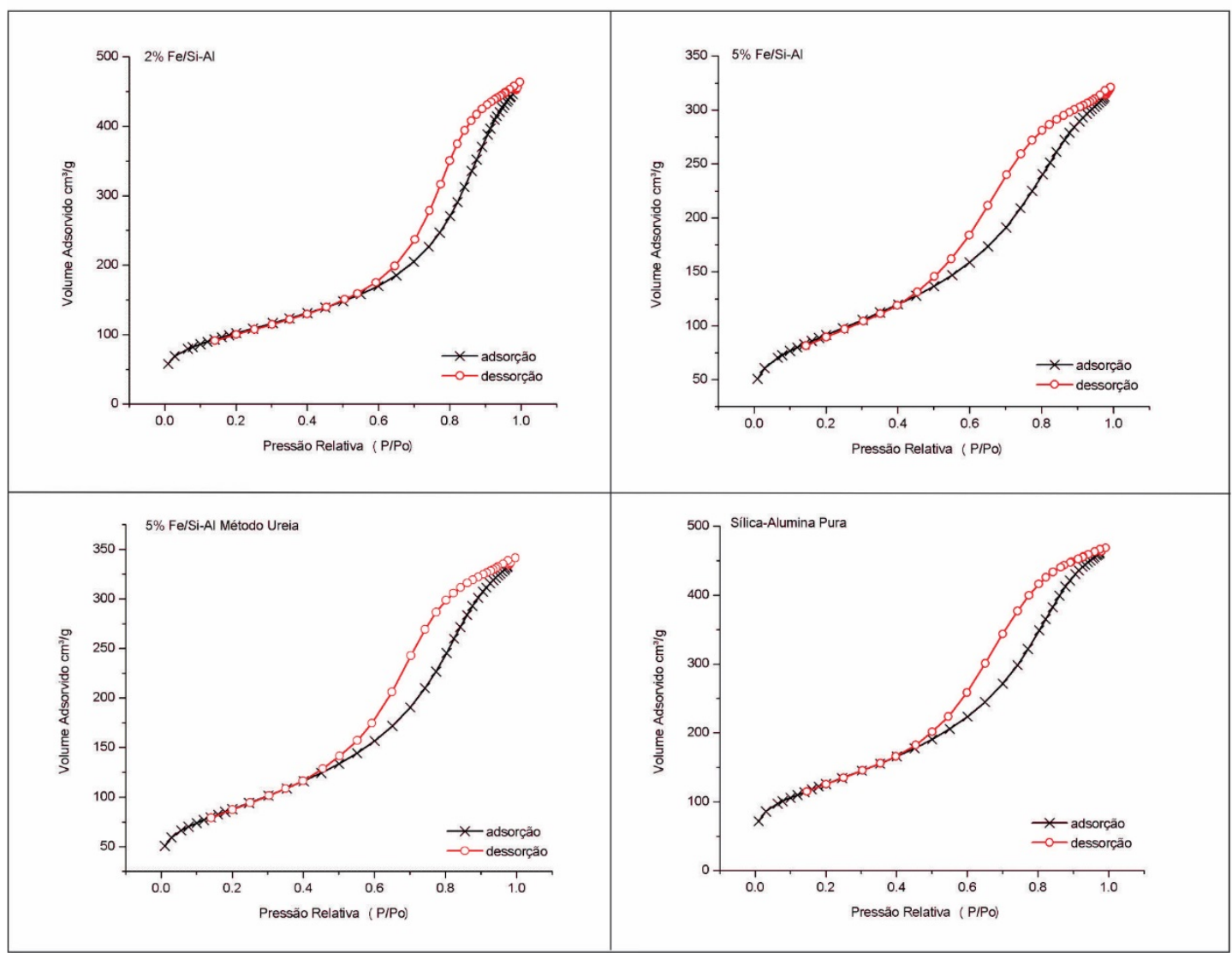

Figura 9. Isotermas de adsorção/dessorção de $\mathrm{N}_{2}$ do suporte de sílica alumina e amostras de $2 \% \mathrm{Fe} / \mathrm{Si}-\mathrm{Al}, 5 \% \mathrm{Fe} / \mathrm{Si}-\mathrm{Al}$ e $5 \% \mathrm{Fe} / \mathrm{Si}-\mathrm{Al}$ método ureia.

O ciclo de histerese é geralmente associado com o enchimento e esvaziamento de mesoporos através condensação capilar; as histereses observadas nas amostras 5\% Fe/Si-Al , 5\%, Fe/Si-Al método ureia e no suporte puro são similares entre elas, mas diferem daquela da amostra $2 \%$ $\mathrm{Fe} / \mathrm{Si}-\mathrm{Al}$, sendo esta menos pronunciada, indicando uma diferença na geometria dos poros desta última. (HORACIO LOPEZ, 2004). Novamente estes resultados coincidem parcialmente com os encontrados por SABER e 
GOBARA (2014) no qual analisaram as propriedades texturais de sílica alumina pura e de platina (Pt) suportada na mesma, mostrando isotermas do tipo IV com leve tendência às do tipo II, mas com histereses do tipo H3, evidenciando que as amostras não possuem estruturas mesoporosas bem definidas.

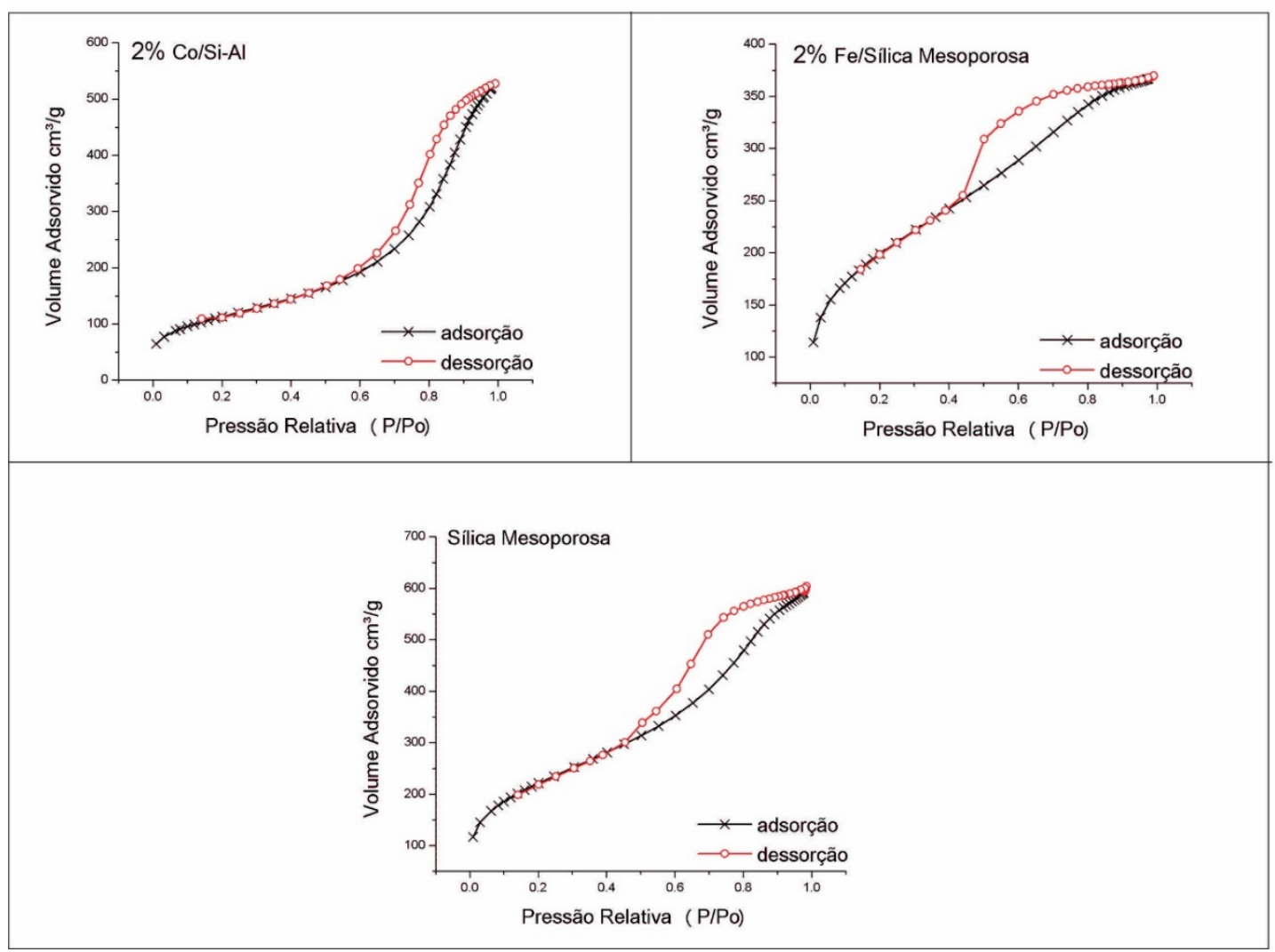

Figura 10. Isotermas de adsorção/dessorção de $\mathrm{N}_{2}$ do suporte de sílica mesoporosa e amostras 2\% Co/Si-Al, 2\% Fe/Sílica mesoporosa.

A distribuição de tamanho de poros obtido a partir do método BJH nas amostras analisadas, está ilustrado, na Figura 11 e 12, onde se distingue uma distribuição estreita de tamanho de poros com forma gaussiana, com um máximo em torno de 8-10 $\mathrm{nm}$ para o suporte de sílica alumina, 6-7 nm para a amostra de 5\% Fe/Si-Al, $10 \mathrm{~nm}$ para amostra de 5\% Fe/Si-Al método Ureia, 10-11 nm para a amostra de $2 \% \mathrm{Fe} / \mathrm{Si}-\mathrm{Al}$. Para amostra de $2 \%$ de Co/Si-Al na 
faixa de 10-20 nm. O suporte de sílica mesoporosa apresentou uma distribuição de tamanho de poros na faixa $7-9 \mathrm{~nm}$, e com a introdução do metal a faixa caiu para $2-3 \mathrm{~nm}$.

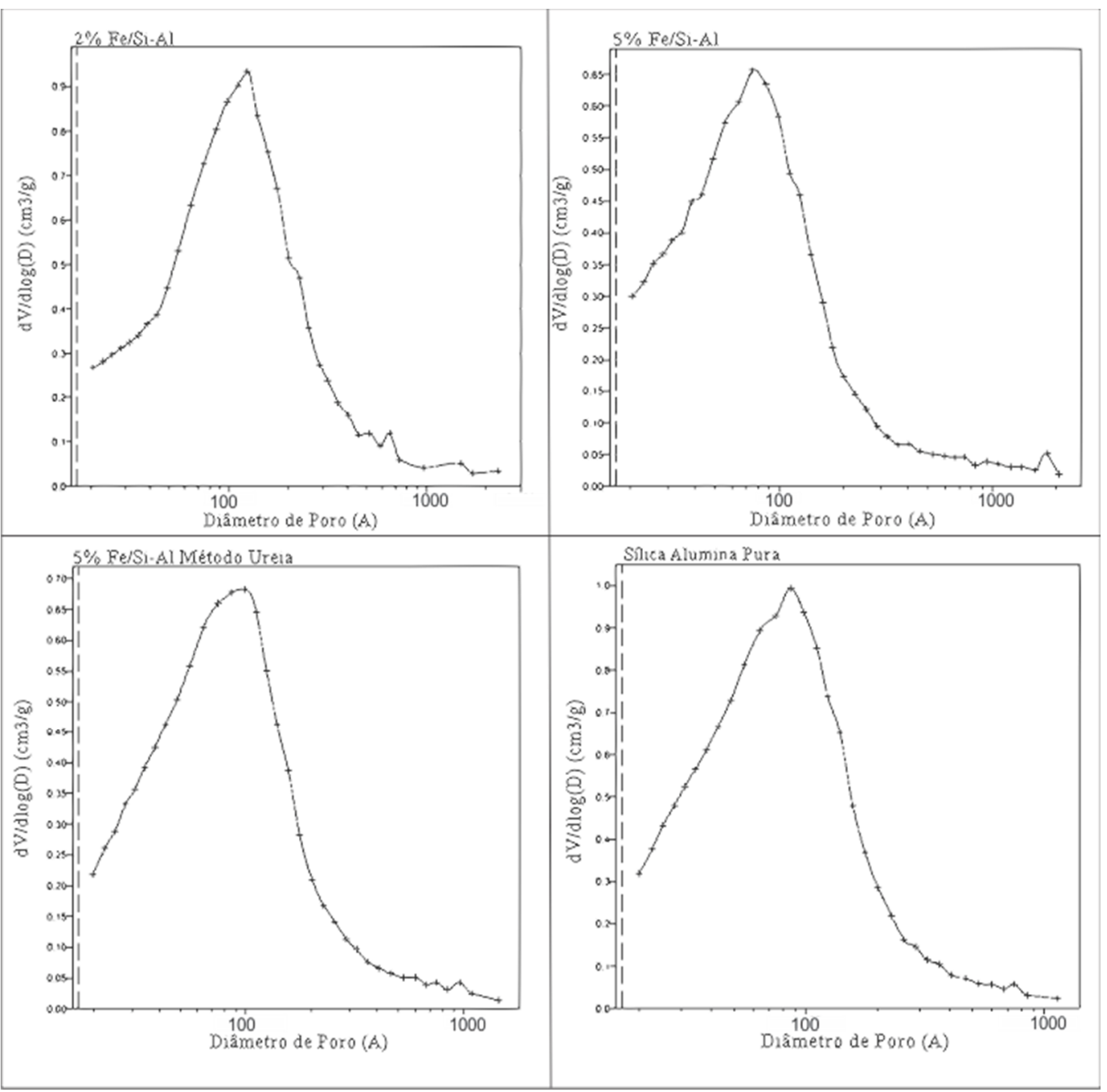

Figura 11. Curva de distribuição de diâmetro de poros para o suporte de sílica alumina e amostras de 5\% Fe/Si-Al método ureia, 2\% Fe/Si-Al e 5\% Fe/Si-Al. 


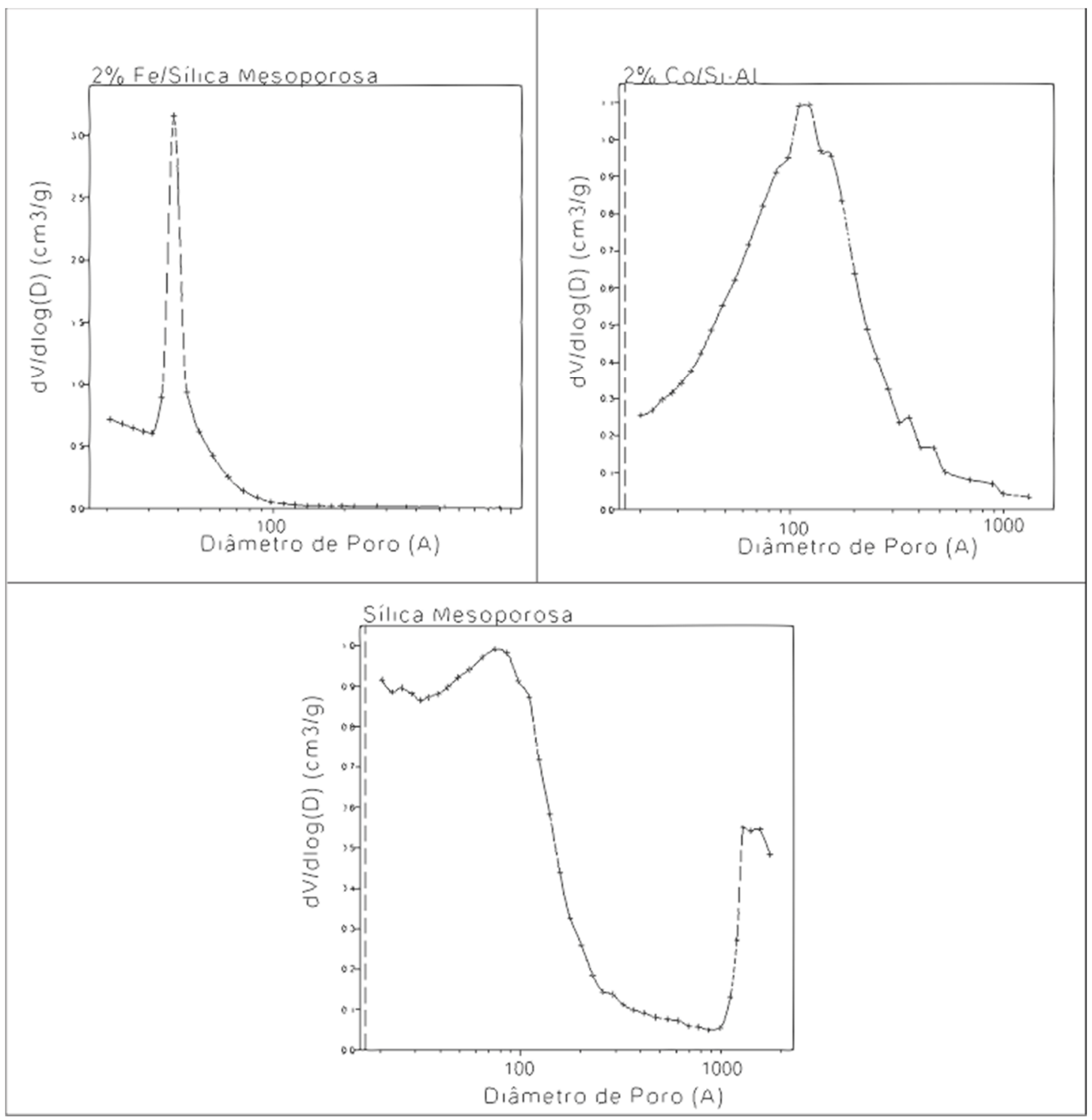

Figura 12. Curva de distribuição de diâmetro de poros para o suporte de sílica mesoporosa e as amostras de $2 \% \mathrm{Co} / \mathrm{Si}-\mathrm{Al}$ e $2 \% \mathrm{Fe} /$ silica mesoporosa. 


\section{4.}

Difração de raios-X (DRX)

A seguir são apresentados os resultados de difração de raios- $X$ e 0 refinamento de Rietveld dos suportes sílica alumina, sílica mesoporosa, para as amostras suportadas, além das nano partículas de ferro. A difração de raios- $X$ foi realizada para caracterizar a estrutura dos suportes e dos catalisadores calcinados e reduzidos.

\subsection{1.}

\section{Suportes}

\subsubsection{1.}

\section{Silica Alumina}

Para o suporte de sílica alumina foi detectado um pico amplo em torno de $2 \theta=25^{\circ}$ indicando uma estrutura de sílica-alumina quase amorfa, com algum grau de cristalinidade devido aos outros picos que aparecem no difratograma. Estes picos são característicos da fase gama alumina: aproximadamente $2 \theta=45^{\circ}$ para o plano de reflexão (222) e $2 \theta=66^{\circ}$ para o plano reflexão (440). Segundo SABER e GOBARA (2014) estes picos (Figura 13) correspondentes a gama alumina aumentam conforme diminui o teor do óxido de silício. Para amostra utilizada com teor de $\mathrm{Al}_{2} \mathrm{O}_{3}: \mathrm{SiO}_{2}$ de 80:20, o alto conteúdo de $\mathrm{Al}_{2} \mathrm{O}_{3}$ em comparação com a $\mathrm{SiO}_{2}$ é o responsável pelos picos $2 \theta$ $=45^{\circ}$ e $2 \theta=66$. O refinamento de Rietveld é apresentado na figura 14 identificando duas fases $\% \gamma-\mathrm{Al}_{2} \mathrm{O} 3=6,56 ; \%$ e $\mathrm{Al}_{2} \mathrm{SiO}_{5}$ (silimanite) $=93,43 \%$ (resultante da interação entre sílica e alumina), com de diâmetro de cristalito estimado, pelo software Maud, em $93.7 \mathrm{~nm}$ e $94.6 \mathrm{~nm}$ para $\mathrm{Al}_{2} \mathrm{O}_{3}$ e $\mathrm{Al}_{2} \mathrm{SiO}_{5}$, respectivamente. 


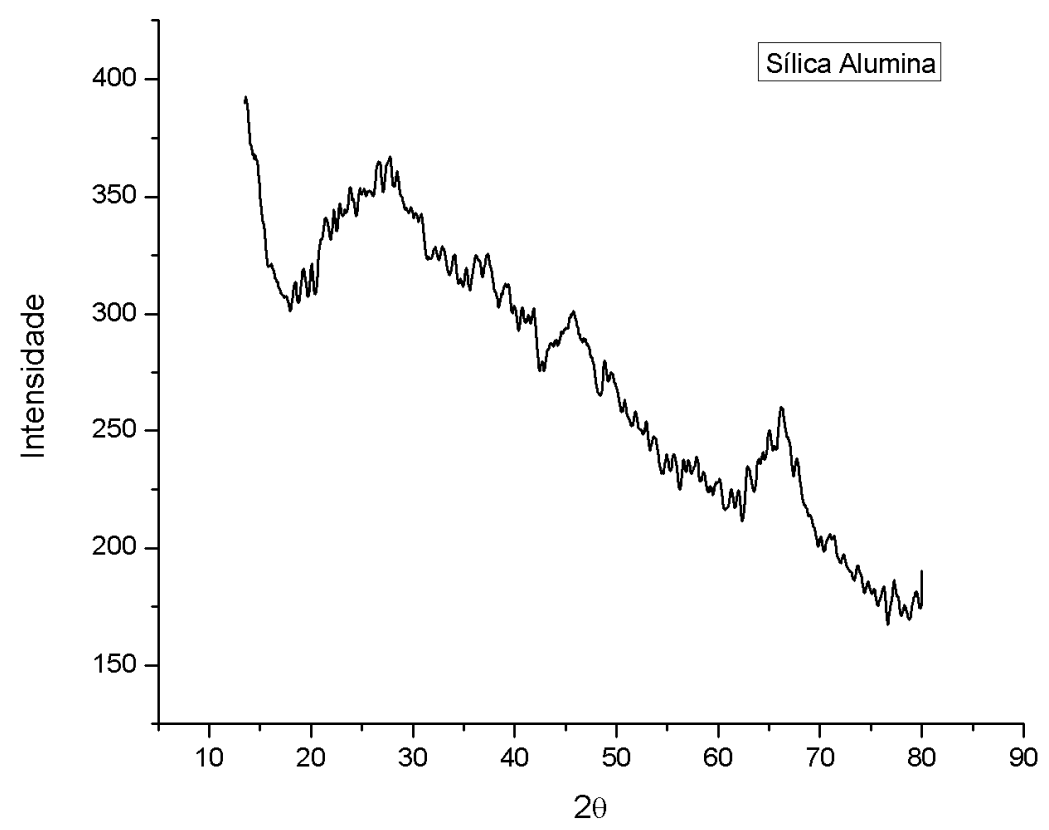

Figura 13. Análise de DRX do suporte de sílica alumina calcinada.

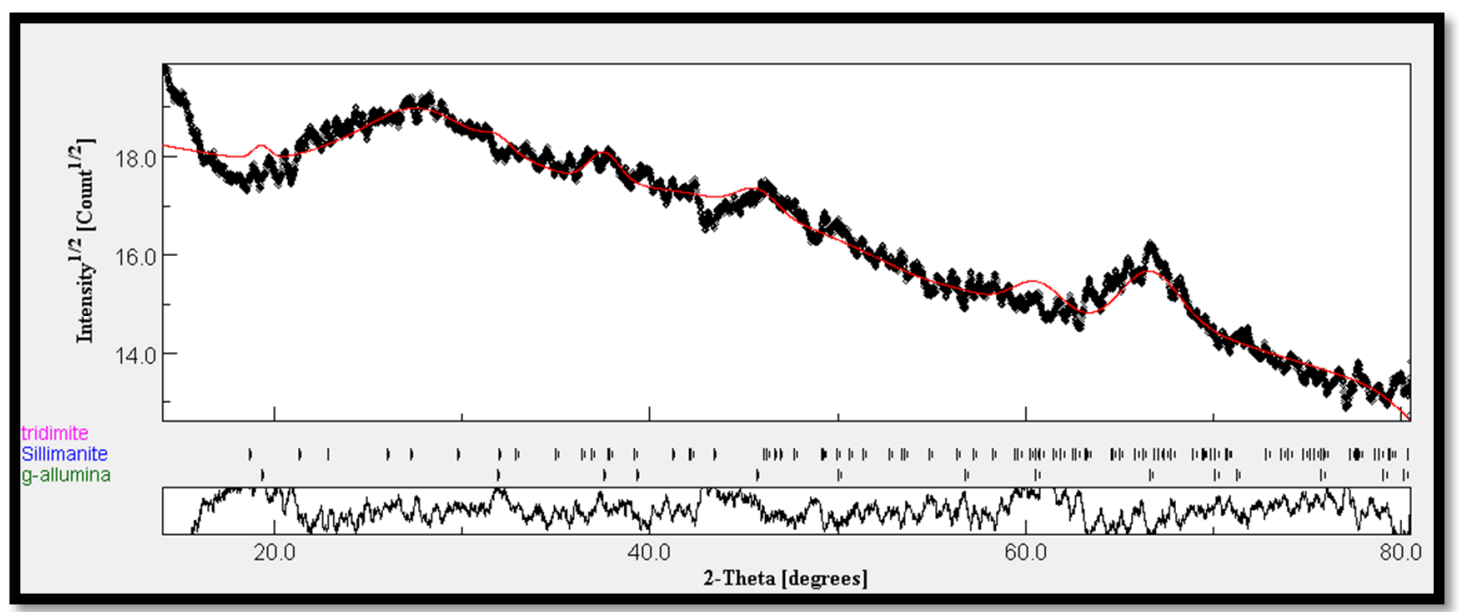

Figura 14. Refinamento de Rietveld para o suporte de sílica alumina calcunada. Índice de qualidade do ajuste (gof-goodnes of fit) $2.45 \%$. 


\subsubsection{2.}

\section{Silica mesoporosa}

Os difratogramas de raios-X obtido, para o suporte de sílica mesoporosa são mostrados na figura 15, indicando uma estrutura completamente amorfa, como esperado para região de $2 \theta>10^{\circ}$ (Figura 15a). Foi também realizada uma análise de difração na faixa de $2 \theta=0-10^{\circ}$ (Figura 15b) e não foram identificados os picos relacionados às sílicas mesoporosas SBA-15, MCM-41 ou HMS. Trata-se, então, de uma sílica mesoporosa amorfa.
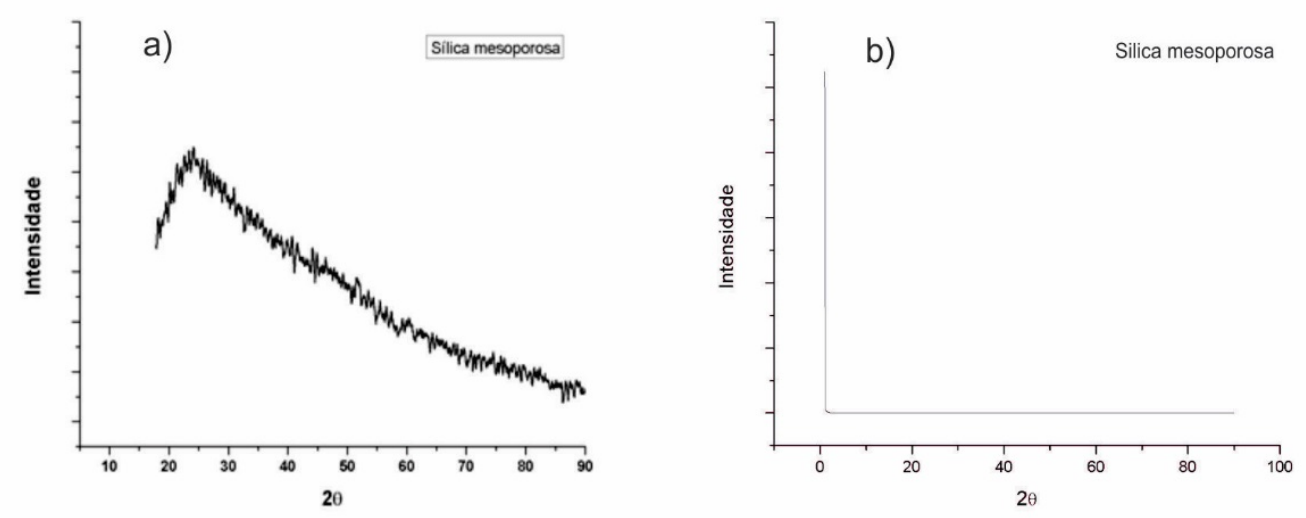

Figura 15. a) Análise de DRX do suporte de sílica mesoporosa calcinada (10$90^{\circ}$ ), b) Análise de DRX do suporte de sílica mesoporosa calcinada (0-90\%.

\subsection{2.}

\section{Catalisadores suportados calcinados}

\subsubsection{1.}

\section{Catalisadores de Fe/Si-Al}

A figura 16 apresenta os difratogramas dos catalisadores de ferro suportados em sílica alumina calcinados. Todos apresentam os mesmos picos em torno de $2 \theta=45^{\circ}$ e $2 \theta=66^{\circ}$, já encontrados no suporte de sílica alumina, com a introdução do ferro ocasionando uma leve variação na largura dos picos. 
Os difratogramas dos catalisadores de ferro suportados em sílica alumina não apresentaram variação visível em comparação com aqueles reduzidos apresentados na figura 19, mas de acordo com a literatura (KEYVANLOO et al., 2014b), o $\mathrm{Fe}_{3} \mathrm{O}_{4}$ apresenta um pico em torno de $2 \theta=44.9$, podendo este ter ficado sobreposto ao pico gerado pelo suporte, devido aos baixos teores de ferro utilizados na preparação das amostras.

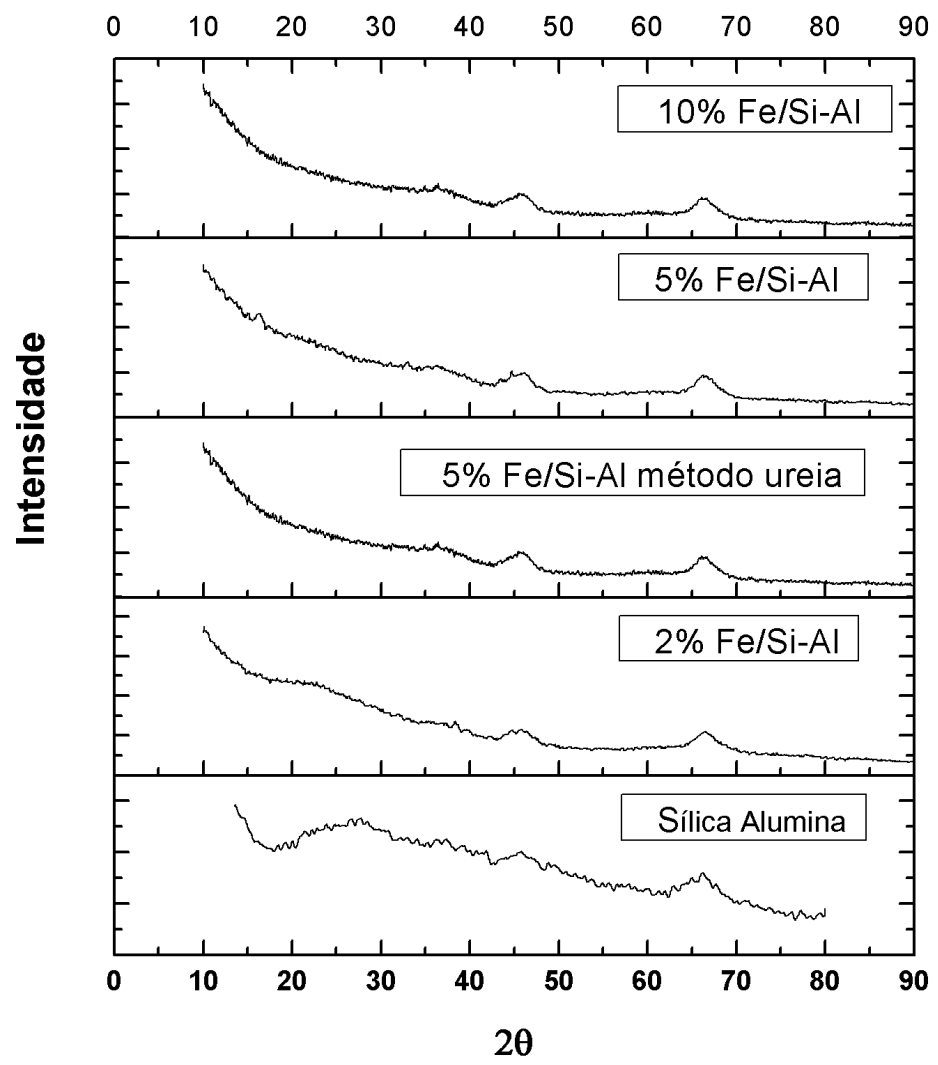

Figura 16. Análise de DRX do suporte de sílica alumina e das amostras de $2 \% \mathrm{Fe} / \mathrm{Si}-\mathrm{Al}, 5 \% \mathrm{Fe} / \mathrm{Si}-\mathrm{Al}$ método ureia, 5\% Fe/Si-Al, 10\% Fe/Si-Al calcinadas.

KEYVANLOO et al., (2014) desenvolveram um trabalho analisando os efeitos do suporte de sílica alumina no catalisador de ferro com teores 
metálicos de $40 \%$ e $20 \%$, os autores também confirmaram a presença de $\gamma$ $\mathrm{Al}_{2} \mathrm{O}_{3}, \mathrm{FeO}$ e / ou $\mathrm{Fe}_{3} \mathrm{O}_{4}$. A única diferença entre a difração de raios- $\mathrm{X}$ das amostras reduzidas era a largura e intensidade dos picos de $\mathrm{FeO}$ e $\mathrm{Fe}_{3} \mathrm{O}_{4}$ localizados em $2 \theta=37.3^{\circ}, 2 \theta=44.9^{\circ}$, respectivamente.

\subsubsection{2.}

\section{Catalisador de $2 \% \mathrm{Co} / \mathrm{Si}-\mathrm{Al}$}

O catalisador de $2 \% \mathrm{Co} / \mathrm{Si}-\mathrm{Al}$ apresentou um difratograma parecido ao do suporte, como pode ser visto na figura 17. Mas, desta vez é possível observar a presença do cobalto depositado sobre o suporte de sílica alumina devido aos picos em $2 \theta=36.9^{\circ}, 46^{\circ}$ e $65.5^{\circ}$ correspondentes ao $\mathrm{Co}_{3} \mathrm{O}_{4}$, de acordo com JUNG et al. (2012) que encontraram picos correspondente ao $\mathrm{Co}_{3} \mathrm{O}_{4} \mathrm{em} 2 \theta=31.3^{\circ}, 36.8^{\circ}, 45^{\circ}, 59.4^{\circ}, 65.4^{\circ}$.

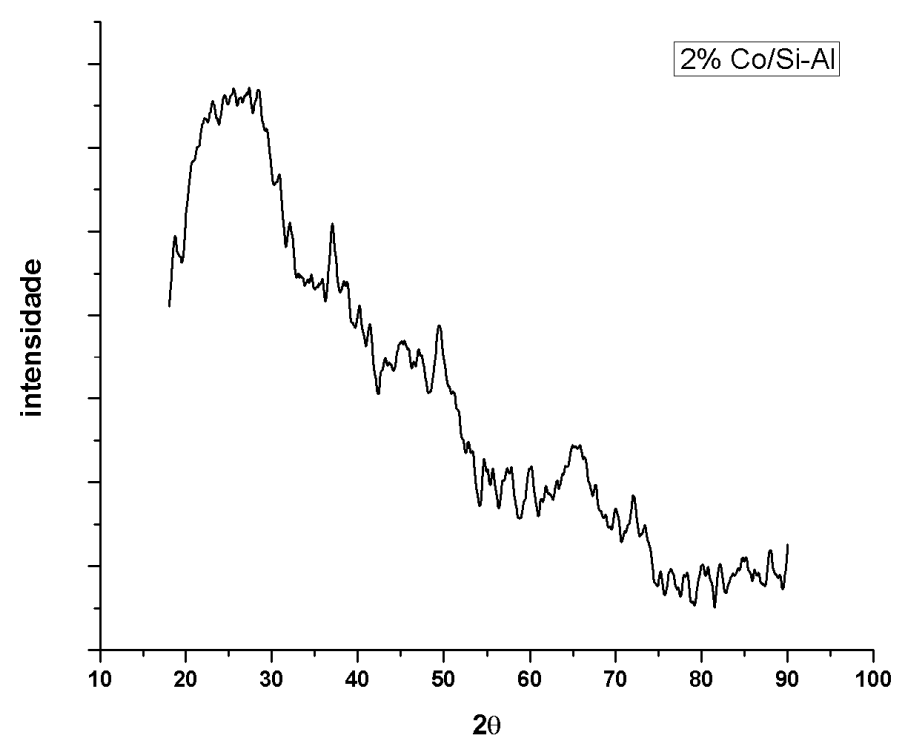

Figura 17. Análise de DRX da amostra 2\% Co/Si-Al calcinada. 


\subsubsection{3.}

\section{Catalisador de $2 \% \mathrm{Fe} /$ sílica mesoporosa}

A figura 18 mostra o difratograma do catalisador de $2 \% \mathrm{Fe} / \mathrm{sílica}$ mesoporosa calcinado. Pode-se observar que, provavelmente, devido ao baixo teor de ferro (2\%) não são observados os picos correspondentes ao óxido de ferro localizados em $2 \theta=37.3^{\circ}, 2 \theta=44.9^{\circ}$ (KEYVANLOO et al., 2014b), permanecendo praticamente o mesmo difratograma do suporte de sílica mesoporosa amorfa mostrado anteriormente na figura 15.

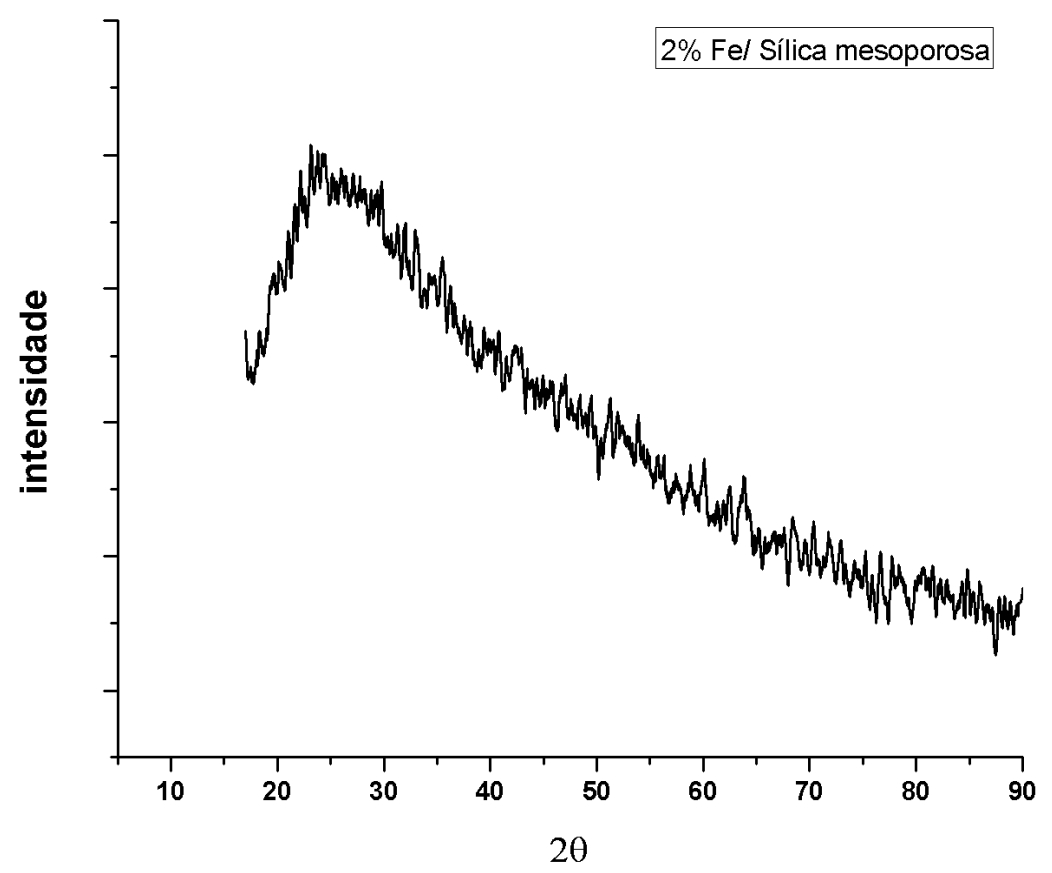

Figura 18. Análise de DRX da amostra 2\% Fe/Si-Al calcinada.

\subsection{3.}

\section{Catalisadores suportados reduzidos}

Com o objetivo de verificar a influência da atmosfera redutora dos óxidos metálicos foram realizadas análises de $\mathrm{DRX}$ usando $\mathrm{H}_{2}$ puro e a própria mistura $\mathrm{CO} / \mathrm{H}_{2}$ carga da reação de Fischer-Tropsch. 


\subsubsection{Catalisadores $\mathrm{Fe} / \mathrm{Si}$-Al reduzidos $\operatorname{com} \mathrm{H}_{2}$ puro}

As amostras 2\% $\mathrm{Fe} / \mathrm{Si}-\mathrm{Al}$, 5\% Fe/Si-Al, 5\% Fe/Si-Al método ureia, 2\% $\mathrm{Fe} / \mathrm{Si}-\mathrm{Al}$ reduzidas usando $\mathrm{H}_{2}$ puro mostraram difractogramas (figura 19) parecidos ao do suporte, indicando que a estrutura da sílica alumina foi mantida, e o ferro incorporado não acarretou diferença representativa no difratograma em comparação com o do suporte, já que os teores metálicos introduzidos foram baixos. Por isso outra amostra contendo $10 \%$ de $\mathrm{Fe} / \mathrm{Si}-\mathrm{Al}$ foi preparada e reduzida para poder identificar no difratograma alguma variação. Nesta mostra foi observado um pico intenso correspondente ao ferro metálico em torno de $2 \theta=44^{\circ}$ de acordo com refinamento de Rietveld realizado no software e apresentado na figura 23.

As figuras 20-23 mostram a análise de refinamento do Rietveld para as amostras de 2\% Fe/Si-Al, 5\% Fe/Si-Al, 5\% Fe/Si-Al método ureia, 10\% Fe/Si$\mathrm{Al}$ e do suporte de sílica alumina puro. Os catalisadores $5 \% \mathrm{Fe} / \mathrm{Si}-\mathrm{Al}, 5 \% \mathrm{Fe} / \mathrm{Si}$ Al método ureia mostraram um pico correspondente ao ferro metálico em torno de $2 \theta=44$, mais evidente ainda no catalisador de $10 \%$ de ferro. $O$ catalisador do $2 \% \mathrm{Fe} / \mathrm{Si}$-Al não apresentou este pico devido aos baixos graus de redução (ver os resultados de RTP) e ao baixo teor de ferro, sendo identificadas 4 fases: $\gamma-\mathrm{Al}_{2} \mathrm{O}_{3} 97,10 \%, \mathrm{FeO} 0,72 \%, \mathrm{Fe}_{3} \mathrm{O}_{4}$ 0,56\% e $\mathrm{Al}_{2} \mathrm{SiO}_{5}$ (silimanite) 1,60\%. $\mathrm{O}$ diâmetro de cristalito foi estimado para $\mathrm{FeO}$ em 100nm. Para amostra de $5 \% \mathrm{Fe} / \mathrm{Si}$-Al método ureia foram identificadas 3 fases: $\gamma-\mathrm{Al}_{2} \mathrm{O}_{3} 96,84 \%, \mathrm{Fe}^{0}$ $3.11 \%, \mathrm{Fe}_{3} \mathrm{O}_{4}$ 0,35\%, sendo o diâmetro de cristalito estimado em $75 \mathrm{~nm}$ para a fase de $\mathrm{Fe}^{0}$. No caso da amostra de $5 \% \mathrm{Fe} / \mathrm{Si}$-Al foram identificadas 3 fases: $\gamma-\mathrm{Al}_{2} \mathrm{O}_{3} 95,45 \%, \mathrm{Fe}^{0} 4,38 \%, \mathrm{Fe}_{3} \mathrm{O}_{4}$ 0,14\%, com diâmetro de cristalito estimado em $75 \mathrm{~nm}$ para a fase de $\mathrm{Fe}^{0}$. A amostra de $10 \% \mathrm{Fe} / \mathrm{Si}-\mathrm{Al}$ apresentou 4 fases: $\gamma-\mathrm{Al}_{2} \mathrm{O}_{3} 10,76 \%, \mathrm{Fe}^{0} 9.1 \%, \mathrm{FeO} 1.94 \%, \mathrm{Al}_{2} \mathrm{SiO}_{5}$ (silimanite) $78.10 \%$ sendo o diâmetro de cristalito estimado em $75 \mathrm{~nm}$ e $100 \mathrm{~nm}$ para $\circ \mathrm{Fe}^{0}$ e $\mathrm{FeO}$, respectivamente. 


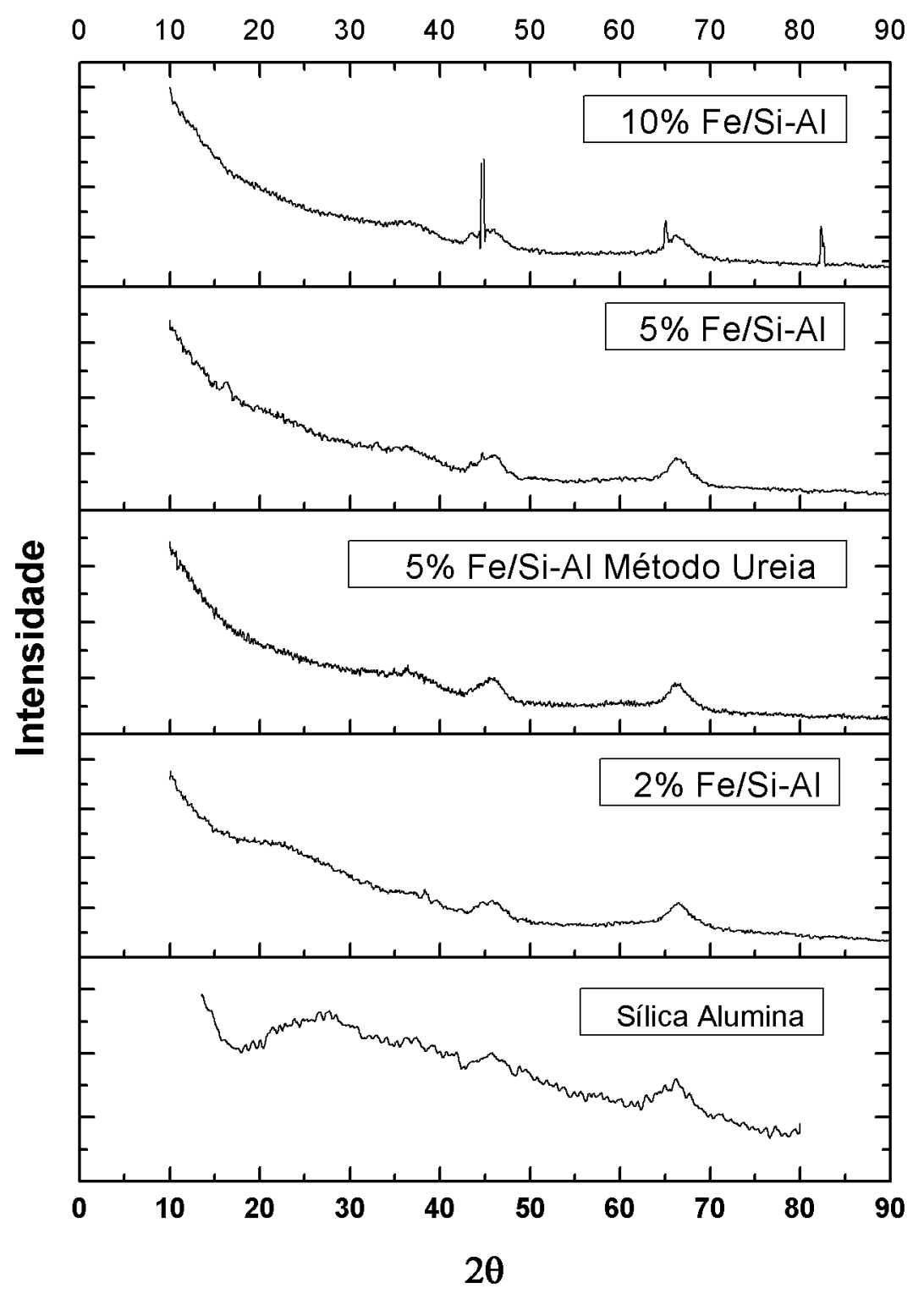

Figura 19. Análise de DRX do suporte de sílica alumina e das amostras de $2 \%$ $\mathrm{Fe} / \mathrm{Si}-\mathrm{Al}, 5 \% \mathrm{Fe} / \mathrm{Si}-\mathrm{Al}$ método ureia, 5\% Fe/Si-Al e 10\% Fe/Si-Al reduzidas. 


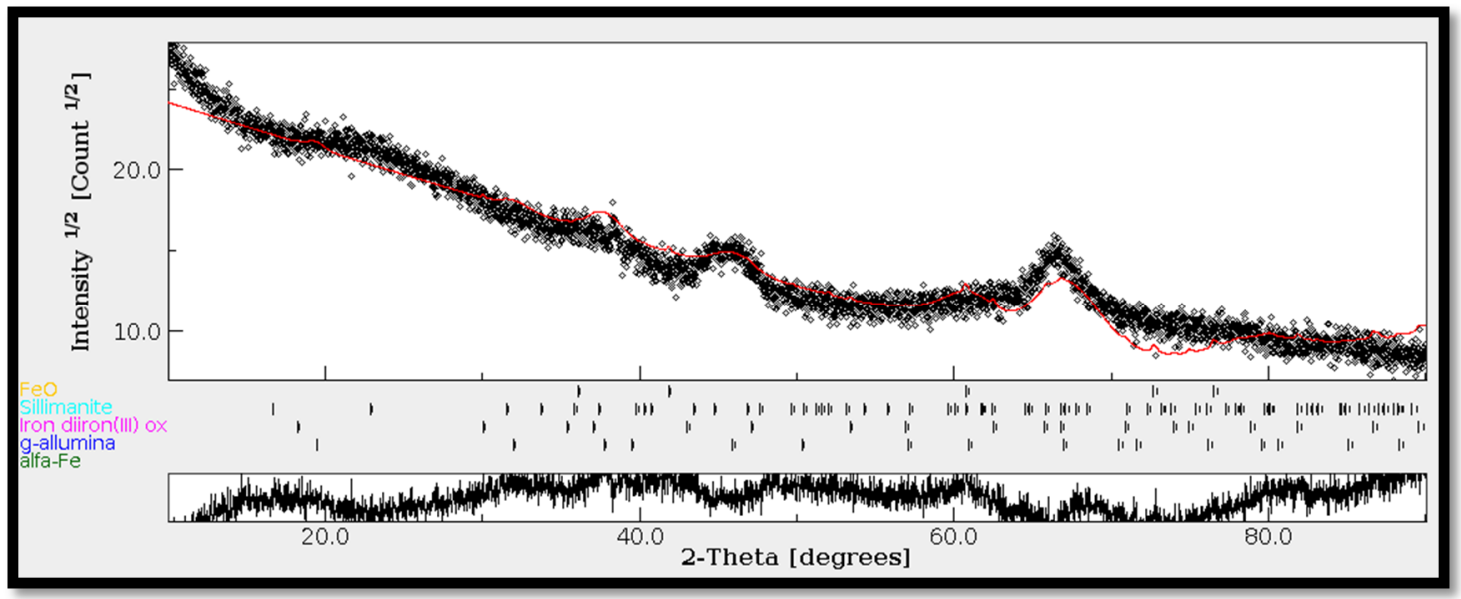

Figura 20. Amostra de $2 \% \mathrm{Fe} / \mathrm{Si}$-Al reduzida. Índice de qualidade do ajuste (gofgoodnes of fit) $2.16 \%, R w p=1.95 \%$.

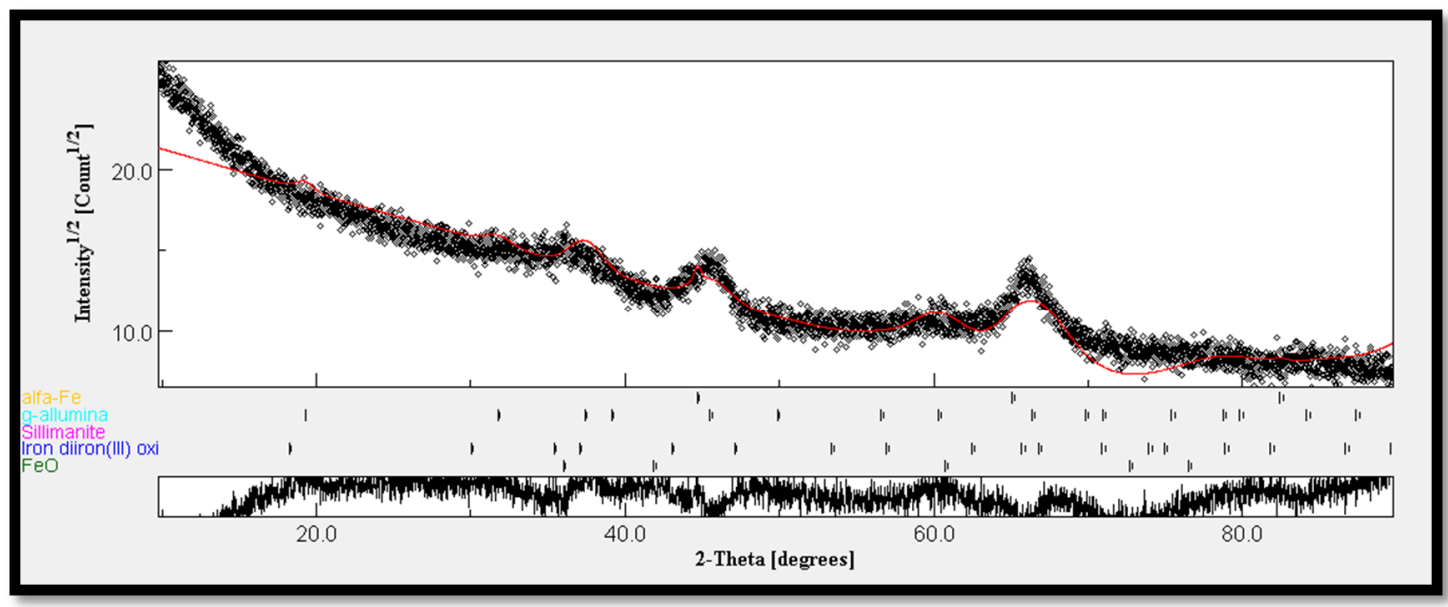

Figura 21. Amostra 5\% Fe/Si-Al método ureia reduzida. Índice de qualidade do ajuste (gof-goodnes of fit) $2.13 \%$, Rwp $=1.94 \%$. 


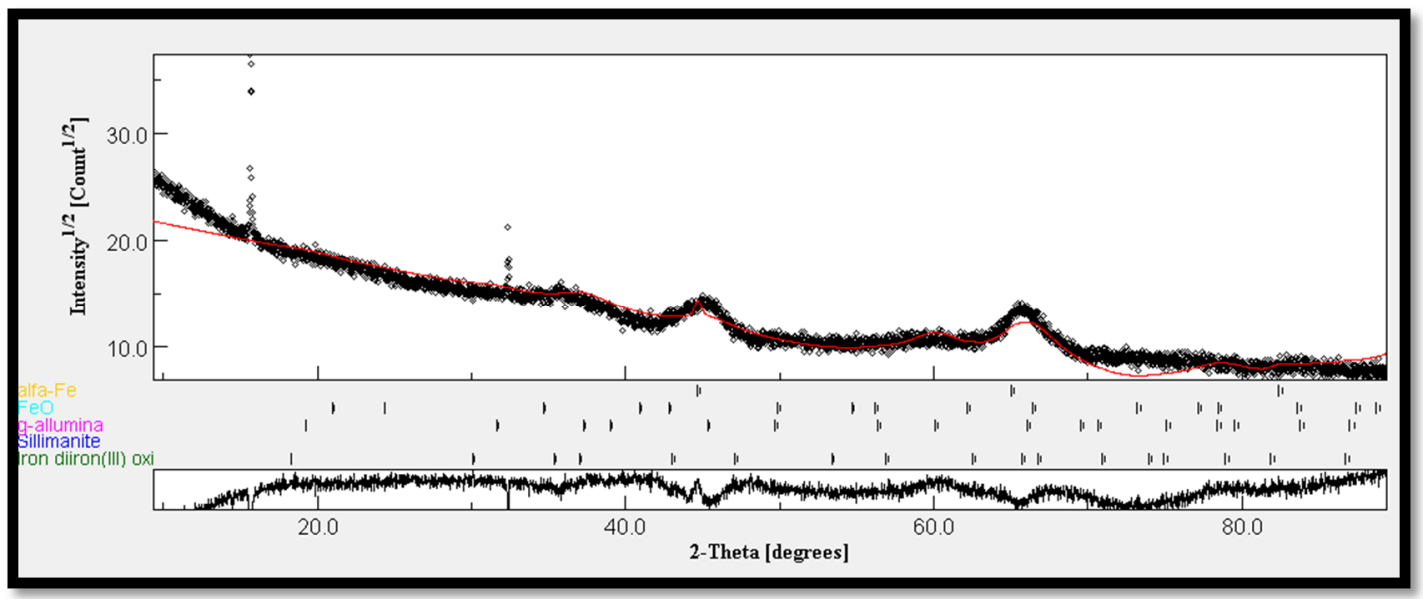

Figura 22. Amostra de 5\% Fe/Si-Al reduzida índice de qualidade do ajuste (gof-goodnes of fit) $2.13 \%, R w p=1.93 \%$.

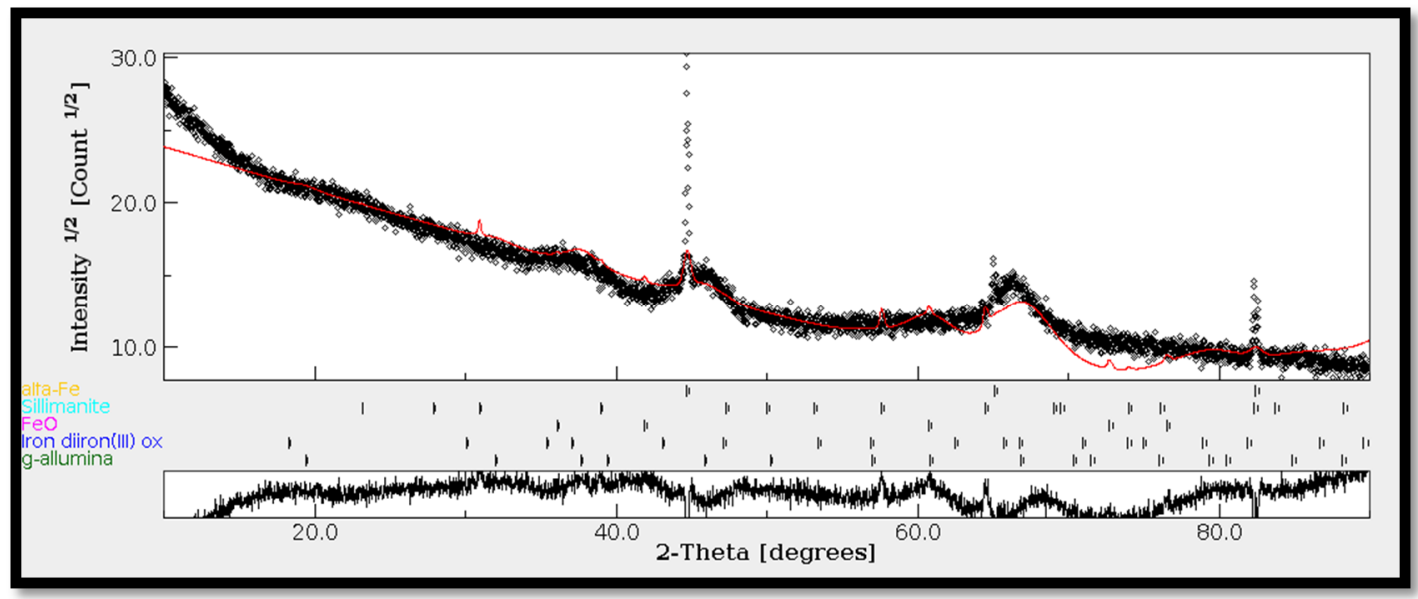

Figura 23. Amostra $10 \% \mathrm{Fe} / \mathrm{Si}$-Al reduzida. Índice de qualidade do ajuste (gof-goodnes of fit) $2.4 \%, R w p=2.1 \%$. 
4.4.3.2.

Catalisador de $5 \% \mathrm{Fe} / \mathrm{Si}-\mathrm{Al}$ reduzido com $\mathrm{CO} / \mathrm{H}_{2}$

A atividade de catalisadores de ferro suportados tem, mais recentemente, sido atribuída à formação de carbetos de ferro $\mathrm{Fe}_{5} \mathrm{C}_{2}$ durante a reação de Fischer-Tropsch (CHENG et al., 2015; PARK et al., 2014). Segundo eles quanto maior o diâmetro de poro do suporte mais efetiva é a formação de carbetos durante a reação de Fischer-Tropsch, resultando em maiores taxas de conversão de $\mathrm{CO}$, maior seletividade para olefinas e $\mathrm{C}_{5}{ }^{+}$.

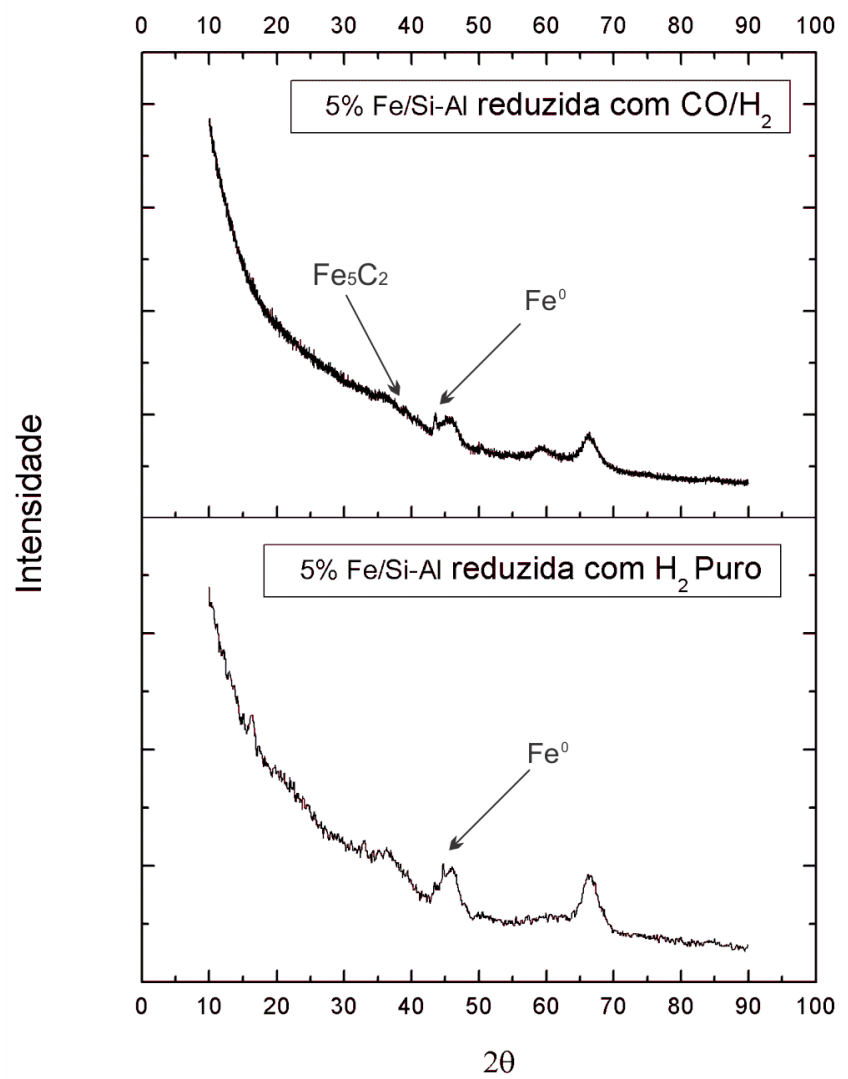

Figura 24. Análise de DRX do catalisador de $5 \% \mathrm{Fe} / \mathrm{Si}$-Al reduzido com $\mathrm{CO} / \mathrm{H}_{2}$ e $5 \% \mathrm{Fe} / \mathrm{Si}$-Al reduzido com $\mathrm{H}_{2}$. 
Assim, a amostra de $5 \% \mathrm{Fe} / \mathrm{Si}-\mathrm{Al}$ foi reduzida com $\mathrm{CO} / \mathrm{H}_{2}$ e analisada no DRX com refinamento de Rietveld para poder investigar a formação destas fases encontrando-se efetivamente a fase de $\mathrm{Fe}_{5} \mathrm{C}_{2}$, conforme difratograma e refinamento de Rietveld apresentados nas figuras 24 e 25, respectivamente. Foi verificada a presença das seguintes fases $\% \gamma-\mathrm{Al}_{2} \mathrm{O}_{3}=76.35$; $\% \mathrm{Fe}_{5} \mathrm{C}_{2}=23.65$.

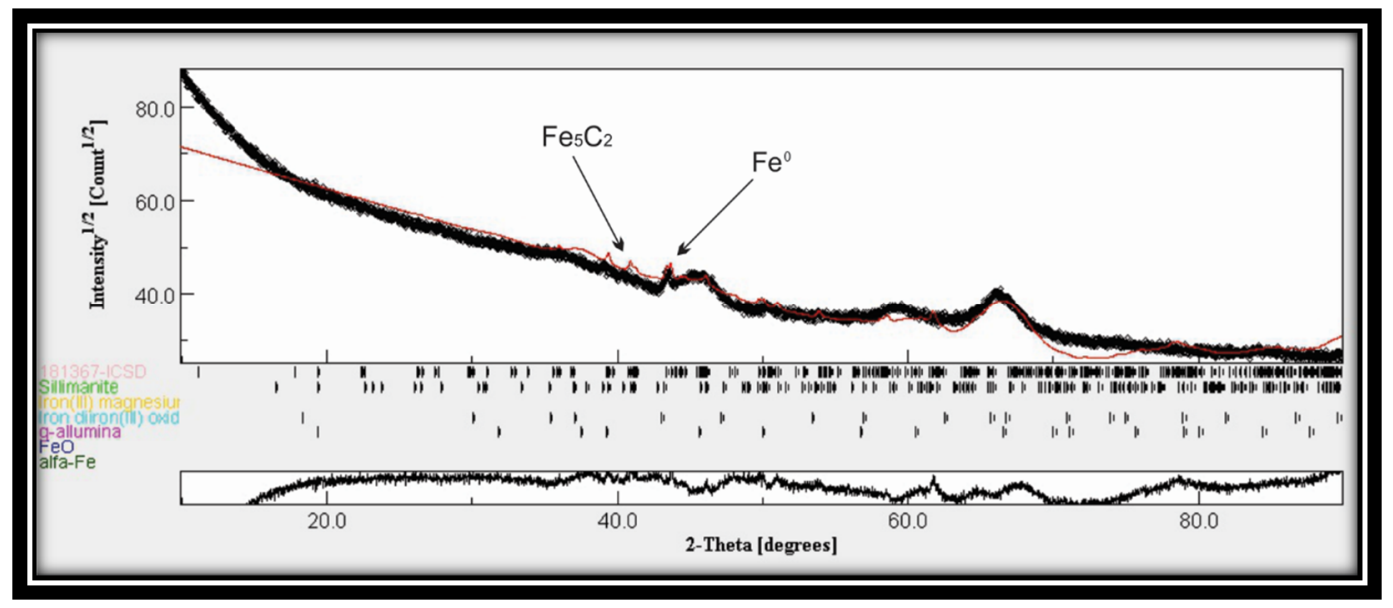

Figura 25. Amostra $5 \% \mathrm{Fe} / \mathrm{Si}$-Al impregnação reduzida com $\mathrm{CO} / \mathrm{H}_{2}$. Índice de qualidade do ajuste (gof-goodnes of fit) $2.47 \%, R w p=2.13 \%$.

\subsubsection{3.}

\section{Catalisador de $2 \% \mathrm{Co} / \mathrm{Si}-\mathrm{Al}$ reduzido $\mathrm{com} \mathrm{H}_{2}$}

$\mathrm{Na}$ figura 26 se mostra o difratograma do catalisador de $2 \% \mathrm{Co} / \mathrm{Si}-\mathrm{Al}$ reduzido. Não foi possível observar a presença das fases $\mathrm{Co}^{\prime \prime}$ e $\mathrm{Co}^{0}$ devido ao baixo teor metálico (2\%) sendo os picos em $2 \theta=36.9^{\circ}, 46^{\circ}$ e $65.5^{\circ}$. relacionados ao $\mathrm{Co}_{3} \mathrm{O}_{4}$ (JUNG et al. 2012) como já visto na mostra não reduzida. A figura 27 mostra o refinamento de Rietveld, encontrando-se as seguintes fases $\gamma-\mathrm{Al}_{2} \mathrm{O}_{3}=68.82 ; A L_{2} \mathrm{SIO}_{5}$ (silimanite) $=30.06 \% ; \% \mathrm{Co}_{3} \mathrm{O}_{4}=1.11$ \%, sendo o diâmetro de cristalito do $\mathrm{Co}_{3} \mathrm{O}_{4}$ estimado em $99 \mathrm{~nm}$. 


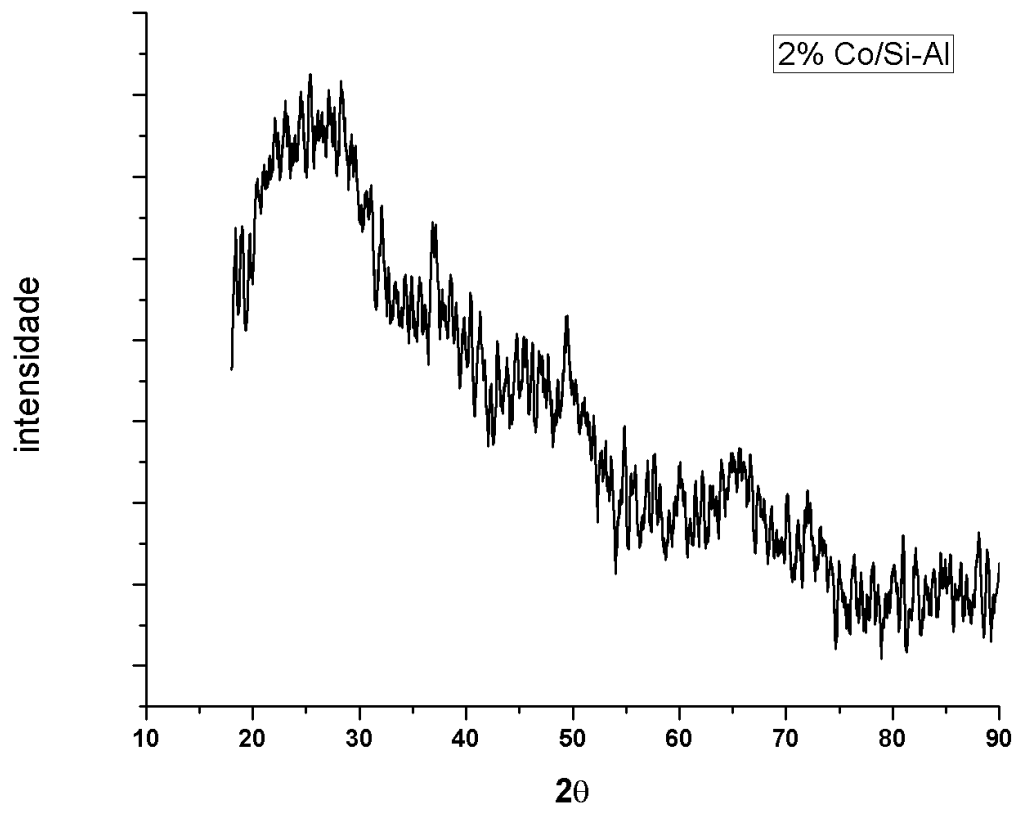

Figura 26. Análise de DRX da amostra 2\% Co/Si-Al reduzida com $\mathrm{H}_{2}$.

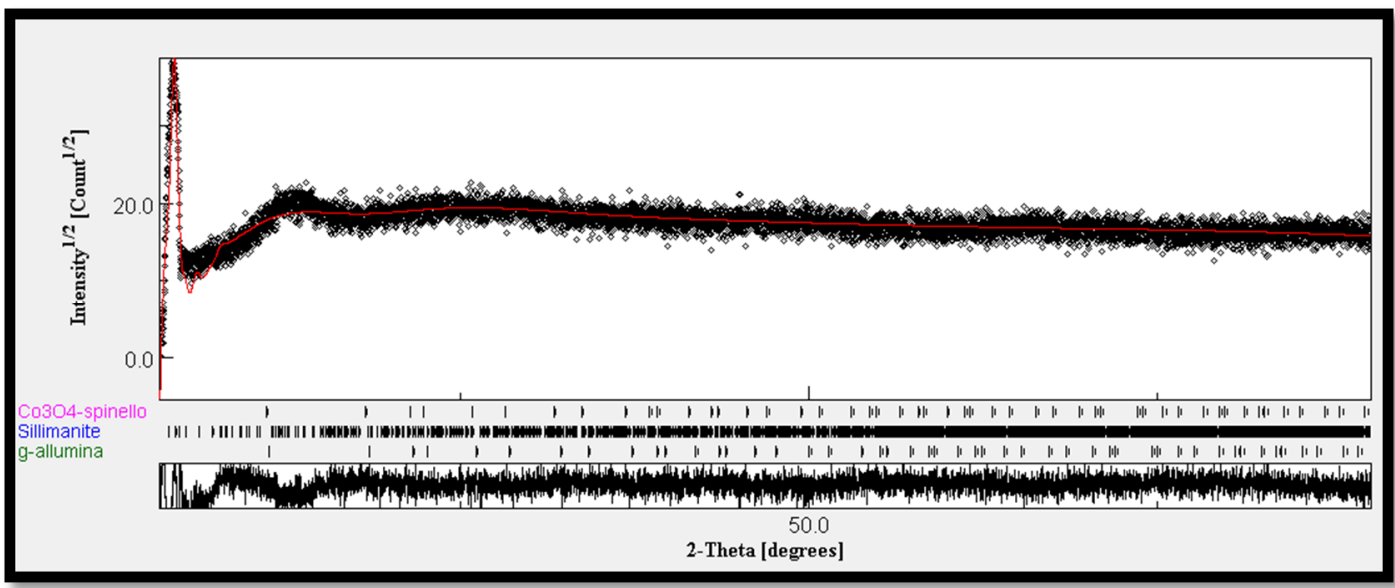

Figura 27. Amostra $2 \% \mathrm{Co} / \mathrm{Si}-\mathrm{Al}$ reduzida $\mathrm{com} \mathrm{H}_{2}$. Índice de qualidade do ajuste (gof-goodnes of fit) $2.03 \%$, Rwp $=1.98 \%$. 
4.4.3.4.

Catalisador de $2 \% \mathrm{Fe} /$ sílica mesoporosa reduzido com $\mathrm{H}_{2}$

A figura 28 mostra o difratograma do catalizador de $2 \% \mathrm{Fe} /$ sílica mesoporosa reduzido com $\mathrm{H}_{2}$ puro. Como já verificado no catalisador calcinado, não foi possível observar os picos correspondentes ao óxido de ferro localizados em $2 \theta=37.3^{\circ}, 2 \theta=44.9^{\circ}$ (KEYVANLOO et al., 2014b), deixando o difratograma parecido ao do suporte de sílica mesoporosa, embora os resultados TPR apresentassem um alto grau de redução (87\%). Provavelmente as partículas de ferro, que estão em pequenas quantidades, se encontram dispersas dentro dos poros e, talvez, por isso não foram observadas no difratograma. A figura 29 mostra o refinamento de Rietveld onde foram encontradas duas fases $\% \mathrm{SiO}_{2}=99.48 ; \% \mathrm{Fe}_{3} \mathrm{O}_{4}=0.52$, com diâmetro de cristalito estimado em $82.2 \mathrm{~nm}$ para $\mathrm{Fe}_{3} \mathrm{O}_{4}$, não sendo possível identificar a fase de $\mathrm{Fe}^{0}$.

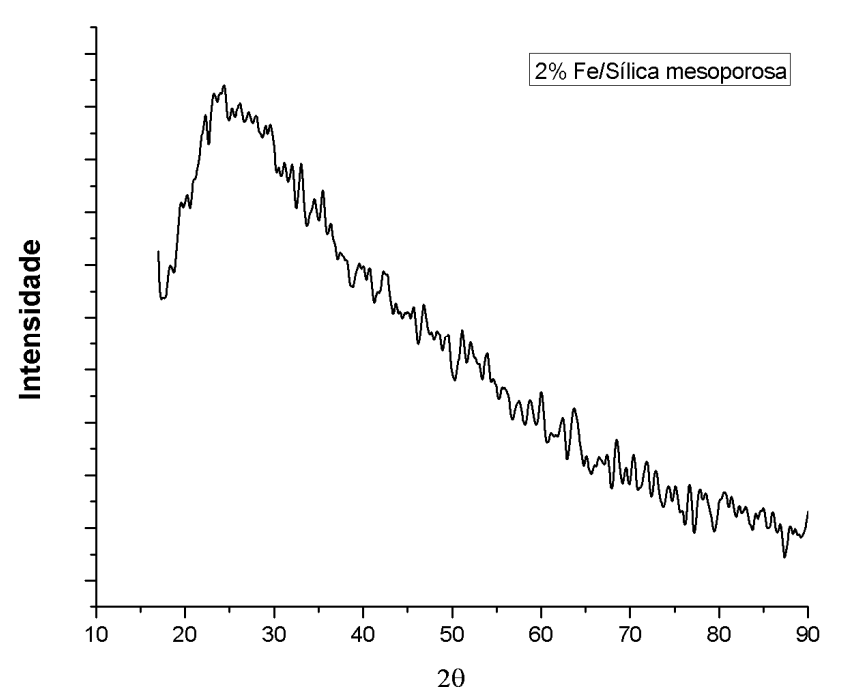

Figura 28. Análise de DRX da amostra 2\% Fe/sílica mesoporosa reduzida com $\mathrm{H}_{2}$. 


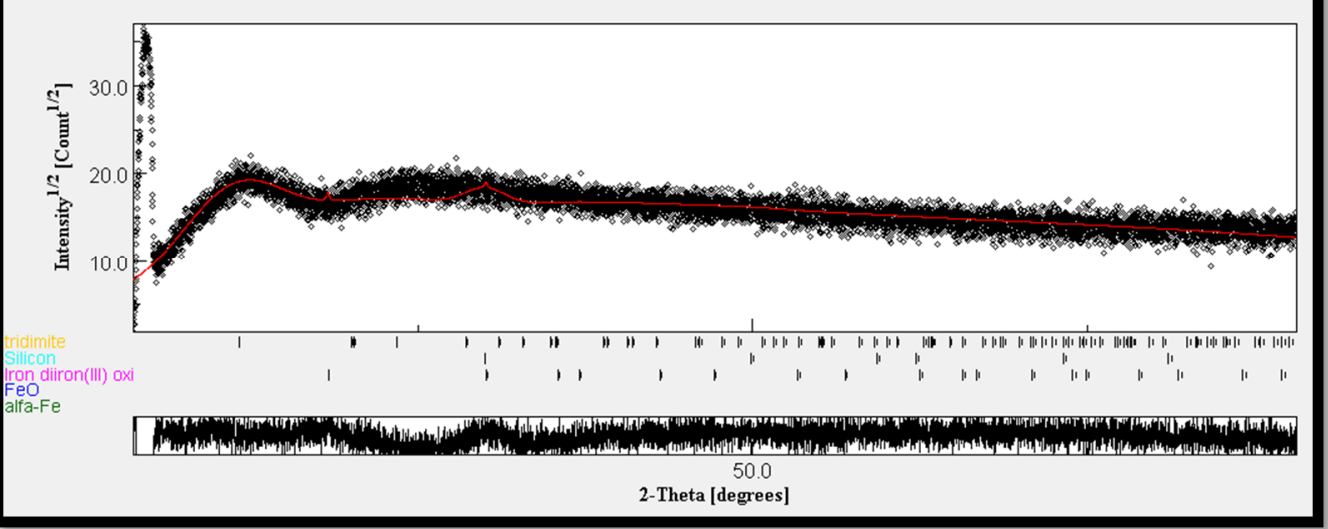

Figura 29. Amostra 2\% Fe/silica mesoporosa reduzida com $\mathrm{H}_{2}$. Índice de qualidade do ajuste (gof-goodnes of fit) 2.02\%, Rwp $=1.99 \%$.

\subsection{4. \\ Catalisador de ferro não suportado FeNP}

As nano partículas de ferro que foram sintetizadas pela redução do boroidreto de sódio ( $\mathrm{NaBH} 4)$ e cloreto férrico hexaidratado $(\mathrm{FeCl} 3 \cdot 6 \mathrm{H} 2 \mathrm{O})$, apresentaram o difratograma mostrado na figura 30. Elas se mostraram cristalinas com o pico principal característico do ferro metálico em $2 \theta=44^{\circ}$, que também foi identificado pelo refinamento de Rietveld mostrado na figura 31. Este resultado concorda com os reportados pelos autores PARK et al., (2001). Nesta análise foram identificadas 4 fases com as seguintes percentagens $\mathrm{Fe}^{0}$ $=34,28 \%, \mathrm{FeO}=63,30 \%, \mathrm{Fe}_{3} \mathrm{O}_{4}=1,73 \%, \mathrm{Fe}_{2} \mathrm{O}_{3}=0,67 \%$, sendo o diâmetro de cristalito estimado paras as fases de $\mathrm{FeO}$ e $\mathrm{Fe}^{0}$ em 98 e 13 nm, respectivamente.

Posteriormente cabe mencionar que estas nano partículas foram submetidas a uma atmosfera de $\mathrm{CO} / \mathrm{H}_{2}$ gerando um difratograma completamente amorfo devido, provavelmente, à deposição de carbono sobre as nano partículas, já que ficou evidenciada durante este processo a conversão de $\mathrm{CO}$ a hidrocarbonetos devido ao forte cheiro de combustível percebido no ambiente. 


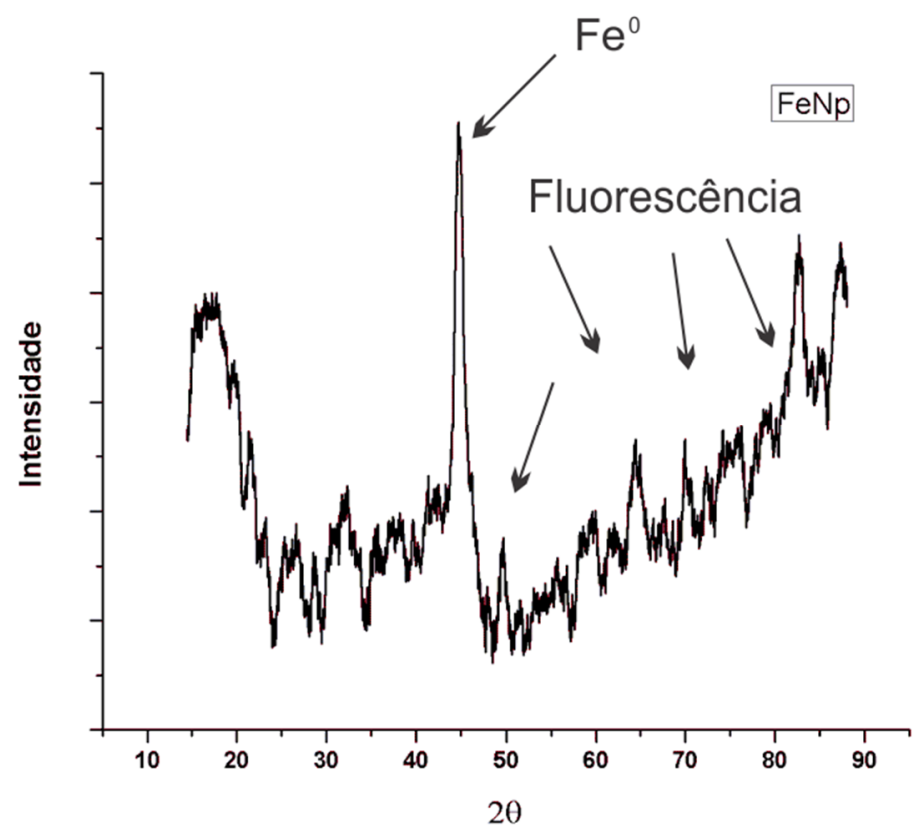

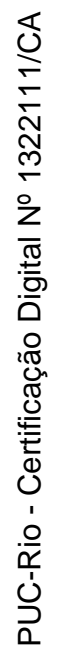

Figura 30. Análise de DRX das nano partículas de ferro não suportadas (FeNp).

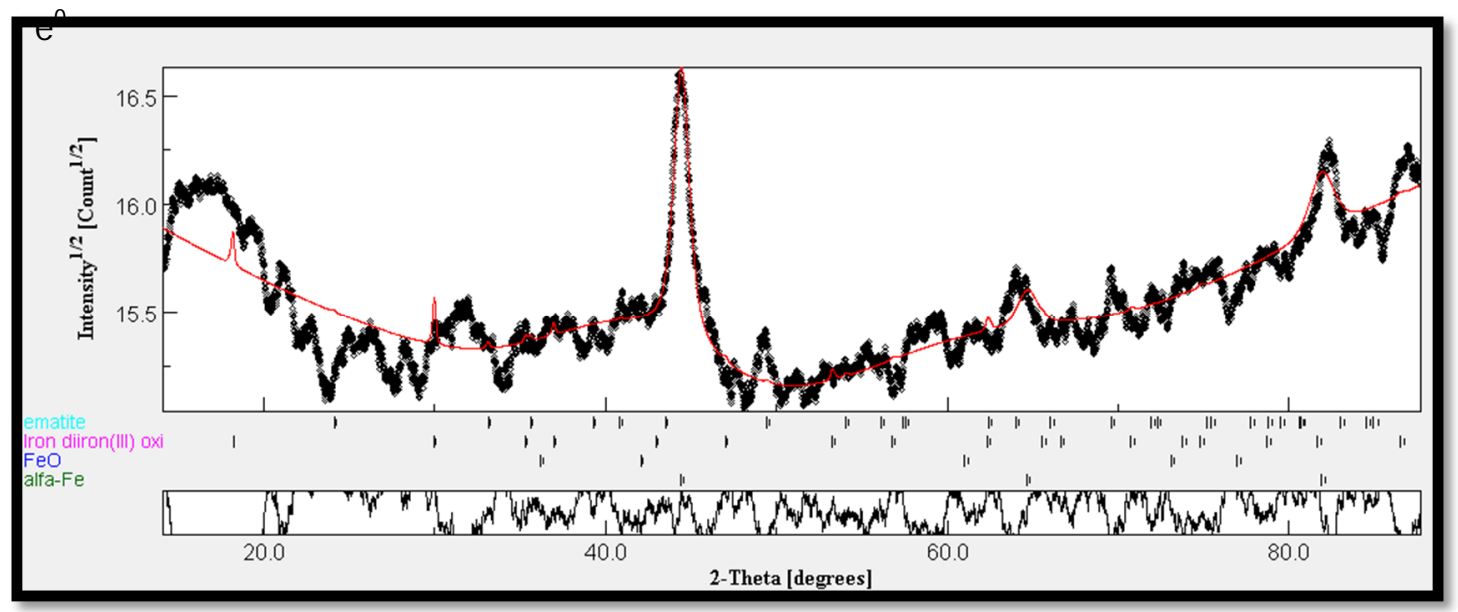

Figura 31. Amostra de FeNp. Índice de qualidade do ajuste (gof-goodnes of fit) $2.49 \%, \operatorname{Rwp}=2.3 \%$. 
4.5.

Redução com Temperatura Programada (RTP)

Os perfis de RTP dos catalisadores de $5 \% \mathrm{Fe} / \mathrm{Si}-\mathrm{Al}, 5 \% \mathrm{Fe} / \mathrm{Si}-\mathrm{Al}$

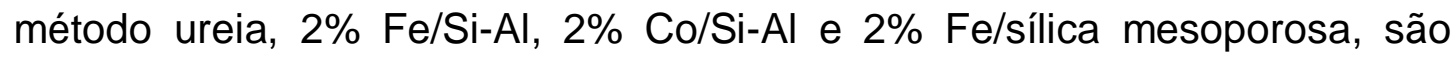
apresentados na figura 32. Na tabela 6 é apresentado o consumo de $\mathrm{H}_{2}$ e o percentagem de redução para cada um dos catalisadores mencionados. Os intervalos de temperatura em que acontecem as reduções para os catalisadores a base de ferro descrevem duas regiões. Para a amostra de $5 \%$ $\mathrm{Fe} / \mathrm{Si}$-Al, o primeiro pico atinge o máximo de temperatura em $360{ }^{\circ} \mathrm{C}$ e o segundo em $694{ }^{\circ} \mathrm{C}$. Ja para a amostra de $5 \%$ de $\mathrm{Fe} / \mathrm{Si}$-Al método ureia também foram identificados dois picos em $251^{\circ} \mathrm{C}$ e $718^{\circ} \mathrm{C}$. A amostra de $2 \%$ de $\mathrm{Fe} / \mathrm{Si}$-Al apresentou dois picos em $375^{\circ} \mathrm{C}$ e $735^{\circ} \mathrm{C}$. Os resultados obtidos por KEYVANLOO et al. (2014b) na redução de catalisadores de ferro suportados em sílica alumina, apresentam três regiões atribuindo as duas primeiras à redução de $\mathrm{Fe}_{2} \mathrm{O}_{3}$ para $\mathrm{FeO}$ e a redução de $\mathrm{FeO}$ a Fe ${ }^{0}$. As reações de redução que acontecem estão ilustradas na figura 33. Eles descrevem ainda uma terceira região que aparece em temperaturas elevadas provavelmente, devido à interação do $\mathrm{Fe} \operatorname{com~} \mathrm{AL}_{2} \mathrm{O}_{3}$ formando aluminato de ferro na superfície da amostra. No caso das amostras deste trabalho só foi encontrado um pico de redução que pode ser atribuído a redução direta de $\mathrm{Fe}_{2} \mathrm{O}_{3}$ a $\mathrm{Fe}^{0} \mathrm{o}$ que já foi verificado em trabalho anterior do laboratório por BRAGANÇA et al., (2013) já que o segundo devido a sua alta temperatura pode ser atribuído à interação de ferro com suporte ou a redução das partículas concordando com os autores KOCK; FORTUIN e GEUS (1985).

A figura 34 apresenta claramente a área abaixo da curva para cada análise da RTP, pode-se observar que o catalisador de $5 \% \mathrm{Fe} / \mathrm{Si}-\mathrm{Al}$ método ureia consumiu mais hidrogênio que o catalisador $5 \% \mathrm{Fe} / \mathrm{Si}-\mathrm{Al}$, apresentando um percentagem de redução $44 \%$ em comparação com $22 \%$ do $5 \% \mathrm{Fe} / \mathrm{Si}$-Al, indicando uma maior dispersão de ferro para o primeiro catalisador. 


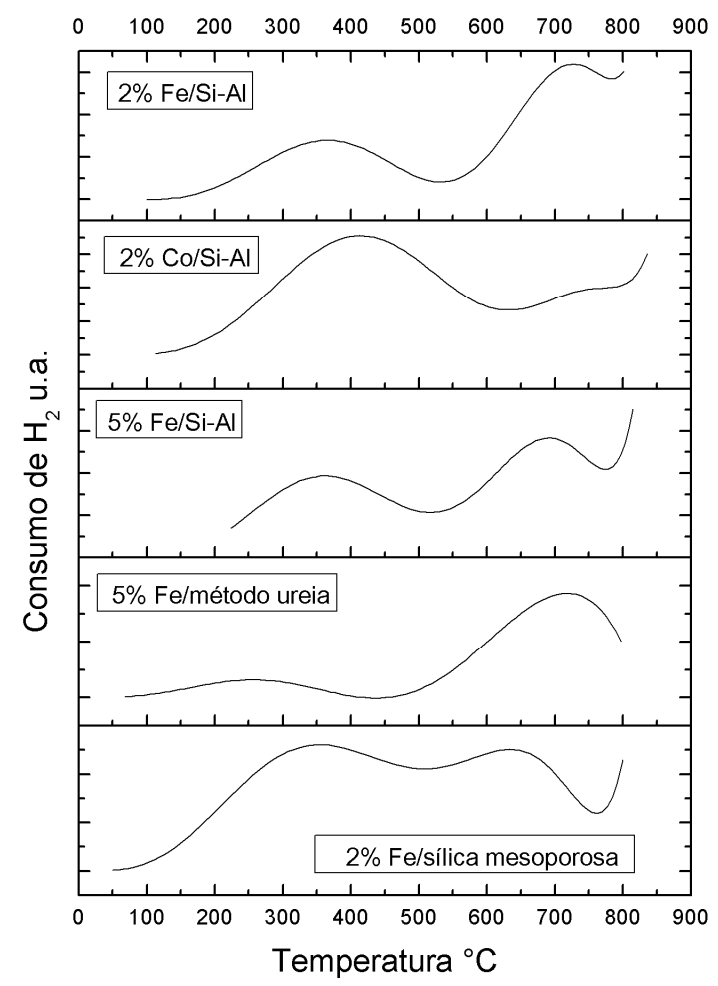

Figura 32. Perfis de RTP para as amostras de $2 \% \mathrm{Fe} / \mathrm{Si}-\mathrm{Al}, 2 \% \mathrm{Co} / \mathrm{Si}-\mathrm{Al}, 5 \%$ $\mathrm{Fe} / \mathrm{Si}-\mathrm{Al}$ e $5 \% \mathrm{Fe} / \mathrm{Si}-\mathrm{Al}$ método ureia e $2 \% \mathrm{Fe} /$ sílica mesoporosa.

$$
\begin{array}{r}
3 \mathrm{Fe}_{2} \mathrm{O}_{3}+\mathrm{H}_{2} \rightleftharpoons 2 \mathrm{Fe}_{3} \mathrm{O}_{4}+\mathrm{H}_{2} \mathrm{O} \\
2 \mathrm{Fe}_{3} \mathrm{O}_{4}+2 \mathrm{H}_{2} \rightleftharpoons 6 \mathrm{FeO}+2 \mathrm{H}_{2} \mathrm{O} \\
6 \mathrm{FeO}+6 \mathrm{H}_{2} \rightleftharpoons 6 \mathrm{Fe}+6 \mathrm{H}_{2} \mathrm{O}
\end{array}
$$

Figura 33. Reações de redução para o ferro. Óxido de ferro (hematita) é sucessivamente reduzida para magnetita, wustite $(\mathrm{FeO})$ e, finalmente, reduzido a ferro metálico.

A amostra de $2 \% \mathrm{Co} / \mathrm{Si}-\mathrm{Al}$ apresentou um pico intenso em torno de 412 ${ }^{\circ} \mathrm{C}$ e outro muito fraco em $747^{\circ} \mathrm{C}$, sendo o primeiro pico referente a redução do oxido de cobalto, e o segundo provavelmente resultante da interação do cobalto com o suporte. Estes resultados não estão coincidindo com os perfis de redução com temperatura programada obtidos pelos autores BOUBEKR et al., (2011), MINNERMANN et al., (2013) e BRAGANÇA et al., (2013) que 
encontraram duas regiões de redução a primeira atribuída a redução de Co ${ }^{\text {III }}$ a Co" e a segunda $\mathrm{Co}^{\prime \prime}$ a $\mathrm{Co}^{\circ}$, ambas em temperaturas inferiores a $500{ }^{\circ} \mathrm{C}$. Esta diferença foi atribuída ao teor baixo $(2 \%)$ de cobalto usado em comparação com os outros trabalhos acima citados. Li et al. (2006) sugeriram que, nos suportes de sílicas mesoporosas MCM-48 e SBA-15, os grupos silanols podem interagir com as partículas de óxido de cobalto e retardar sua redução. Khodakov et al. (1997) estudaram a redução de partículas de óxido de diferentes tamanhos e sugeriram que as pequenas partículas de óxido de cobalto com forte interação na sílica podem ser reduzidas em temperatura mais elevada.

Amostra de 2\% Fe/sílica mesoporosa apresentou dois picos, sendo o primeiro em torno de $352^{\circ} \mathrm{C}$ e o segundo em torno de $661^{\circ} \mathrm{C}$ como as amostras de ferro suportadas em silica aumina. O primeiro pico está relacionado com a redução de $\mathrm{Fe}_{2} \mathrm{O}_{3}$ a $\mathrm{FeO}$ e o segundo pode ser atribuído como já visto nos demais catalisadores. Na figura 34 pode-se observar que a maior área de baixo da curva na análise de RTP corresponde ao catalisador de $2 \% \mathrm{Fe} /$ sílica mesoporosa, indicando que este catalisador apresenta $87 \%$ de redução, sendo este valor mais elevado que os apresentados pelos demais catalisadores (tabela 6), indicando uma alta dispersão de ferro sobre a superfície da sílica mesoporosa. As baixas percentagens de redução são atribuidas a alta dispersão e forte interação entre os óxidos do metal e o suporte (ARENA et al., 2006; LIU et al., 005;HUANG; ANDERSON, 1975; GAO et al., 1993) 


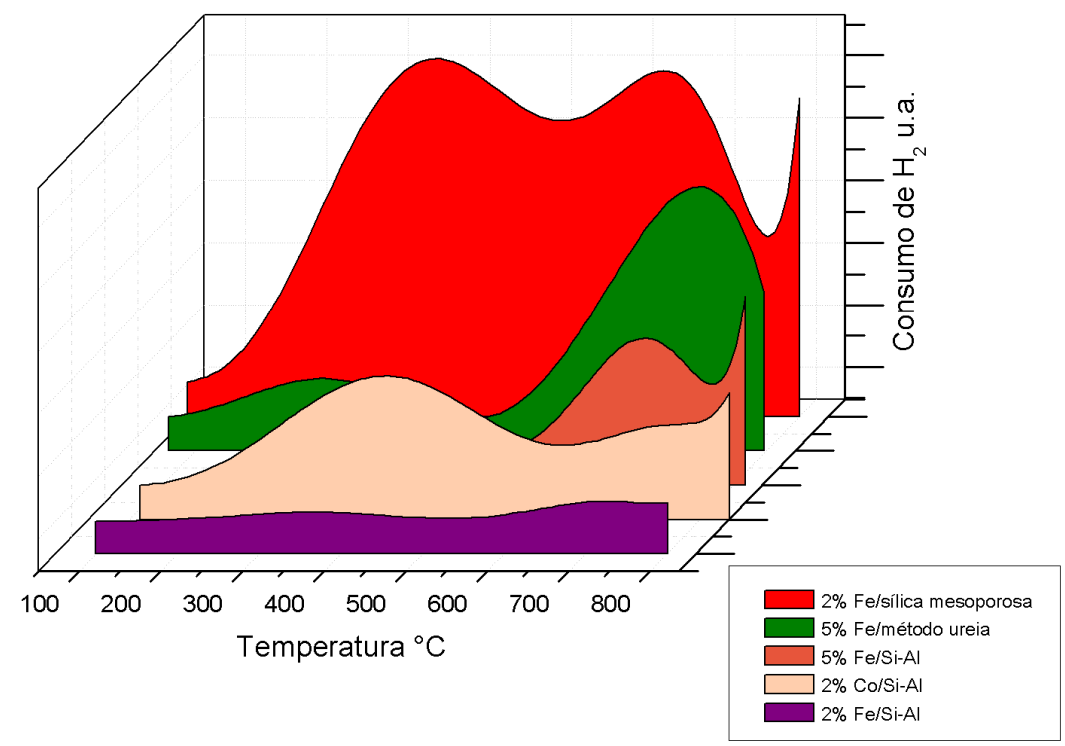

Figura 34. Análise de RTP para as amostras 2\% Fe/Si-Al, 2\% Co/Si-Al, 5\% Fe/SiAl, $5 \%$ Fe/Si-Al método ureia e 2\% Fe/sílica mesoporosa

Tabela 6. Consumo de hidrogênio e grau de redução dos catalisadores suportados.

\begin{tabular}{|l|c|c|}
\hline \multicolumn{1}{|c|}{ Amostra } & Consumo de $\mathrm{H}_{2}(\mathrm{~mol})$ & $\begin{array}{c}\text { Grau de redução } \\
(\%)\end{array}$ \\
\hline \hline $5 \% \mathrm{Fe} / \mathrm{Si}-\mathrm{Al}$ & $4.90 \mathrm{E}-05$ & 22 \\
\hline $5 \% \mathrm{Fe} / \mathrm{Si}-\mathrm{Al}$ método ureia & $9.80 \mathrm{E}-03$ & 44 \\
\hline $2 \% \mathrm{Fe} / \mathrm{Si}-\mathrm{Al}$ & $1.30 \mathrm{E}-04$ & 12 \\
\hline $2 \% \mathrm{CO} / \mathrm{Si}-\mathrm{Al}$ & $6.03 \mathrm{E}-05$ & 30 \\
\hline $2 \% \mathrm{Fe} /$ silica mesoporosa & $1.86 \mathrm{E}-04$ & 87 \\
\hline
\end{tabular}




\section{6. Microscopia Eletrônica de Transmissão}

As imagens obtidas para as mostras reduzidas com $\mathrm{H}_{2}$ de $(2 \% \mathrm{Fe} / \mathrm{Si}-\mathrm{Al}$, $5 \% \mathrm{Fe} / \mathrm{Si}-\mathrm{Al}$, $5 \% \mathrm{Fe} / \mathrm{Si}-\mathrm{Al}$ método ureia) são apresentadas a seguir. Nas figuras $35 \mathrm{a}$ e $35 \mathrm{~b}$ da amostra de $2 \% \mathrm{Fe} / \mathrm{Si}$-Al foram observados aglomerados de partículas com forma esférica. $O$ histograma desta amostra ilustrado na figura $35 \mathrm{c}$ indicou um maior percentual de partículas com tamanhos entre 5 e $20 \mathrm{~nm}$, embora alguns aglomerados de até $50 \mathrm{~nm}$ foram também encontrados. Não é possível ver uma grande quantidade de partículas de ferro já que não ocorreu a redução total do metal como indicado na análise de RTP e pelo DRX (refinamento de Rietveld).

As figuras 36 a, b e $37 \mathrm{c}, \mathrm{d}$, mostram as imagens obtidas pela MET para o suporte de sílica alumina. Nestas fotos pode-se observar a morfologia do mesmo, com regiões ampliadas mostradas nas figuras $36 a+, b+e 37 c+, d+$. Estas imagens permitem conferir que as partículas apresentam uma textura mesoporosa com canais característicos da sílica alumina (MEYNEN; COOL; VANSANT, 2009).

As imagens de microscopia eletrônica de transmissão das amostras de $5 \% \mathrm{Fe} / \mathrm{Si}$-Al método ureia e 5\%Fe/Si-Al estão ilustradas nas figuras 38 e 39 respetivamente. Elas mostram a presença de aglomerados com formatos irregulares de partículas, não sendo encontradas partículas de óxido de ferro com forma esféricas como no catalisador de $2 \%$ Fe/Si-Al, embora a análise de RTP ter mostrado um maior grau de redução para estes dois catalisadores em comparação com o catalisador de $2 \% \mathrm{Fe} / \mathrm{Si}$-Al. Este resultado pode ser contraditório com o esperado, mas concorda com o observado no DRX onde não foram claramente observados picos das fases de óxido de ferro e $\mathrm{Fe}^{0}$, sendo necessário o uso do refinamento de Rietveld para identificar a presença 
destas fases. Portanto pode-se dizer que as regiões de aglomerados mais escuros corresponderiam aos óxidos de ferro e $\mathrm{Fe}^{0}$. As imagens das figuras 38a, 38b, 39a e 39b mostram a presença de partículas com textura característica de material mesoporoso correspondente à sílica alumina, observando-se os mesoporos nas regiões mais claras das imagens. As imagens das figuras $38 \mathrm{c}$ e $39 \mathrm{c}$ representam o campo escuro das figuras $38 \mathrm{~b}$ e 39b identificando os pontos claros como as partículas dos óxidos de ferro e de ferro metálico.
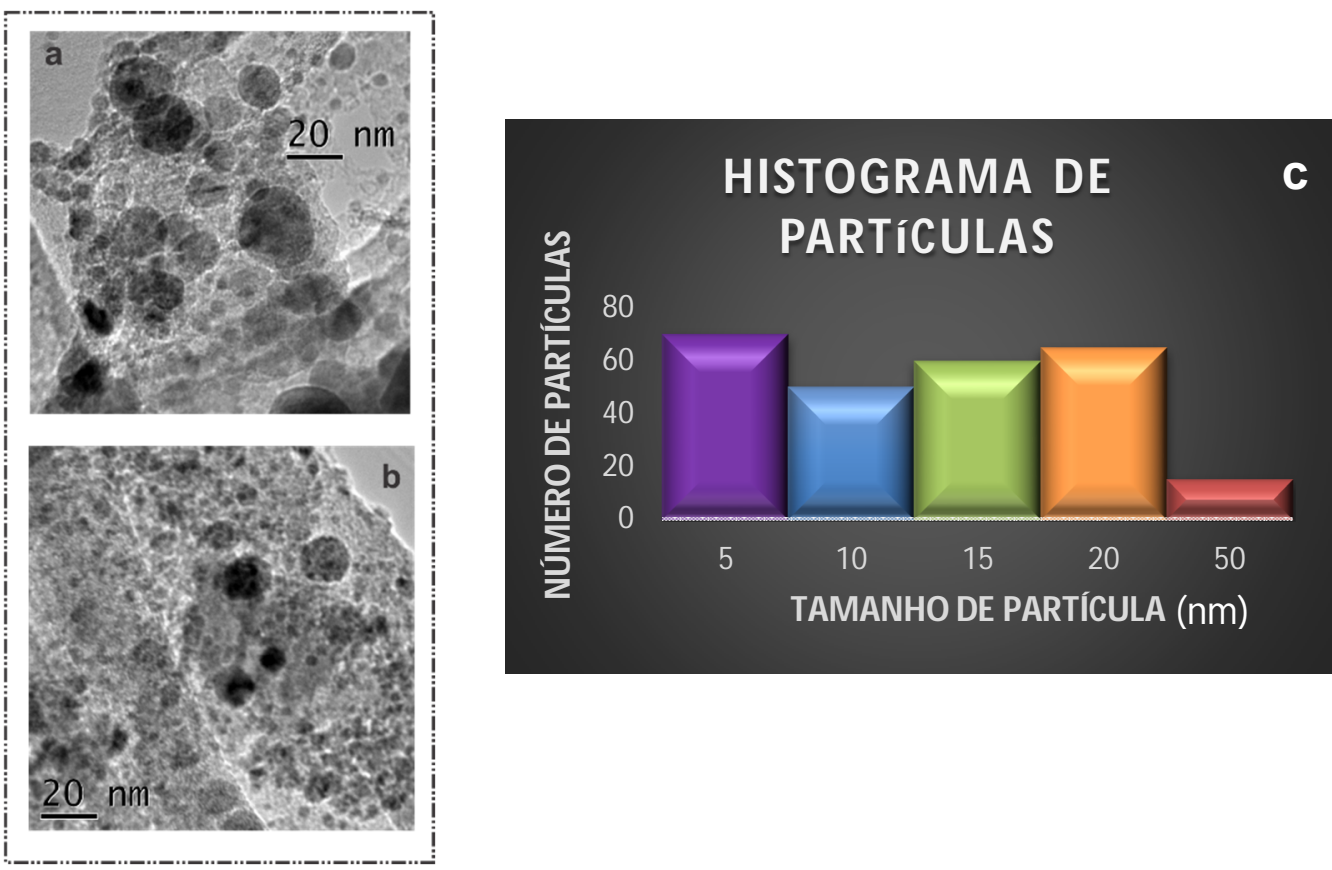

Figura 35. Imagens obtidas por MET para a amostra de $2 \% \mathrm{Fe} / \mathrm{Si}-\mathrm{Al}$ a e b; histogramas de distribuição de tamanho de partícula c. 

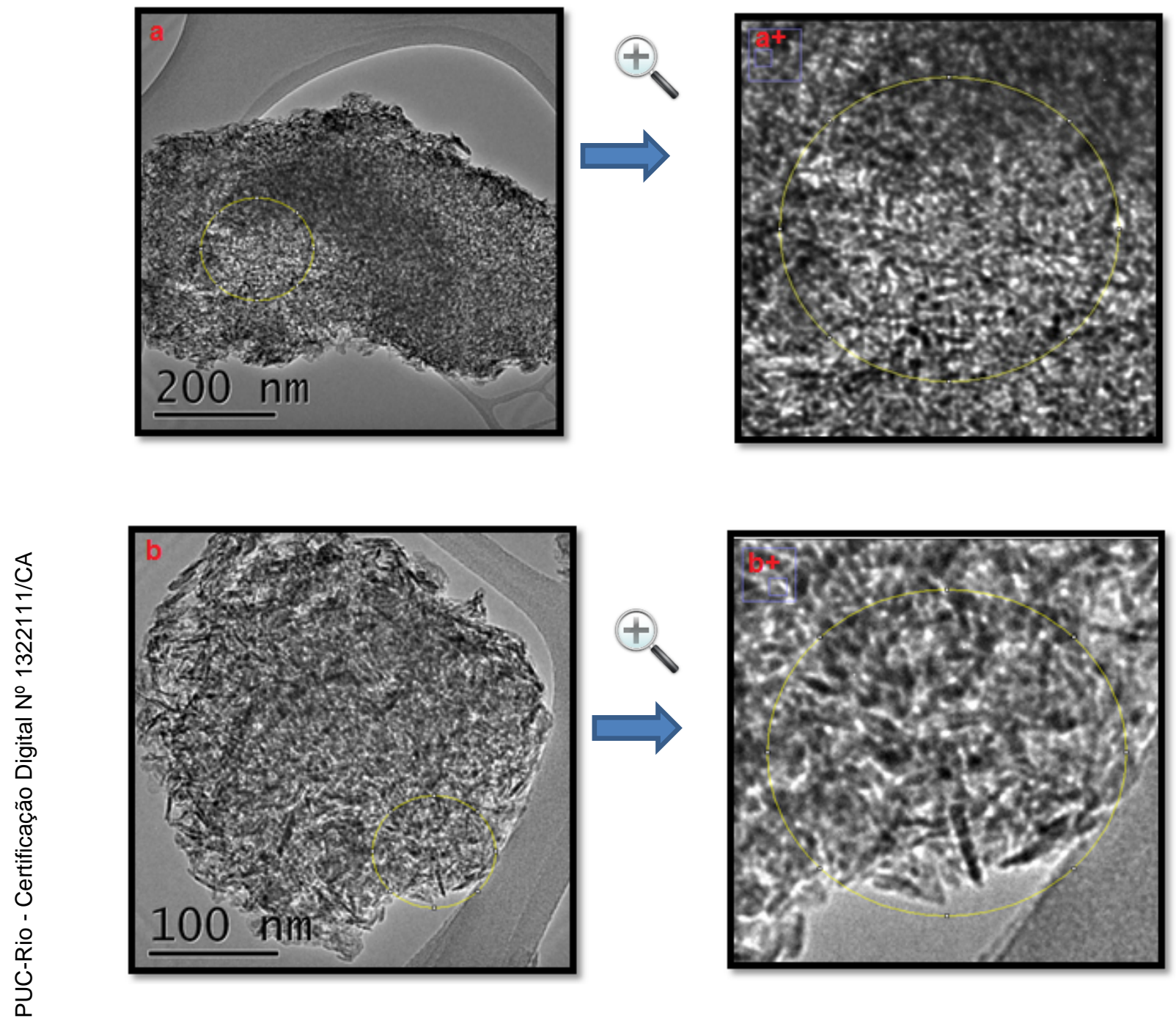

Figura 36. Imagens $a$ e $b$ e seus respetivas regiões ampliadas $a+e b+$ obtidas por MET para o suporte de sílica alumina. 

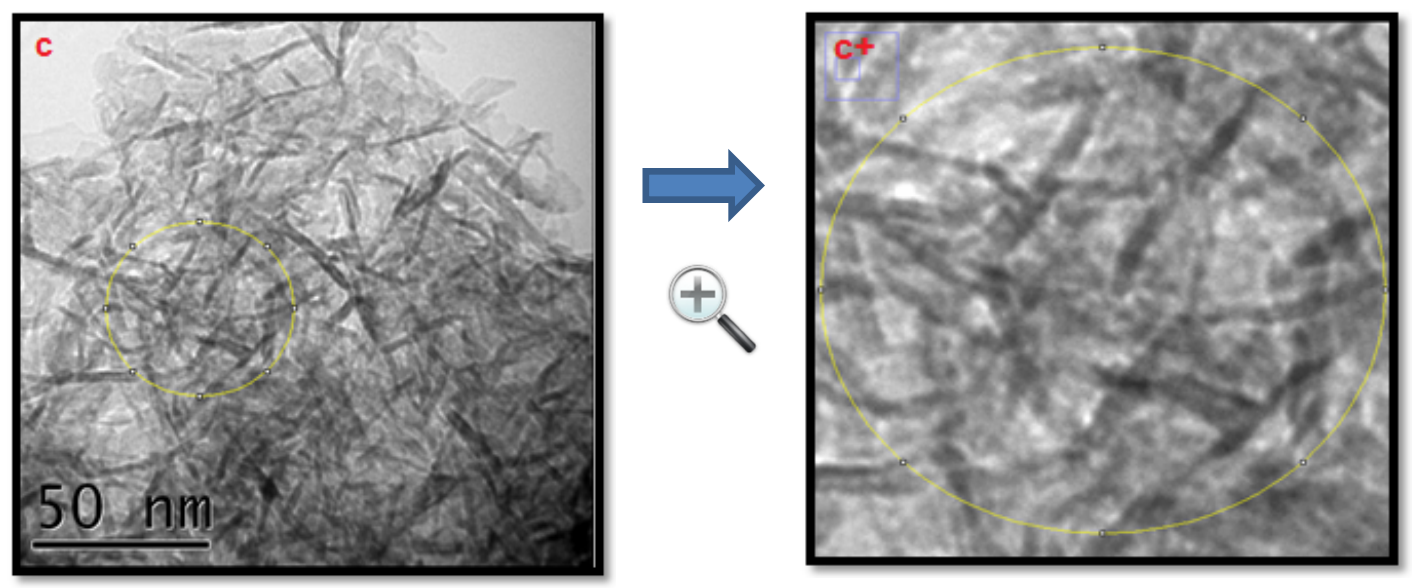

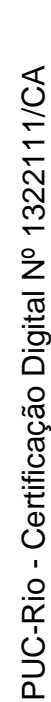
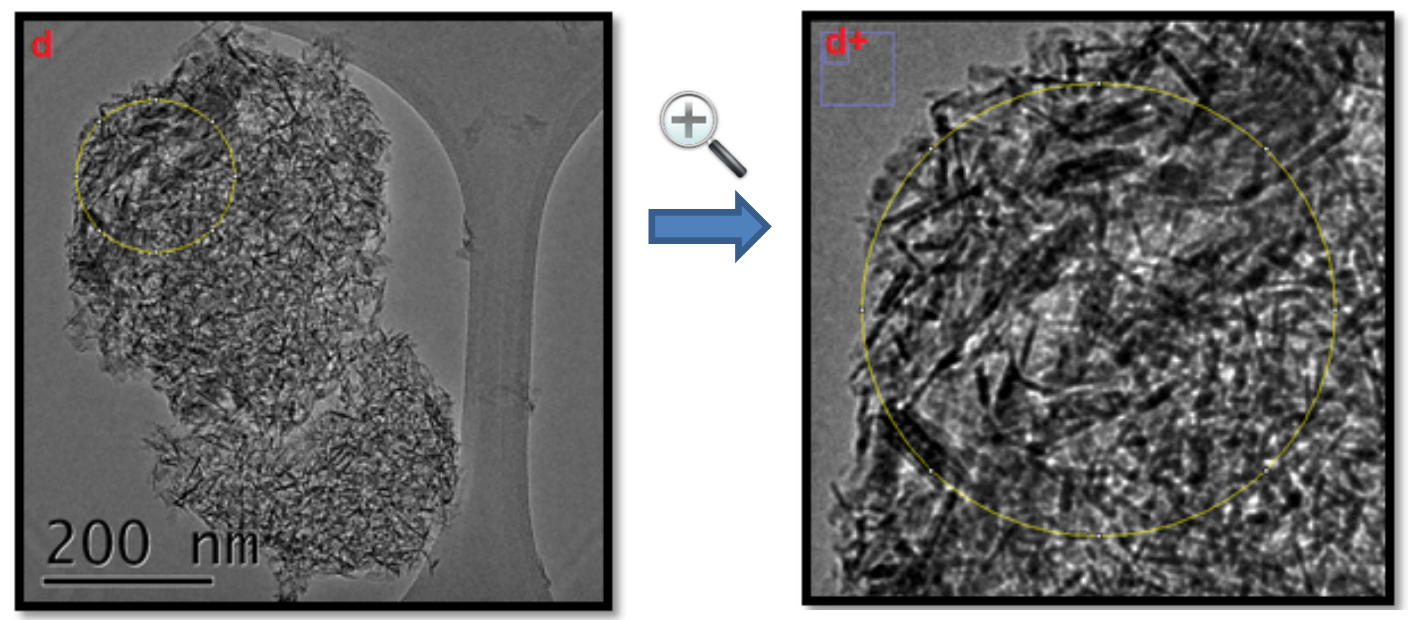

Figura 37. Imagens c e d e seus respetivas regiões ampliadas $c+e d+$ obtidas por MET para o suporte de sílica alumina. 

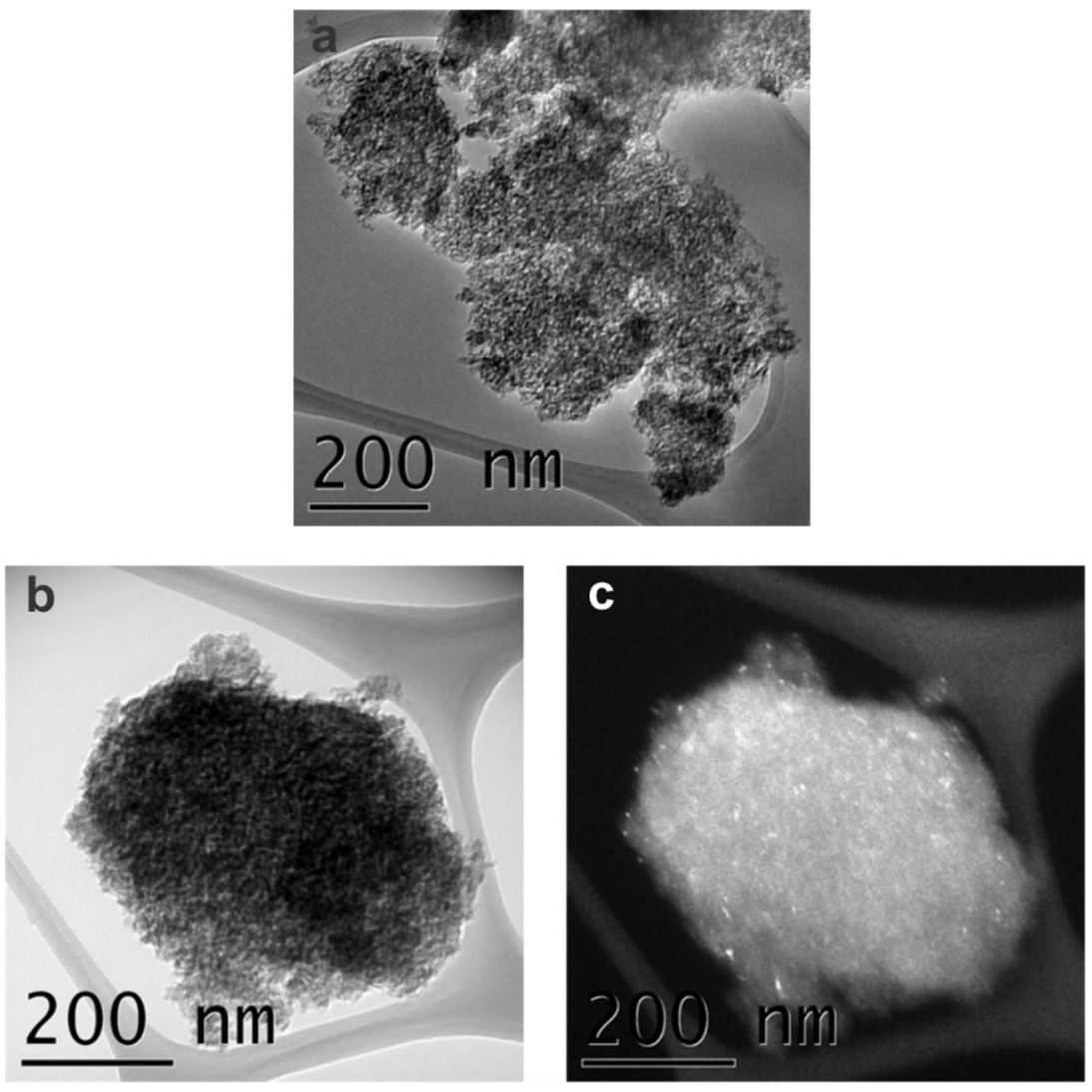

campo claro

campo escuro

Figura 38. Imagens obtidas por MET para a amostra de 5\% Fe/Si-Al método ureia, a), b) campo claro e c) campo escuro. 


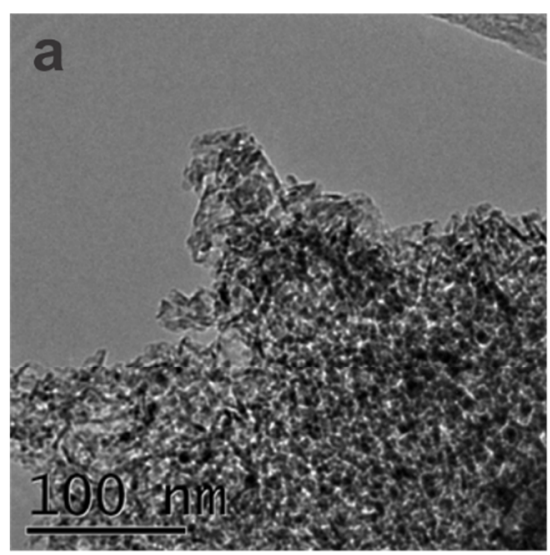

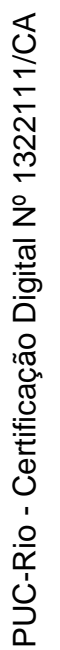
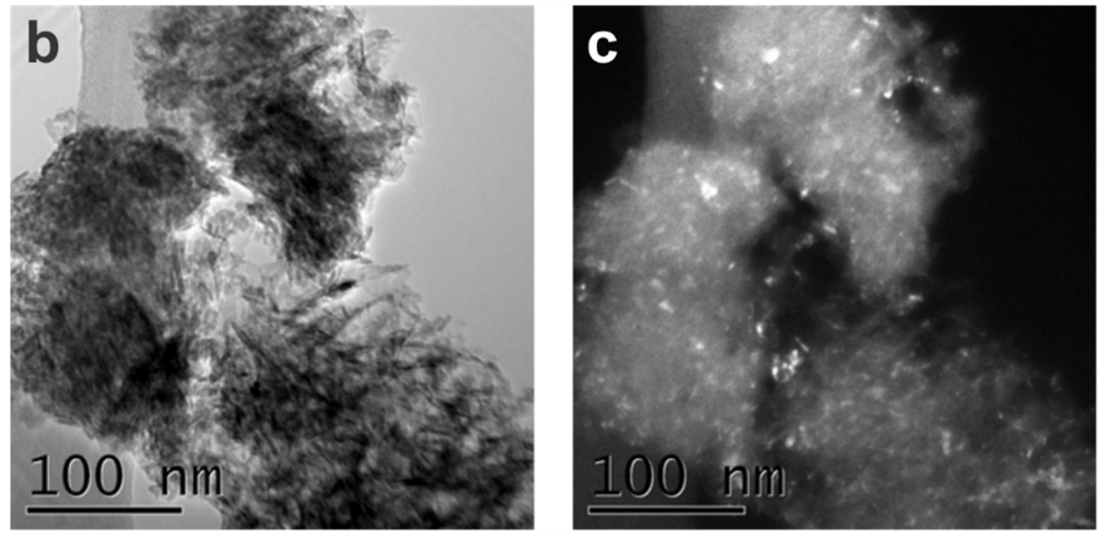

Figura 39. Imagens obtidas por MET para a amostra de 5\% Fe/Si-Al. 
$\mathrm{Na}$ figura 40 podem ser observadas as imagens das nanopartículas de ferro, apresentando tamanhos entre 15 e $40 \mathrm{~nm}$ com formato esférico, sendo também observadas partículas maiores com diâmetros na faixa de 100-120 $\mathrm{nm}$ ambas atribuídas principalmente ao $\mathrm{Fe}^{0}$ e $\mathrm{FeO}$, tal como indica o refinamento de Rietveld.

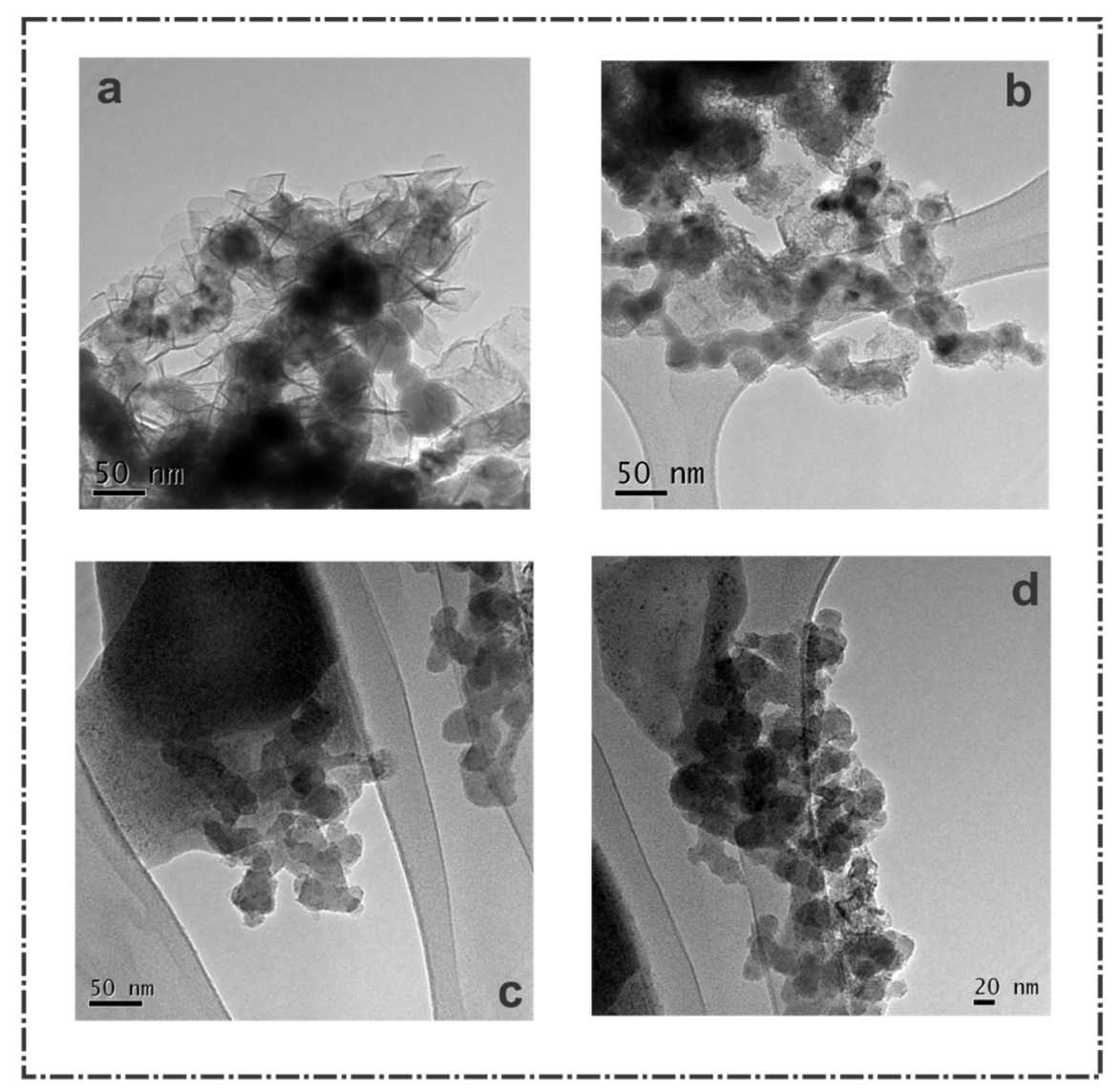

Figura 40. Imagens obtidas por MET para a amostra de nano partículas de ferro não suportadas FeNp. 


\section{5 Conclusões}

Os catalisadores de ferro e cobalto suportados em sílica alumina e sílica mesoporosa estudados neste trabalho, preparados pelos métodos de impregnação de ponto úmido e impregnação utilizando ureia apresentaram teores molares de acordo com o preparado experimentalmente, garantindo que o método de preparação foi realizado a contento.

A análise de ATG confirmou uma perda de massa total nos suportes de sílica alumina e sílica mesoporosa de $28 \%$ e $29 \%$ respetivamente, e demostrou que todo o direcionador foi removido em temperaturas inferiores a 820 K. A análise de ATG ajudou a determinar a temperatura adequada de calcinação.

A introdução de ferro e cobalto não provocou alterações estruturais nos suportes de sílica alumina e sílica mesoporosa já que os difratogramas de raios $X$ não apresentaram variação significativa entre eles. Similarmente as propriedades texturais não apresentaram variação significativa como pode ser visto a partir das isotermas de adsorção/dessorção, com exceção dos resultados de área especifica os quais mostraram uma leve variação quando o metal foi introduzido devido ao pequeno bloqueio dos poros provocado pela impregnação.

Foi verificada uma única etapa de redução de $\mathrm{Co}_{3} \mathrm{O}_{4}$ para $\mathrm{CoO}$, indicando que não ocorreu a segunda etapa de redução a $\mathrm{Co}^{0}$ no catalisador usado pelo analise de RTP. Mas o difratograma de raios $X$ não identificou nem óxido de cobalto nem cobalto metálico $\left(\mathrm{CoO}\right.$ e $\left.\mathrm{Co}^{0}\right)$. Os graus de redução apresentaram grande variação entre eles, sendo que amostra de $2 \%$ Fe/sílica 
mesoporosa apresentou o maior valor, mostrando que o suporte tem influência sobre o grau de redução devido a interação do ferro com o mesmo.

O uso da ureia durante a impregnação parece ter favorecido a redução das espécies de ferro impregnadas sobre o suporte

As partículas de ferro, observadas por MET, apresentaram tamanhos entre 5 -20 nm com formato esférico para amostra de $2 \% \mathrm{Fe} / \mathrm{Si}$-Al constituídas provavelmente por uma mistura de óxidos, tal como indica o refinamento de Rietveld. Para as amostras de $5 \% \mathrm{Fe} / \mathrm{Si}-\mathrm{Al}$ e $5 \% \mathrm{Fe} / \mathrm{Si}$-Al método ureia não foi possível visualizar partículas de ferro com formato regular, entretanto foram encontradas regiões escuras de aglomerados atribuídas provavelmente as partículas de óxido de ferro. Já as nanopartículas de ferro apresentaram principalmente tamanhos entre 15 e $40 \mathrm{~nm}$ com formato esférico, atribuídas ao $\mathrm{FeO}$ e $\mathrm{Fe}^{0}$, tal como indica o refinamento de Rietveld.

$\mathrm{O}$ catalisador de $5 \% \mathrm{Fe} / \mathrm{Si}$-Al reduzido com $\mathrm{CO} / \mathrm{H}_{2}$ apresentou formação de carbeto de ferro, indicando que esta fase está de fato presente durante a reação de Fischer Tropsch. 


\section{6 Sugestões}

- Utilizar as técnicas de Mossbauer e XPS para caracterizar o estado do ferro e cobalto na superfície do suporte mesoporoso.

- Utilizar a técnica de EXAFS/XANES para fornecer informação dos diferentes estados de oxidação de ferro e cobalto.

- Realizar análises de EDS para verificar a presença de ferro e cobalto em ambos suportes.

- Avaliar a possibilidade de uso de promotores co-impregnados nos diversos catalisadores suportados na sílica alumina e sílica mesoporosa.

- Testar todos os catalisadores em ambas atmosferas de redução $\left(\mathrm{H}_{2}\right.$ puro e $\mathrm{CO} / \mathrm{H}_{2}$ ) na reação de Fischer Tropsch determinando \% conversão de $\mathrm{CO}$, a seletividade em hidrocarbonetos e a probabilidade de crescimento da cadeia. 


\section{Referências Bibliográficas}

AN, X. et al. Comparative study of iron-based Fischer-Tropsch synthesis catalyst promoted with potassium or sodium. Catalysis Communications, v. 8, n. 12, p. 1957-1962, 2007.

ANDREW, J. Catalysis Science \& Technology Fischer - Tropsch synthesis of hydrocarbons from. p. 2210-2229, 2014.

ARENA, F. et al. Activity pattern of low-loaded $\mathrm{FeOx} / \mathrm{SiO} 2$ catalysts in the selective oxidation of $\mathrm{C} 1$ and $\mathrm{C} 3$ alkanes with oxygen. Catalysis Today, v. 117, n. 1-3, p. 75-79, 2006.

ARMOR, J. N. The multiple roles for catalysis in the production of $\mathrm{H} 2 . \mathrm{v} .176$, n. 1999, 2005.

ARSALANFAR, M. et al. Effect of support and promoter on the catalytic performance and structural properties of the Fe-Co-Mn catalysts for FischerTropsch synthesis. Journal of Industrial and Engineering Chemistry, v. 20, n. 4, p. 1313-1323, jul. 2014.

ATWOOD, H. E.; BENNETT, C. O. Kinetics of Fischer-Tropsch Reaction over Iron. Industrial \& Engineering Chemistry Process Design and Development, v. 18, n. 1, p. 163-170, 1979.

BACHARI, K.; TOUILEB, A.; LAMOUCHI, M. Characterization of ironmesoporous molecular sieves obtained by a microwave-hydrothermal process. Transition Metal Chemistry, v. 34, n. 5, p. 529-537, 2009.

BALIBAN, R. C.; ELIA, J. A.; FLOUDAS, C. A. Biomass to liquid transportation fuels (BTL) systems: process synthesis and global optimization framework. Energy \& Environmental Science, v. 6, n. 1, p. 267, 2013.

BOUBEKR, F. et al. Ex-nitrate Co/SBA-15 catalysts prepared with calibrated silica grains: Information given by TPR, TEM, SAXS and WAXS. Microporous and Mesoporous Materials, v. 141, n. 1-3, p. 157-166, 2011. 
BRAGANÇA, L. F. F. P. G. et al. Synthesis and characterization of Co-Fe nanoparticles supported on mesoporous silicas. Materials Chemistry and Physics, v. 138, n. 1, p. 17-28, 2013.

BRIEN, R. J. O. et al. Activation Study of Precipitated Iron Fischer - Tropsch. Energy \& Fuels, v. 10, n. 10, p. 921-926, 1996.

BRUNAUER, S. et al. On a Theory of the van der Waals Adsorption of Gases. J. Am. Chem. Soc., v. 62, n. 6, p. 1723-1732, 1940.

BUKUR, D. B.; LANG, X.; DING, Y. Pretreatment effect studies with a precipitated iron Fischer-Tropsch catalyst in a slurry reactor. Applied Catalysis A: General, v. 186, n. 1-2, p. 255-275, 1999.

BUKUR, D. B.; SIVARAJ, C. Supported iron catalysts for slurry phase FischerTropsch synthesis. Applied Catalysis A: General, v. 231, p. 201-214, 2002.

CAGNOLI, M. M. V et al. Influence of the Support on the Activity and Selectivity of High dispersion Fe Catalysts in the Fischer-Tropsch Reaction. Journal of Catalysis, v. 123, p. 21-30, 1990.

CHENG, K. et al. Pore size effects in high-temperature Fischer-Tropsch synthesis over supported iron catalysts. Journal of Catalysis, v. 328, p. 139150, 2015.

CHONCO, Z. H. et al. Comparing silver and copper as promoters in Fe-based Fischer-Tropsch catalysts using delafossite as a model compound. Journal of Catalysis, v. 307, p. 283-294, nov. 2013.

DA SILVA, J. Jaqueline Farias da Silva Catalisadores Suportados em Peneiras Moleculares Micro e Mesoporosas para a Síntese de Fischer-Tropsch Jaqueline Farias da Silva Catalisadores Moleculares Suportados Micro e em Peneiras para a Mesoporosas Síntese de Fischer-Trops. 2004.

DAVIS, B. H. Fischer-Tropsch synthesis: current mechanism and futuristic needs. Fuel Processing Technology, v. 71, n. 1-3, p. 157-166, jun. 2001.

DAVIS, B. H. Fischer-Tropsch synthesis: Relationship between iron catalyst composition and process variables. Catalysis Today, v. 84, n. 1-2, p. 83-98, 2003.

DE BARROS, A. L. B. et al. Synthesis, characterization, and biodistribution studies of $99 \mathrm{mTc}$-labeled SBA-16 mesoporous silica nanoparticles. Materials Science and Engineering: C, v. 56, p. 181-188, 2015. 
DLAMINI, $\mathrm{H}$. et al. Changes in physico-chemical properties of iron-based Fischer-Tropsch catalyst induced by $\mathrm{SiO} 2$ addition. Catalysis Letters, v. 78, n. 1-4, p. 201-207, 2002.

DRY, M. E. The Fischer-Tropsch process: 1950-2000. Catalysis Today, v. 71, n. 3-4, p. 227-241, jan. 2002.

DRY, M. E.; ANDERSON, J. R.; BOUDART, M., E. The Fischer-Tropsch synthesis. Catalysis Science and Technology, v. Vol. 1, p. 159-255, 1981.

EINDHOVEN, T. U.; DE, V. The Fischer-Tropsch synthesis : A mechanistic study using transient isotopic tracing Proefschrift Henricus Adrianus Johannes van Dijk. [s.I: s.n.].

ELIASON, S. A.; BARTHOLOMEW, C. H. Reaction and deactivation kinetics for Fischer-Tropsch synthesis on unpromoted and potassium-promoted iron catalysts. Applied Catalysis A: General, v. 186, p. 229-243, 1999.

ELISEEV, O. L. Gas-to-liquid technologies. Russian Journal of General Chemistry, v. 79, n. 11, p. 2509-2519, 7 jan. 2010.

ESPINOZA, R. L. et al. Low temperature Fischer-Tropsch synthesis from a Sasol perspective. Applied Catalysis A: General, v. 186, n. 1-2, p. 13-26, out. 1999.

GAO, X. et al. Reduction of supported iron oxide studied by temperatureprogrammed reduction combined with mossbauer spectroscopy and X-ray diffraction. Journal of the Chemical Society, Faraday Transactions, v. 89, n. 7, p. 1079, 1993.

HERRANZ, T. et al. Genesis of iron carbides and their role in the synthesis of hydrocarbons from synthesis gas. Journal of Catalysis, v. 243, p. 199-211, 2006.

HORACIO LOPEZ, R. Adsorción en Sólidos Mesoporosos. 3.1. Caracterización de medios porosos y procesos percolaticvos y transporte, p. 19-51, 2004.

HUANG, Y.-Y.; ANDERSON, J. R. On the Reduction of Supported Iron Catalysts Studied by Mijssbauer Spectroscopy. v. 153, p. 143-153, 1975.

JUNG, J. S.; KIM, S. W.; MOON, D. J. Fischer-Tropsch Synthesis over cobalt based catalyst supported on different mesoporous silica. Catalysis Today, v. 185, n. 1, p. 168-174, 2012. 
KEYVANLOO, K. et al. Supported iron Fischer-Tropsch catalyst: Superior activity and stability using a thermally stable silica-doped alumina support. ACS Catalysis, v. 4, p. 1071-1077, 2014a.

KEYVANLOO, K. et al. Highly active and stable supported iron FischerTropsch catalysts: Effects of support properties and $\mathrm{SiO} 2$ stabilizer on catalyst performance. Journal of Catalysis, v. 319, p. 220-231, nov. 2014b.

KOCK, A. J.; FORTUIN, H. M.; GEUS, J. W. The Reduction Behavior of Supported Iron Catalysts in Hydrogen on Carbon Monoxide Atmospheres. Journal of Catalysis, v. 96, p. 261-275, 1985.

KÖLBEL, H.; RALEK, M. The Fischer-Tropsch Synthesis in the Liquid Phase. Catalysis Reviews: Science and Engineering, v. 21, n. 225, 1980.

LESAINT, C. et al. Synthesis and characterization of mesoporous alumina with large pore size and their performance in Fischer-Tropsch synthesis. Applied Catalysis A: General, v. 351, p. 131-135, 2008.

$\mathrm{LI}$, S. et al. Structural analysis of unpromoted Fe-based Fischer-Tropsch catalysts using X-ray absorption spectroscopy. Applied Catalysis A: General, v. 219, n. 1-2, p. 215-222, 2001.

LIU, S. et al. Influence of the initial iron concentration on the iron-loading in MCM-41 and thermal decomposition of the supported iron complexes. Microporous and Mesoporous Materials, v. 79, n. 1-3, p. 299-305, 2005.

MARTÍNEZ, A. et al. Fischer-Tropsch synthesis of hydrocarbons over mesoporous Co/SBA-15 catalysts: The influence of metal loading, cobalt precursor, and promoters. Journal of Catalysis, v. 220, p. 486-499, 2003.

MEYNEN, V.; COOL, P.; VANSANT, E. F. Verified syntheses of mesoporous materials. Microporous and Mesoporous Materials, v. 125, n. 3, p. 170-223, 2009.

MINNERMANN, M. et al. Double flame spray pyrolysis as a novel technique to synthesize alumina-supported cobalt Fischer-Tropsch catalysts. Catalysis Today, v. 214, p. 90-99, 2013.

MOULIJN, J. A.; VAN DIEPEN, A. E.; KAPTEIJN, F. Catalyst deactivation: Is it predictable? What to do? Applied Catalysis A: General, v. 212, n. 1-2, p. 316, 2001.

NAKHAEI POUR, A. et al. Deactivation studies of Co/CNTs catalyst in FischerTropsch synthesis. Journal of Natural Gas Science and Engineering, v. 18, p. 104-111, 2014. 
NIEMANTSVERDRIET, J. W. et al. Behavior of metallic iron catalysts during Fischer-Tropsch synthesis studied with Moessbauer spectroscopy, x-ray diffraction, carbon content determination, and reaction kinetic measurements. The Journal of Physical Chemistry, v. 84, n. 25, p. 3363-3370, 1980.

NIKPARSAA, P.; MIRZAEIA, A. A.; ATASHIB, H. Effect of reaction conditions and Kinetic study on the Fischer-Tropsch synthesis over fused Co-Ni/Al2O3 catalyst. Journal of Fuel Chemistry and Technology, v. 42, n. 6, p. 710-718, 2014.

O'BRIEN, R. J. et al. Fischer-Tropsch synthesis: Impact of potassium and zirconium promoters on the activity and structure of an ultrafine iron oxide catalyst. Topics in Catalysis, v. 2, n. 1-4, p. 1-15, 1995.

O'BRIEN, R. J. et al. Activity, selectivity and attrition characteristics of supported iron Fischer-Tropsch catalysts. Applied Catalysis A: General, v. 196, p. 173-178, 2000.

PARK, E. et al. Characterization of phases formed in the iron carbide process by X-ray diffraction, mossbauer, X-ray photoelectron spectroscopy, and raman spectroscopy analyses. Metallurgical and Materials Transactions B, v. 32, n. 5, p. 839-845, 2001.

PARK, J. C. et al. Highly activated K-doped iron carbide nanocatalysts designed by computational simulation for Fischer-Tropsch synthesis. Journal of Materials Chemistry A, v. 2, n. 35, p. 14371, 2014.

RAUPP, G. B.; DELGASS, W. N. Mössbauer Investigation of Supported Fe Catalysts. Journal of Catalysis, v. 58, p. 361-369, 1979.

REUEL, R. C.; BARTHOLOMEW, C. H. Effects of support and dispersion on the $\mathrm{CO}$ hydrogenation activity/selectivity properties of cobalt. Journal of Catalysis, v. 85, p. 78-88, 1984.

SABER, O.; GOBARA, H. M. Optimization of silica content in alumina-silica nanocomposites to achieve high catalytic dehydrogenation activity of supported Pt catalyst. Egyptian Journal of Petroleum, v. 23, n. 4, p. 445454, 2014.

$\mathrm{SHI}$, L. et al. An introduction of $\mathrm{CO} 2$ conversion by dry reforming with methane and new route of low-temperature methanol synthesis. Accounts of Chemical Research, v. 46, n. 8, p. 1838-1847, 2013.

SHROFF, M. D. et al. Activation of precipeted iron Fischer-Tropsch synthesis catalystsJournal of Catalysis, 1995. 
VAN STEEN, E.; SCHULZ, H. Polymerisation kinetics of the Fischer-Tropsch $\mathrm{CO}$ hydrogenation using iron and cobalt based catalysts. Applied Catalysis A: General, v. 186, n. 1-2, p. 309-320, 1999.

VOSLOO, A. C. Fischer - Tropsch : a futuristic view. p. 149-155, 2001.

WAN, H. J. et al. Study of an iron-based Fischer-Tropsch synthesis catalyst incorporated with SiO2. Journal of Molecular Catalysis A: Chemical, v. 260, p. 255-263, 2006.

XIONG, $\mathrm{H}$. et al. Fischer-Tropsch synthesis over model iron catalysts supported on carbon spheres: The effect of iron precursor, support pretreatment, catalyst preparation method and promoters. Applied Catalysis, v. 388, n. 1-2, p. 169-178, 2010.

XIONG, $\mathrm{H}$. et al. Fischer-Tropsch synthesis: Iron catalysts supported on $\mathrm{N}$ doped carbon spheres prepared by chemical vapor deposition and hydrothermal approaches. Journal of Catalysis, v. 311, p. 80-87, mar. 2014.

XIONG, H. et al. Effect of Group I alkali metal promoters on Fe/CNT catalysts in Fischer-Tropsch synthesis. Fuel, v. 150, p. 687-696, jun. 2015.

YANG, Y. et al. Structure and Fischer-Tropsch performance of iron-manganese catalyst incorporated with SiO2. Applied Catalysis A: General, v. 284, n. 1-2, p. 105-122, 2005. 